JOANA DE OLIVEIRA FERRAZ SUBTIL

ANÁLISE DE MÉTODOS DE AVALIAÇÃO DE ECO EFICIÊNCIA

São Paulo

2015 
JOANA DE OLIVEIRA FERRAZ SUBTIL

\section{ANÁLISE DE MÉTODOS DE AVALIAÇÃO DE ECO EFICIÊNCIA}

Dissertação apresentada à Escola Politécnica da Universidade de São Paulo como requisito obrigatório para a obtenção do título de Mestre em Engenharia

\section{São Paulo}


JOANA DE OLIVEIRA FERRAZ SUBTIL

\title{
ANÁLISE DE MÉTODOS DE AVALIAÇÃO DE ECO EFICIÊNCIA
}

\author{
Dissertação apresentada à Escola \\ Politécnica da Universidade de São \\ Paulo como requisito obrigatório \\ para a obtenção do título de Mestre \\ em Engenharia \\ Área de Concentração \\ Engenharia Química
}

Orientador:

Prof. Dr. Gil A. da Silva

\section{São Paulo}


Catalogação-na-publicação

\section{Subtil, Joana de Oliveira Ferraz}

Análise de Métodos de Avaliação Eco Eficiência / J. O. F. Subtil -- São Paulo, 2015.

$104 \mathrm{p}$.

Dissertação (Mestrado) - Escola Politécnica da Universidade de São Paulo. Departamento de Engenharia Química.

1.eco eficiência 2.avaliação de eco eficiência 3.indicador de sustentabilidade 4.desempenho ambiental I.Universidade de São Paulo. Escola Politécnica. Departamento de Engenharia Química II.t. 
À Deus, detentor de todo o conhecimento, e à minha família, pelo suporte e amizade sempre. 


\section{AGRADECIMENTOS}

Agradeço ao Prof. Gil A. da Silva pela oportunidade e por seu apoio durante este tempo.

Agradeço ao Prof. Luiz A. Kulay pelo compartilhamento de suas idéias que foram fundamentais para o direcionamento deste trabalho.

Agradeço à toda equipe do Grupo de Prevenção da Prevenção (GP2) que constantemente me auxiliaram e aconselharam em diversos momentos.

Agradeço a Sueli A. Oliveira pelo seu interesse pelo projeto e por dividir seu conhecimento.

Um agradecimento especial ao meu esposo, Suedem, sem a sua compreensão e apoio com certeza não teria sido possível chegar até aqui.

A minha imensa gratidão aos meus queridos pais, Carlos e Inês, pelos seus preciosos ensiamentos e por sonharem comigo sempre.

Ao meu irmão, Daniel, por estar junto comigo nesse projeto e ter ajudado com as suas habilidades.

Aos meus queridos amigos, obrigada pelas palavras de suporte e compreensão. 


\section{RESUMO}

Para que a sustentabilidade seja gerenciada e praticada de maneira efetiva, ela deve ser mensurada, utilizando-se de métodos de avaliação da sustentabilidade. Estão disponíveis diferentes métodos de avaliação, que geralmente reduzem o resultado desse levantamento à indicadores de desempenho ambiental, econômico e social (POPEA; ANNANDALE; MORISON-SAUNDERSB, 2004). Uma das denominações mais bem aceitas e difundidas para a conjunção da dimensão ambiental e econômica é conhecida por avaliação de eco eficiência (AEE). Eco eficiência é o "aspecto da sustentabilidade que relaciona o desempenho ambiental de um sistema de produto ao valor do sistema de produto" (ISO, 2012). Estão disponíveis diferentes métodos de $A E E$, porém sem evidência das suas semelhanças e particularidades e como essas características influenciam na escolha do método mais adequado de AEE em relação às potenciais aplicações $O$ objetivo desta pesquisa é, portanto, analisar e indicar os tipos de métodos de avaliação de eco eficiência (AEE) mais adequados para ações gerenciais nas quais caibam tais abordagens. Foram selecionados onze métodos de $A E E$, a partir do estabelecimento de critérios de caracterização desses métodos, a saber: BASF, Bayer, EcoWater, Hahn et al., Kuosmanen e Kortelainen, MIPS, NRTEE, UN ESCAP, UN, TU Delft, e WBCSD. Identificaram-se, ainda, quatro potenciais aplicações: (i) Monitoramento de processo com vistas à melhoria contínua; (ii) Selecção e classificação de produtos; (iii) Atendimento a requisitos legais e outros requisitos; e, (iv) Marketing, rotulagem de produtos e comunicação ambiental. A partir dos elementos metodológicos estabelecidos pela norma ISSO 14045 (2012) e do conhecimento obtido dos métodos de AEE, determinaram-se quatro requisitos pelos quais os métodos e os potenciais aplicações foram avaliados: (i) Tipo de indicador de desempenho ambiental; (ii) Tipo de indicador de valor de sistema de produto; (iii) Abrangência de aplicação; e, (iv) Tipo de indicador de eco eficiência. Aplicando-se estes requisitos nos métodos de AEE e nos potenciais usos, concluiu-se que quanto à aplicações em termos de monitoramento de processos com vistas à melhoria continua os métodos de AEE recomendados foram Bayer, NRTEE, WBCSD e 
UN. Para situações de seleção e classificação de produtos os métodos BASF, EcoWater, Kuosmanen e Kortelainen, MIPS, Hahn et al., TU Delft, UN ESCAP e UN demonstraram ter boa aderência. No que se refere a usos voltados ao atendimento de requisitos legais e/ou de outras naturezas, os métodos NRTEE, WBCSD e UN são os mais indicados. Em aplicações de marketing, rotulagem e comunicação foram indicados os métodos BASF, EcoWater e MIPS. Finalmente, concluiu-se que, para a escolha adequada da metodologia para uma AEE, conhecimento prévio das características de cada abordagem é necessário.

Palavras-Chave: Eco eficiência; Avaliação de Eco eficiência; Indicador de Sustentabilidade; Desempenho Ambiental. 


\begin{abstract}
It is necessary to measure sustainability to effectively manage and practice it. This measurement is possible by using sustainability assessment methods. Different evaluation methods are avalible, which generally result in environmental, economic and social performance indicators (POPPEA; ANNANDALE; MORISON-SAUNDERSB, 2004). The eco-efficieny assessment (EEA) is one of the most accepted and disseminated donominations of the conjunction of environmental and economic dimensions. Eco-efficiency is the "aspect of sustainability relating the environmental performance of a product system to its product system value" (ISO, 2012). Different EEA methods are available, however lack evidence of their similarities and particularities and how these features influence the choice of the most appropriate EEA method for certain potential applications. The objective of this research is therefore to analyze and indicate the types of EEA methods most suitable in management applications. Eleven EEA methods were selected by the establishment of characterization criterias of these methods: BASF, Bayer, EcoWater, Hahn et al., Kuosmanen and Kortelainen, MIPS, NRTEE, UN ESCAP, UN, TU Delft, and WBCSD. Four potential applications were also identified: (i) process monitoring for continuous improvement; (ii) product selection and classification; (iii) compliance to legal and/or other requirements; and (iv) marketing, product labeling and environmental communication. Based on the methodological elements set out by the standard ISO 14045 and the knowledge obtained from EEA methods, four requirements were determined for which the methods and potential applications were evaluated: (i) Type of environmental performance indicator, (ii) Type of product value system indicator, (iii) Scope of application Scope; and (vi) Type indicator of eco-efficiency. The application of the requirements to the AEE methods and potential uses led to the conclusion that for monitoring of processes for continuous improvement the recommended EEA methods are Bayer, NRTEE, WBCSD and UN. For the product selection and classification situations methods BASF, EcoWater, Kuosmanen and Kortelainen, MIPS, Hahn et al., TU Delft, UN ESCAP and UN have shown to be most suitable. Regarding the use aimed at complying with legal and/or other requirements, methods NRTEE, WBCSD and UN are most indicated. In
\end{abstract}


marketing, labeling and communication application the methods BASF, EcoWater and MIPS were recommended. Finally, it was concluded that for an appropriate EEA method choice previous knowledge on the methods approach is necessary.

Keywords: Eco-efficiency; Eco-efficiency assessment; Sustainability Indicator; Environmental Performance. 


\section{LISTA DE FIGURAS}

Figura 3.1 - Eco eficiência em relação a outros conceitos de gerenciamento ambiental.

Figura 7.1 - Representação dos Impactos Ambientais da AEE.......................33

Figura 7.2 - Gráfico Bidimensional para representar resultados da AEE.........34

Figura 7.3 - Áreas temáticas e respectivos parâmetros....................................36

Figura 7.4 - Gráfico dos resultados do método Eco-check..............................36

Figura 7.5 - Sistema de Uso da Água em nível Meso.....................................38

Figura 7.6 - RCR de $\mathrm{CO}_{2}$ para a empresa TKS de 2002 a 2004....................44

Figura 7.7 - Indicador MIPS de recurso abiótico (kg/pessoa-km) …...............48

Figura 7.8 - Possíveis limites para os indicadores de eco eficiência.................50

Figura 7.9 - Exemplo de perfil de variação do indicadorde consumo de

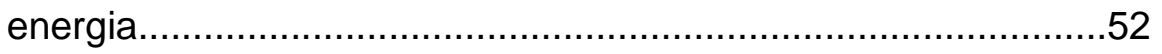

Figura 7.10 - Intensidade de uso de energia (kg equivalente de óleo/\$) na região nordeste Ásia..............................................................5

Figura 7.11 - Etapas para obtenção do Eco custo..............................................59

Figura 7.12 - Indicadores de Eco Eficiência de uma empresa ao longo do

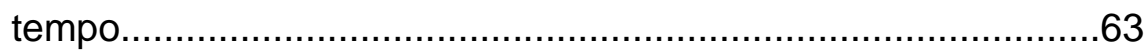




\section{LISTA DE TABELAS}

Tabela 3.1 - Possíveis funções para relacionar as dimensões ambiental e econômica.

Tabela 7.1 - Métodos de AEE selecionados.

Tabela 7.2 - Indicadores de AEE de dois sistemas de corantes (padrão e natural)

Tabela 7.3 - Exemplos de indicadores de Eco Eficiência do método da UN ESCAP. 53

Tabela 7.4 - Indicadores Geralmente Aplicáveis. .62

Tabela 8.1 - Requisitos para caracterização de Métodos de AEE. .66

Tabela 9.1 - Confrotação dos métodos de AEE com requisitos para sua caracterização .74

Tabela 9.2 - Características das potenciais aplicações de métodos de AEE...87 


\section{LISTA DE ABREVIATURAS E SIGLAS}

$\begin{array}{ll}\text { AEE } & \text { Avaliação de Eco Eficiência } \\ \text { ACV } & \text { Avaliação de Ciclo de Vida } \\ \text { ACVa } & \text { Avaliação de Ciclo de Vida ambiental } \\ \text { DEA } & \text { Data Envelopment Analysis } \\ \text { ESCAP } & \text { Economic and Social Commission for Asia and the Pacific } \\ \text { EVR } & \text { Eco cost Value Ratio } \\ \text { GRI } & \text { Global Reporting Initiative } \\ \text { MIPS } & \text { Material input per service unit } \\ \text { NRTEE } & \text { National Round Table on the Environment and the Economy } \\ \text { OECD } & \text { Organisation for Economic Cooperation and Development } \\ \text { RCR } & \text { Return to Cost Ratio } \\ \text { UN } & \text { United Nations (Nações Unidas) } \\ \text { UNCTAD } & \text { United Nations Conference on Trade and Development } \\ \text { WBCSD } & \text { World Business Council of Sustainable Development }\end{array}$




\section{SUMÁRIO}

1 INTRODUÇÃO

2 OBJETIVO

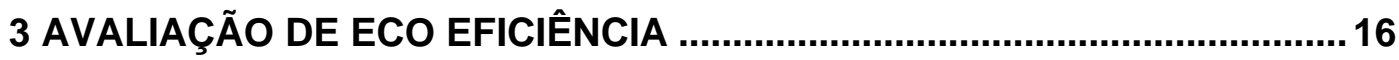

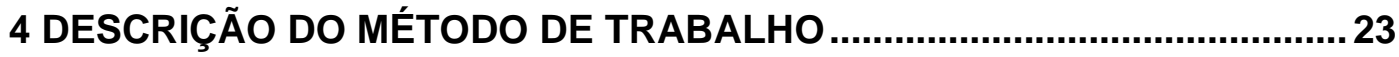

5 LEVANTAMENTO DE REFERÊNCIAS A MÉTODOS DE AEE..................... 24

6 FORMULAÇÃO E APLICAÇÃO DE REQUISITO PARA SELEÇÃO DE

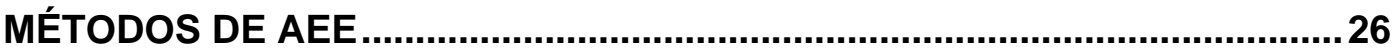

6.1 Formulação de requisito geral de seleção dos métodos de AEE ............26

6.1.1 Apresentação de conceito de eco eficiência ......................................26

6.1.2 Apresentação da estrutura metodológica da AEE.............................26

6.2 Aplicação do requisito de seleção dos métodos de AEE sobre as

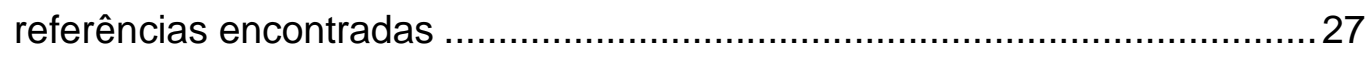

7 CARACTERIZAÇÃO DOS MÉTODOS DE AEE SELECIONADOS ..............29

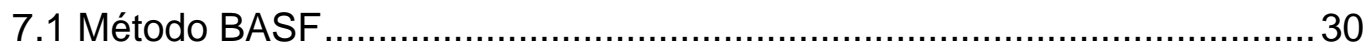

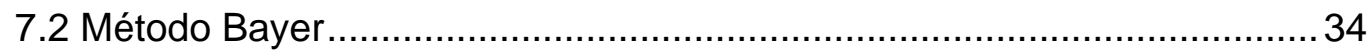

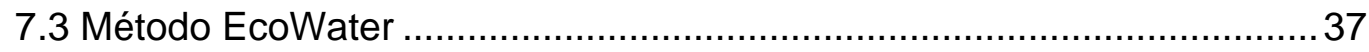

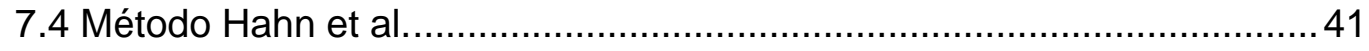

7.5 Método Kuosmanen e Kortelainen …………………............................ 44

7.6 Método MIPS (Material Input per Service unit).........................................46

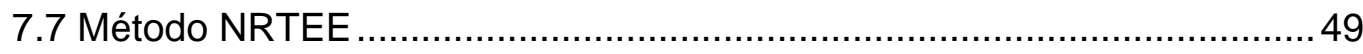

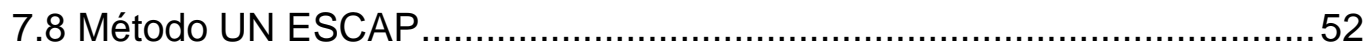

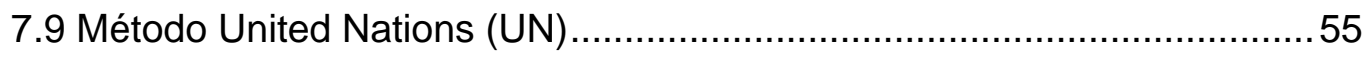

7.10 Método TU Delft (Universidade Delft de Tecnologia) ...............................57

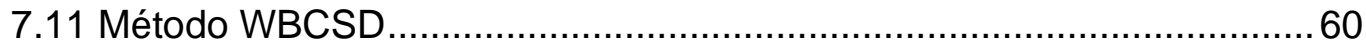

8 FORMULAÇÃO DE REQUISITOS DE CARACTERIZAÇÃO DE MÉTODOS DE AEE 
8.1 Requisito 1 - Tipo de indicador de desempenho ambiental 66

8.2 Requisito 2 - Tipo de indicador valor do sistema de produto 69

8.3 Requisito 3 - Abrangência de aplicação ……………………………....... 70

8.4 Requisito 4 - Tipo de Indicador de eco eficiência.....................................71

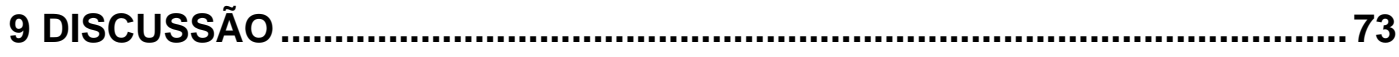

9.1 Caracterização dos métodos de AEE..................................................... 73

9.1.1 Análises dos métodos de AEE quanto ao Requisito 1 - Tipo de

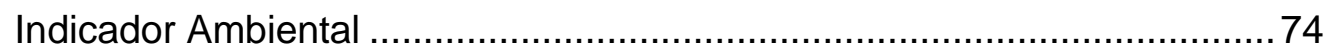

9.1.2 Análises dos métodos de AEE quanto ao Requisito 2 - Tipo de Indicador de Valor de Sistema de Produto ...............................................76

9.1.3 Análises dos métodos de AEE quanto ao Requisito 3 - Abrangência

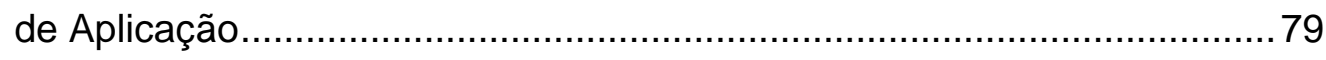

9.1.4 Análises dos métodos de AEE quanto ao Requisito 4 - Tipo de

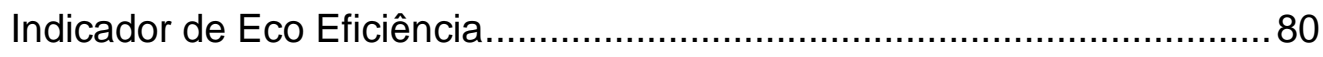

9.2 Usos possíveis para métodos de AEE e suas características em

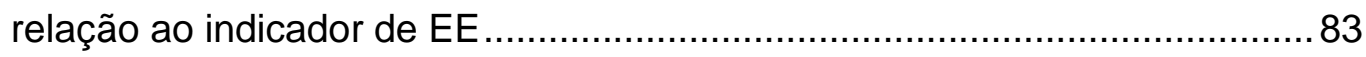

9.2.1 Determinação dos usos possíveis para um método de AEE..........83

9.2.2 Especificação das características do indicador de EE para cada

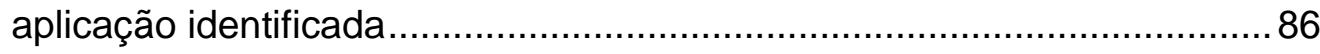

9.2.2.1 Monitoramento de processo com vistas à melhoria contínua ....88

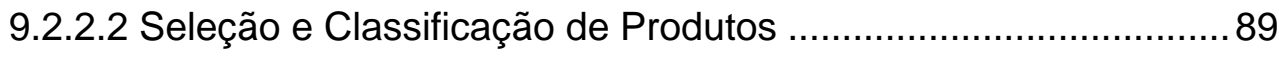

9.2.2.3 Atendimento a requisitos legais e outros requisitos ...................90

9.2.2.4 Marketing, rotulagem de produtos e comunicação ambiental ....91

9.3 Especificação de usos efetivos potenciais dos métodos de AEE .............92

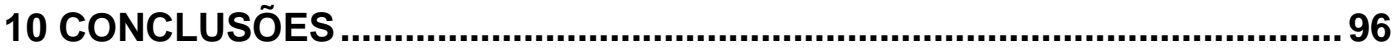

11 RECOMENDAÇÕES DE TRABALHOS FUTUROS ....................................98

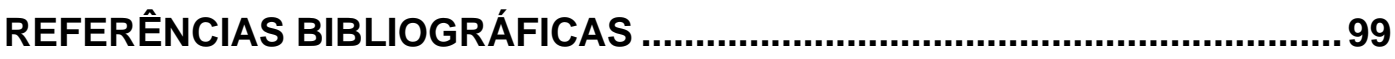

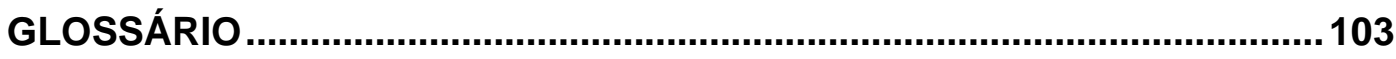




\section{INTRODUÇÃO}

A sustentabilidade pode ser definida como o uso dos recursos naturais do planeta de forma a minimizar a redução desse recurso, visando a continuidade do atendimento das necessidades das futuras gerações (SILVA, 2012). Os recursos naturais do planeta (água, madeira, petróleo, gás natural, minerais, entre outros) são consumidos para atender necessidades e desejos dos homens, para a manutenção de sua qualidade de vida, por meio da sua transformação em produtos. Portanto, todos os recursos naturais são consumidos para produção de bens de consumo devendo, portanto, ser sustentados para manutenção da qualidade de vida (SILVA, 2012).

Devido ao aumento da preocupação com os recursos limitados do meio ambiente e, ao mesmo tempo, o crescimento da população, a sustentabilidade vem ganhando importância nas últimas décadas e está cada vez mais difundida nos diferentes setores da economia, consolidando-se como uma necessidade para manutenção da competitividade de mercado e cumprimento de políticas públicas.

Para que a sustentabilidade seja gerenciada e praticada de maneira efetiva, ela deve ser mensurada, utilizando-se de métodos de avaliação da sustentabilidade. Estão disponíveis diferentes métodos de avaliação, que geralmente reduzem o resultado desse levantamento à indicadores de desempenho. O enfoque Triple Bottom Line da sustentabilidade considera pesos equivalentes às três dimensões que a sustentam: ambiental econômica e social (POPEA; ANNANDALE; MORISON-SAUNDERSB, 2004).

Os métodos para avaliação dessas dimensões podem considerar apenas uma dimensão, a conjunção entre duas dimensões ou as três simultaneamente, sendo esta última a mais desejável. No entanto, os métodos de avaliação dessas dimensões estão em diferentes fases de avanço. Os métodos de avaliação de desempenho ambiental são os que receberam maior foco e são os mais aplicados para a avaliação da sustentabilidade até o momento. A dimensão social, por sua vez, apenas agora começa a ser alvo de procedimentos sistemáticos. 
A conjunção da dimensão ambiental e econômica tem sido alvo de estudos e desenvolvimento de métodos de avaliação devido a sua valia para a gestão das organizações, não apenas no âmbito interno, mas também na relação com seus stakeholders e com o público consumidor. Uma das denominações mais bem aceita e difundida é a conhecida por avaliação de eco eficiência (AEE), a despeito da variabilidade de conceituações.

A utilização da AEE pode ajudar empresas a obter maior valor com menor impacto ambiental, proporcionando produtos mais sustentáveis e vantagem competitiva (GABRIEL; BRAUM, 2005), auxiliar na escolha de produtos e tecnologias de produção por meio da comparação sistemática entre eles e complementar avaliações de ciclo de vida ambiental (KUOSMANEN, 2005; SANJUAN et al., 2011; UNITED NATIONS, 2004).

Eco eficiência é o "aspecto da sustentabilidade que relaciona o desempenho ambiental de um sistema de produto ao valor do sistema de produto" (ISO, 2012). Nessa definição, o sistema de produto representa o escopo da AEE, definindo quais etapas da produção deste produto serão avaliadas. A dimensão ambiental é representada pelo "desempenho ambiental de um sistema de produto" e a dimensão econômica pelo "valor do sistema de produto".

Desde o surgimento do conceito de eco eficiência, foram propostos diferentes métodos de AEE. A maioria foi proposta com enfoques distintos por diferentes empresas e organizações de forma independente, resultando em uma variedade de abordagens. Em vista disso, não estão evidentes quais são as opções de métodos de AEE disponíveis, quais as semelhanças e particularidades entre eles e como essas características influenciam na escolha do método mais adequado de AEE em relação às potenciais aplicações. 


\section{OBJETIVO}

Tendo em vista o contexto apresentado no capítulo anterior, este estudo acadêmico se propõe, no nível de objetivo geral, a especificar os tipos de métodos de avaliação de eco eficiência (AEE) mais adequados para ações gerenciais nas quais caibam tais abordagens.

Como dividendos correlatos, mas nem por isso menos importantes, dessa pesquisa podem ser ainda formulados os seguintes objetivos complementares:

- Identificação do acervo de métodos de AEE constante de diferentes fontes de comunicação;

- Caracterização da sistemática operacional de métodos de AEE, destacando seus usos e aplicações potenciais, além de benefícios e limitações. 


\section{AVALIAÇÃO DE ECO EFICIÊNCIA}

Além do conceito de eco eficiência, existem ainda outros conceitos de gerenciamento ambiental correlatos ou, eventualmente, até mesmo complementares. Entre eles pode-se citar a Produção Mais Limpa $(P+L)$, Prevenção da Poluição, Controle da Poluição, Ecologia Industrial, entre outros. Fet e Michelsen (2002) apresentam eco eficiência como um "tema do âmbito da Ecologia Industrial", relacionando esses dois conceitos. Outros enfoques de diversos conceitos de gerenciamento ambiental também foram ilustrados por Van Berkel (2000) (Figura 3.1). O autor destaca a proximidade dos conceitos de P+L e eco eficiência, definindo-os como "conceitos complementares, com eco eficiência focando no lado estratégico no negócio (criação de valor) e Produção Mais Limpa no lado operacional do negócio (produção)" (VAN BERKEL, 2000).

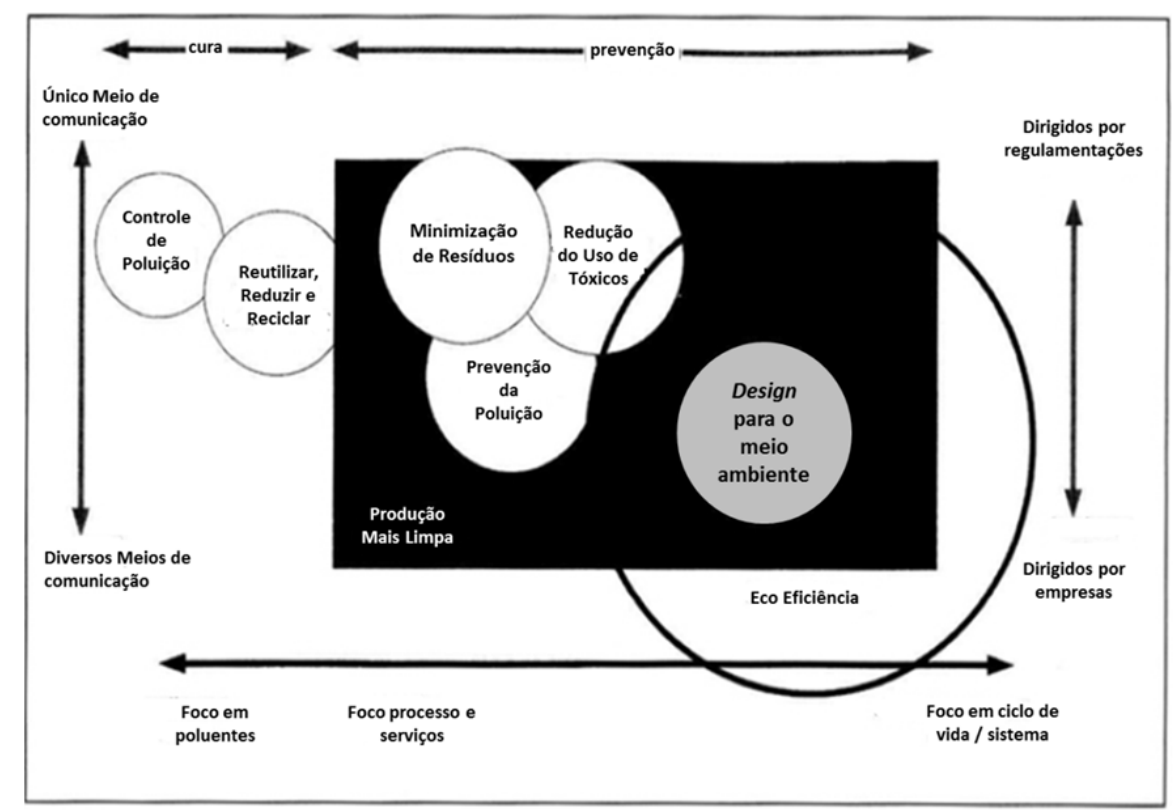

Figura 3.1 - Eco eficiência em relação a outros conceitos de gerenciamento ambiental Fonte: Van Berkel (2000).

O conceito de eco eficiência ganhou relevância por ter sido tema de discussão no Earth Summit, realizado no Rio de Janeiro em 1992, onde foi reconhecido como a forma das empresas contribuírem para o desenvolvimento 
sustentável $^{1}$. Desta forma, o mesmo ganhou importância no âmbito da gestão empresarial internacional sendo desde então alvo de discussões na literatura específica.

O conceito de eco eficiência foi descrito naquele mesmo ano na publicação Changing Courses da WBCSD (World Business Council of Sustainable Development) que indicou que eco eficiência "é atingida ao oferecer bens e serviços com preços competitivos que satisfaçam as necessidades humanas e tragam qualidade de vida, enquanto reduzem progressivamente os impactos ecológicos e intensidade de recursos durante o ciclo de vida até chegar ao nível condizente com a capacidade da terra" (FET; MICHELSEN, 2002; EHRENFELD, 2005). Essa definição, uma das mais difundidas, faz a relação entre as dimensões ambiental e econômico utilizando-se dos termos "reduzem progressivamente impactos ecológicos e intensidade de recursos" e "bens e serviços com preços competitivos", respectivamente. A OECD (Organisation for Economic Cooperation and Development) havia definido eco eficiência como "a eficiência com que os recursos ambientais são utilizados para atender as necessidades dos homens" (OECD, 1998). Essas definições, porém, um tanto abrangentes, permitiram a proposição de definições quantitativas.

Entre estas propostas está a de Huppes e Ishikawa (2005a) que definiram eco eficiência como "um instrumento para análise de sustentabilidade, indicando uma relação empírica de atividades econômicas entre custo ou valor ambiental e impacto ambiental". Foi também definida como "a otimização ecológica de sistemas globais sem desprezar os fatores econômicos" (VERCALSTEREN; SPIRINCKX; GEERKEN, 2010) ou, ainda, "a junção do valor do produto ou serviço e aspectos ecológicos em uma relação de eficiência" (VERCALSTEREN; SPIRINCKX; GEERKEN, 2010). Outra proposta ainda apresenta que a eco eficiência visa a "otimização da relação entre a utilidade econômica e os encargos ambientais de uma atividade" (GABRIEL; BRAUNE, 2005).

Huppes e Ishikawa (2005b) discutiram ainda conceitos sobre os tipos de indicadores de eco eficiência possíveis em virtude das diferentes formas de representar a relação entre as dimensões ambiental (representação por impacto

${ }^{1}$ Desenvolvimento Sustentável: "É aquele que atende as necessidades das gerações atuais sem comprometer a capacidade das gerações futuras em atender suas necessidades" (BRUNTLAND, 1987 apud SILVA, 2012). 
ambiental ou melhoria ambiental) e econômica (representado por valor de produção ou custo). Os autores os denominaram de: produtividade ambiental, intensidade de produção ambiental, melhoria de custo ambiental e efetividade de custos ambientais (Tabela 3.1).

Tabela 3.1 - Possíveis funções para relacionar as dimensões ambiental e econômica

\begin{tabular}{cll}
\hline $\begin{array}{c}\text { Dimensões da } \\
\text { Sustentabilidade }\end{array}$ & \multicolumn{1}{c}{$\begin{array}{c}\text { Produto ou produção } \\
\text { primária }\end{array}$} & Melhoria ambiental primária \\
\hline Econômica / Ambiental & $\begin{array}{l}\text { Valor de produção / impacto } \\
\text { ambiental, ou produtividade } \\
\text { ambiental }\end{array}$ & $\begin{array}{l}\text { Custo / melhoria ambiental, ou } \\
\text { custo de melhoria ambiental }\end{array}$ \\
\hline Ambiental / Econômica & $\begin{array}{l}\text { Impacto ambiental / valor de } \\
\text { produção, ou intensidade } \\
\text { ambiental }\end{array}$ & $\begin{array}{l}\text { Melhoria ambiental / custo, ou } \\
\text { eficácia de custo ambiental }\end{array}$ \\
\hline
\end{tabular}

Fonte: Adaptado de Huppes e Ishikawa (2005b)

Em paralelo com as discussões conceituais de eco eficiência, foram propostos métodos quantitativos de AEE por empresas, instituições de pesquisa e instituições independentes. No período do início dos anos 2000 está concentrada a maior parte das propostas que são objeto de estudo deste trabalho.

A WBCSD foi uma das pioneiras ao publicar um guia de AEE para obtenção de indicadores de eco eficiência em 2000 (VERFAILLIE; BIDWELL, 2000), com foco na aplicação do método em estágios de produção sob o controle das empresas. A NRTEE (National Round Table on the Environment and the Economy) (NRTEE, 2001), baseando-se na WBCSD, também publicou um guia, aprofundando-se na obtenção dos indicadores específicos de eco eficiência referentes ao despejo de resíduos sólidos, consumo de água e consumo de energia.

Outro método, apresentado pela empresa BASF em 2002 (SALING et al., 2002), e mais adiante descrito também por Uhlman e Saling (2010), embasou-se na extensão do ciclo de vida $^{2}$, utilizando-se desde a produção das matérias primas até o descarte do produto como escopo para a realização da AEE. A empresa Bayer (KURUSAARI; ROEVEKAMP; OKANO, 2003), também

${ }^{2}$ Ciclo de vida: "o sistema constituído pelo conjunto de todas as ações antrópicas ocorridas para que o produto cumpra sua função" (SILVA, 2012). 
apresentou um método, denominado EcoCheck, com a finalidade de propor uma ferramenta simples de gerenciamento de eco eficiência, comparando-se com a algumas etapas da estrutura metodológica do método da empresa BASF.

A proposta de método da UNCTAD (United Nations Conference on Trade and Development) foi publicada em 2004 pelas Nações Unidas (UNITED NATIONS, 2004) com os objetivos de apresentar um guia para a definição, reconhecimento, medição e divulgação de informações ambientais e financeiras utilizando de meios tradicionais de contabilidade e reportagem. Também tem o objetivo de melhorar e harmonizar métodos para que a divulgação de indicadores de eco eficiência seja padronizada e relevante para decisões e possam ser comparados entre empresas. A extensão da United Nations na Ásia e Pacífico, denominada UN ESCAP (United Nations Economic and Social Comission for Asia and the Pacific), propôs ainda um método de AEE onde apresentou os passos metodológicos para a obtenção de indicadores de eco eficiência para aplicação na economia (de forma geral) como também em setores econômicos como a indústria e agricultura (UN ESCAP, 2009).

Hahn et al. (2010) apresentaram a abordagem RCR (Return to Cost Ratio/Razão de Retorno de Investimento) como uma nova forma de realizar a AEE utilizando-se do conceito de custo de oportunidade para representar o indicador ambiental. A motivação dessa proposta foi sanar fraquezas das demais propostas (porém, sem identificá-las), criando uma maneira considerada simples de interpretar no meio empresarial e identificar os efeitos que influenciam a eco eficiência ao longo do tempo. A motivação para a proposta desse método são algumas fraquezas das abordagens de AEE atualmente utilizadas, tais como, 1) a relação pela qual a eco eficiência é apresentada é difícil de interpretar por gerentes não familiarizados com assuntos ambientais e 2) os motivos pelos quais a eco eficiência se altera com o tempo não são facilmente identificados por ser apresentada como uma combinação entre medidas econômicas e ambientais.

Um programa de pesquisa apoiado pela União Européia propôs um método denominado EcoWater (ECOWATER, 2015). O objetivo do mesmo é desenvolver indicadores de eco eficiência para avaliar a utilização de novas tecnologias, com foco nos sistemas de uso de água (KOURENTZIS, 2012; ANGELIS-DIMAKIS, 2015). 
Outras abordagens de métodos de AEE, ainda, foram propostas de forma independente, sem relação explícita com outros métodos. Entre elas estão as propostas por instituições de pesquisa, como a EVR (Eco Value Ratio / Eco custo Valor) proposta pela Universidade Delft de Tecnologia (VOGTLANDER; BREZET; HENDRICKS, 2001). Sua abordagem se diferencia pela utilização do "eco custo", definição introduzida pelos autores, para representar a dimensão ambiental do indicador de eco eficiência.

O método, proposto por Kuosmanen e Kortelein (2005), tem o objetivo de permitir a obtenção de um único indicador de eco eficiência resultante da AEE, utilizando-se da ferramenta matemática DEA (Data Envelopment Analysis) para realização de agrupamento dos indicadores da dimensão ambiental.

Por último, identificou-se a utilização do conceito MIPS (Material Input per Service Unit/ Entrada de Material por Unidade de Serviço) como método de AEE. Sua diferenciação está na representação da dimensão econômica pelo número de vezes que o produto analisado oferece um determinado serviço (unidade de serviço) (HINTERBERGER; SCHIMIDT-BLEEK, 1999).

Pode-se ainda, avaliar aplicações de métodos de AEE em estudos de caso. Sanjuan et al. (2011) efetuaram-se a avaliação da eco eficiência de 16 cenários de produção de determinado tipo de queijo. O método utilizado foi o DEA (Data Envelopment Analysis) que resultou em indicadores de eco eficiência que permitiu a identificação dos três cenários produtivos com maior eco eficiencia.

A análise de eco eficiência pode, ainda, complementar as análises de indicadores ambientais que utilizam a Avaliação de Ciclo de Vida ambiental (ACVa). Vercalsteren, Spirinckx e Geerken (2010) observaram que por ser expresso em diversas categorias de impactos ambientais o resultado da ACVa, não foi conclusivo para uma análise de diferentes opções de copos descartáveis e reutilizáveis (PC, PP, Papelão e PLA) utilizados em eventos de pequena e larga escala realizados na Bélgica. A avaliação ocorreu para oito categorias de impacto (carcinogênicos, efeitos respiratórios causados por compostos orgânicos, efeitos respiratórios causados por compostos inorgânicos, mudança climática, destruição da camada de ozônio, extração de minerais, extrações de combustíveis fósseis, acidificação e emissão de eco tóxicos). 
A AEE, portanto, foi utilizada para dar continuidade ao estudo e introduzir a variável da dimensão econômica nos cenários analisados. Os indicadores das dimensões ambiental e econômica foram relacionados utilizando-se de uma apresentação gráfica bidimensional, onde cada dimensão foi representada por um eixo.

Concluiu-se que copos de papelão, PLA e PP possuem o mesmo impacto ambiental e menor custo em relação ao copo PC que apresenta impacto ambiental menor, porém com custo maior. Para situações em que o consumo de copos ocorre em larga escala, todas as opções apresentaram o mesmo desempenho ambiental, mas com diferentes custos. Nesta aplicação de AEE, as dimensões ambiental e econômica foram incorporadas no estudo e analisadas simultaneamente, porém sem agrupá-los em um único indicador de eco eficiência.

Este cenário de aplicações e propostas de métodos de AEE, com diferentes abordagens e enfoques, culminou na publicação da norma ISO 14045 (2012). Esta norma faz parte da série 14000 para a padronização dos sistemas de gestão ambiental (CAVALCANTI, 2000). Os objetivos da norma 14045 (2012) são: estabelecimento de terminologia clara; estrutura metodológica comum; uso prático da AEE para diferentes sistemas de produto; orientação para interpretação de resultados; e, para o encorajamento de comunicação adequada nesse campo (ISO, 2012).

A norma ISO 14045 (ISO, 2012) definiu como o "aspecto da sustentabilidade que relaciona o desempenho ambiental de um sistema de produto ao valor do sistema de produto". O sistema de produto, por sua vez, é definido como o "conjunto de processos elementares, com fluxos elementares e de produto, desempenhando uma ou mais funções definidas e que modela o ciclo de vida de um produto" (ISO, 2012). "O fluxo de produto, ainda, é a entrada ou saída de produtos provenientes de ou com destino a outro sistema de produto" (ISO, 2012). Desta forma, a terminologia utilizada para a dimensão ambiental da sustentabilidade é "desempenho ambiental de um sistema de produto" e para a dimensão econômica da sustentabilidade é "valor de sistema de produto" (ISO, 2012). Para fins dessa pesquisa, foi adotada a definição de eco eficiência apresentada pela norma ISO 14045 (ISO, 2012) devido à aceitabilidade e reconhecimento internacional da instituição proponente. Pelos mesmos motivos, 
foi utilizada como referência para identificação dos requisitos específicos para a avaliação dos aspectos relevantes de caracterização dos métodos de AEE. Por último, a norma ISO 14045 (2012) serviu também de base para aferição de terminologias.

Devido às diferentes propostas de métodos de $A E E$, depara-se com a necessidade de seleção, caracterização e avaliação dos métodos de AEE existentes. Essas etapas serão apresentadas, a seguir, no Capítulo 4. 


\section{DESCRIÇÃO DO MÉTODO DE TRABALHO}

A fim de atender de maneira satisfatória os objetivos estabelecidos, o presente estudo foi conduzido por meio do cumprimento das seguintes ações:

a) identificação junto à literatura científica, como também, à fontes não técnicas de métodos de AEE;

b) formulação e aplicação de requisito para seleção dos métodos de AEE a serem avaliados pela pesquisa;

c) caracterização detalhada de aspectos conceituais, de estrutura, bem como, usos e aplicações dos métodos de AEE selecionados;

d) formulação de requisito capaz de avaliar os métodos supracitados em termos dessas mesmas características e especificidades;

e) especificação de aplicações potenciais da AEE;

f) verificação da inter-relação entre as características dos métodos de AEE e os usos para os quais a abordagem potencialmente se destina.

Essa organização pautou também a forma de apresentação deste documento. Assim sendo, no Capítulo 5 é descrito o procedimento para a condução da pesquisa bibliográfica para obtenção das referências sobre métodos de AEE. No Capítulo 6 são descritas as ações empreendidas para formulação e aplicação dos requisitos de seleção preliminar daquelas sistemáticas. No Capítulo 7 registram-se, com grau de aprofundamento, aspectos conceituais e aplicados para os métodos de AEE selecionados. Em seguida, no Capítulo 8, são formulados e justificados os requisitos para avaliação dos métodos de AEE. No Capítulo 9 é descrita a aplicação desses requisitos sobre os métodos de AEE selecionados com vistas a identificar a abordagem mais recomendável para cada aplicação. No capítulo 10 destacam-se as principais conclusões obtidas pela pesquisa. Finalmente, no capítulo 11 são apresentadas as recomendações para trabalhos futuros. 


\section{LEVANTAMENTO DE REFERÊNCIAS A MÉTODOS DE AEE}

A revisão bibliográfica deste estudo consiste do levantamento de referências que descrevam e disponham sobre métodos de AEE. A fim de ampliar o espectro de busca e, portanto, coletar o maior número de referências possível, foram também consideradas para compor o elenco de fontes possíveis de informação, ademais de referências científicas, também aquelas obtidas de fontes não técnicas.

Para o levantamento efetuado junto à literatura de natureza científica, fezse uso da base de dados Web of Science para um horizonte temporal compreendido entre 1990 a 2015. Como indicadores de referência foram empregados na coleta: (i) o número de citações da produção; (ii) sua data de publicação; e (iii) suas aderência e relevância para com o objetivo do estudo.

Foram realizadas buscas em periódicos cuja temática de abordagem inclui o objeto de avaliação deste estudo. São eles: International Journal of Life Cycle Assessment, Journal of Cleaner Production e Journal of Ecological Economics.

A busca por literatura não científica ocorreu em portais de livre acesso com intuito de encontrar literatura técnica, apresentada em formato de artigos, guias, manuais e normas. Por outro lado, foram desconsideradas informações de fontes não fidedignas, comprováveis e não referenciáveis.

Para ambas as abordagens, iniciou-se a busca utilizando como palavraschave os nomes de métodos de AEE listados por Marzullo (2007) referenciando uma pesquisa realizada pela TÜV Anlagentechnik GmgH em 2001. A pesquisa citada pela autora não está disponível ao público, porém os nomes dos métodos de AEE analisados são apresentados: BASF, WBCSD, Shell, Storebrand, EFFAS, MIPS, COMPASS, WiFolnst Wien, DOW, Wirth, Leiden Uni, Bayer, Euromat, IÖW, Wackernagel, Sinum, Ecoindicator 95, Ecoindicator 99, EPZ Finanz, Eyerer, New Value AG e Ellipson. Estes nomes foram utilizados como palavras-chaves, combinados com o termo "eco-efficiency (eco eficiência)". Como produto dessa ação foram obtidas onze referência sobre vinte e dois dos métodos citados em Marzullo (2007), enquanto para os onze restantes - Compass, EPZ Finanz, Euromat, Eyerer, IÖW, New Value AG, Shell, Sinum, Wackernagel, Wifolnst Wien e Wirth - não foi possível coletar qualquer informação. 
Em seguida, em uma busca genérica utilizaram-se apenas as palavraschaves "eco-efficiency assessment" (AEE) e "eco-efficiency method", com o intuito de ampliar o escopo dos levantamentos para períodos de tempo posteriores às referências de Marzullo (2007). Essa ação proporcionou a identificação de outras catorze referências de métodos de AEE totalizando assim um universo potencial de vinte e cinco abordagens. Doravante, tais referências passarão a ser designadas a partir de suas origens, utilizando-se de nomes das razões sociais e/ou siglas de empresas e organizações, títulos de métodos e/ou a combinação desses títulos. São elas: BASF, DOW (Eco-Compass), Eco-Check (Bayer), EcoPas, EFFAS, Ecoindicator 95, Ecoindicator 99, EcoWater, EE Modeling based on LCA, Ellipson, GRI, Kuosmanen e Kortelainen (DEA), Leiden Uni, MIPS, Novo Nordisk, NRTEE, NSF Tool, OECD, RCR (Return to Cost Ratio), Roche (EER), Storebrand e UN ESCAP, UN (United Nations), Universidade Delft de Tecnologia (EVR) e WBCSD.

A revisão de literatura identificou ainda estudos de caso em que ocorreram aplicações de métodos de AEE, bem como, reflexões de fundo conceitual sobre o tema. Estas referências foram igualmente incorporadas ao acervo bibliográfico que suporta este estudo. Concluída essa etapa, o conjunto de referências selecionado passou a ser então analisado a partir da aplicação de requisitos de seleção que aparecem descritos em maiores detalhes a seguir no Capítulo 6. 


\section{FORMULAÇÃO E APLICAÇÃO DE REQUISITO PARA SELEÇÃO DE MÉTODOS DE AEE}

Este capítulo dispõe sobre o requisito para a seleção de métodos de AEE. Tal procedimento visa garantir que as sistemáticas a serem utilizados nesta pesquisa atendam aos requisitos minimamente aderentes com os objetivos para ela estabelecidos. Nesses termos, foram considerados como requisitos de seleção: (i) existência de conteúdo cenceitual de eco eficiência; e (ii) o grau de detelhamento e a clareza com que é apresentada a estrutura metodológica da AEE. O processo de seleção de métodos predispôs o atendimento simultâneo de ambos os requisitos e, para os casos em que isso não foi possível, o método de AEE em questão foi desconsiderado para efeito de estudo.

\subsection{Formulação de requisito geral de seleção dos métodos de AEE}

\subsubsection{Apresentação de conceito de eco eficiência}

Este requisito verifica a aderência do conceito de eco eficiência praticado pelos métodos de AEE com o objetivo deste estudo. A averiguação ocorreu por confrontação com a relação à definição constante da norma ISO 14045 (2012) tomada como referência. Em termos operacionais, permaneceram no estudo todos os métodos de AEE que praticassem conceitos iguais àquele definido pela norma, ou que guardassem graus de equivalência e/ou similaridade elevados com esse padrão.

\subsubsection{Apresentação da estrutura metodológica da AEE}

Um exame preliminar da variada gama de publicações referente à AEE, indicou que em algumas situações o termo AEE era citado sem, no entanto trazer associada uma proposta de método. Em outras situações percebeu-se que a citação de determinado método de AEE remetia a uma referência da qual, em verdade, não constava igualmente uma proposta metodológica. 
Diante desse quadro, decidiu-se que poderiam ser considerados neste estudo apenas métodos de AEE para os quais existisse uma apresentação clara, consubstanciada e, na medida da possibilidade, reprodutível quanto à estrutura metodológica.

\subsection{Aplicação do requisito de seleção dos métodos de AEE sobre as referências encontradas}

As referências a potenciais métodos de AEE foram analisadas a partir de uma sistemática que de início tratou de identificar o conceito de eco eficiência, para só então, nos casos desse requisito satisfeito, verificar a existência de estrutura metodológica bem fundamentada da AEE. O primeiro requisito foi, portanto, utilizado como eliminatório. Como resultado foram selecionadas onze referências a métodos de AEE.

Os métodos de AEE que não atenderam aos dois requisitos podem ser ainda, divididos em dois subgrupos.

O primeiro subgrupo se constitui de referências em que não se identificou com clareza um conceito de eco eficiência. São elas: Eco-Compass (Dow), EcoPas, GRI, Ecoindicator 95 e Ecoindicator 99. Uma análise das publicações que tratam do Ecoindicador 95 e Ecoindicador 99 concluiu serem estes métodos para, tão somente, a obtenção de indicadores ambientais. Já a busca por maiores detalhes quanto ao método de AEE da DOW (Eco-Compass) não proporcionou avanços além da citação do nome do método. As referências apresentaram os métodos EcoPas e GRI como abordagens para, respectivamente, a construção de indicadores e a divulgação de informações a respeito de sustentabilidade. A referência ao método de EcoPas relaciona um indicador ambiental com um parâmetro funcional ao invés do indicador de valor de sistema do produto. O GRI, de sua parte, mostra tanto indicadores de sustentabilidade, como também de eco eficiência, sempre com objetivo de divulgá-los ao público.

O segundo subgrupo de métodos é composto por aqueles cuja definição de eco eficiência ocorre por meio de fonte primária ou secundária. Nesses casos, porém, não estava disponível a estrutura metodológica para análise ou, ainda, as publicações encontradas não coadunam com a apresentação. Fazem parte desse 
subgrupo: EE Modeling based on LCA, NSF Tool, Leiden Uni, Roche, Novo Nordisk, Sotrebrand, EFFAS e OECD. O termo "Leiden Uni" faz referência às pesquisas de eco eficiência realizadas pela Universidade Leiden, de quem foram encontrados diversas publicações (HUPPES; ISHIKAWA 2005a, HUPPES; ISHIKAWA 2005b, HUPPES; ISHIKAWA 2005c). Essas foram caracterizadas como referências conceituais e guias gerais para os métodos de AEE (semelhante à norma ISO 14045) e não como um método em si.

Concluído o processo, onze métodos de AEE atenderam aos requisitos de seleção aplicados. São eles: BASF, Bayer, EcoWater, Hahn et al., Kuosmanen e Kortelainen, MIPS, NRTEE, UN ESCAP, UN, Universidade Delft de Tecnologia, e WBCSD. Suas estruturas metodológicas e particularidades são apresentadas no Capítulo 7.

Cabe por fim um esclarecimento: muito embora atenda a ambos os requisitos, a norma ISO 14045 (2012) consiste em um guia para elaboração de estudos de AEE e não é um método propriamente dito. Isso é devido a sua natureza normativa e também aos objetivos a que se propõe (apresentados no Capítulo 3). Além disso, a ISO 14045 foi criada a posteriori da grande maioria dos métodos, fato que inviabilizou sua consulta para efeito de concepção e/ou adequação dessas mesmas abordagens. Por tais motivos, a norma foi utilizada nesta pesquisa, como referência para identificação dos requisitos específicos para a avaliação dos aspectos relevantes e caracterização dos métodos.

Além disso, foram adotadas terminologias por ela propostas tal como já apresentado. Desta forma, a dimensão ambiental será nominada de indicador de "desempenho ambiental" e a dimensão econômica de indicador de "valor", ambos referentes ao sistema de produto. 


\section{CARACTERIZAÇÃO DOS MÉTODOS DE AEE SELECIONADOS}

Estão apresentados a seguir aspectos conceituais e metodológicos e as especificidades dos onze métodos de AEE considerados neste estudo. A Tabela 7.1 sintetiza as seguintes informações introdutórias dessas abordagens: (i) razão social da organização ou autor proponente; (ii) título do método; e (iii) principal referência técnica sobre o tema considerada para efeito desta análise. A sequência escolhida para apresentação dos métodos ocorre por ordenação alfabética da razão social da organização ou autor proponente dos métodos.

Tabela 7.1 - Métodos de AEE selecionados

\begin{tabular}{|c|c|c|}
\hline $\begin{array}{l}\text { Razão social da } \\
\text { organização ou autor } \\
\text { proponente }\end{array}$ & Título do Método & Principal Referência \\
\hline BASF & Método BASF & Uhlman e Saling (2010) \\
\hline Bayer & EcoCheck & $\begin{array}{l}\text { Kurunsaari, Roevekamp e } \\
\text { Okano (2003) }\end{array}$ \\
\hline EcoWater & $\begin{array}{l}\text { Programa de Pesquisa EcoWater - } \\
\text { Indicadores de eco eficiência de nível } \\
\text { meso para avaliar tecnologias e sua } \\
\text { absorção em setores de uso da água }\end{array}$ & EcoWater (2015) \\
\hline Hahn et al. & $\begin{array}{l}\text { RCR (Return to Cost Ration / Razão } \\
\text { de Retorno de Custo) }\end{array}$ & Hahn et al. (2010) \\
\hline $\begin{array}{l}\text { Kuosmanen e } \\
\text { Kortelainen }\end{array}$ & $\begin{array}{l}\text { Medindo eco eficiência de produção } \\
\text { através Análise Envoltória de Dados } \\
\text { (DEA - Data Envelopment Analysis)) }\end{array}$ & $\begin{array}{l}\text { Kuosmanen e Kortelainen } \\
\text { (2005) }\end{array}$ \\
\hline MIPS & $\begin{array}{l}\text { Schimdt-Bleek/ MIPS (Material Input } \\
\text { per Service Unit) }\end{array}$ & $\begin{array}{l}\text { Hinterberger e Schimidt- } \\
\text { Bleek (1999) }\end{array}$ \\
\hline NRTEE & $\begin{array}{l}\text { Calculando Indicadores de Eco } \\
\text { eficiência: Um Manual para a Indústria }\end{array}$ & NRTEE (2001) \\
\hline $\begin{array}{l}\text { United Nations (UN) } \\
\text { ESCAP }\end{array}$ & $\begin{array}{l}\text { Eco-efficiency indicators: measuring } \\
\text { resource-use efficiency and the impact } \\
\text { of economic activities on the } \\
\text { environment }\end{array}$ & UN ESCAP (2009) \\
\hline United Nations (UN) & $\begin{array}{l}\text { Um manual para elaboradores e } \\
\text { usuários de indicadores de eco } \\
\text { eficiência }\end{array}$ & UN (2004) \\
\hline $\begin{array}{l}\text { Universidade Delft de } \\
\text { Tecnologia (Delft } \\
\text { University of } \\
\text { Technology - TU Delft) }\end{array}$ & Modelo EVR (Eco cost Value Ratio) & $\begin{array}{l}\text { Hendricks , Vogtlander e } \\
\text { Janssen (2006) }\end{array}$ \\
\hline WBCSD & $\begin{array}{l}\text { Medindo Eco eficiência: um guia para } \\
\text { relatar o desempenho da empresa }\end{array}$ & Verfaillie e Bidwell (2000) \\
\hline
\end{tabular}




\subsection{Método BASF}

A multinacional BASF foi uma das pioneiras na proposição de um método de AEE (ULMAN; SALING, 2010). No Brasil, o método é disseminado pela Fundação Espaço $E c o ®$, uma organização independente da BASF que oferece consultoria para realização da AEE. O conceito de eco eficiência e as etapas metodológicas foram apresentados por meio de artigos científicos, sendo Saling et al. (2002) o primeiro, e foi descrito mais recentemente por Uhlman e Saling (2010). A BASF desenvolveu também outro método para quantificação de indicadores de sustentabilidade denominado SEEBalance ${ }^{\circledR}$, que além das dimensões ambiental e econômica, considera ainda a dimensão social da sustentabilidade (SCHMIDT, 2004).

Nesse contexto, a eco eficiência é apresentada como sendo a “(...) otimização ecológica dos sistemas globais enquanto não desconsiderando os fatores econômicos" (VON WEIZSACKER EU, 1999 apud SALING et al., 2002) e "(...) expressa a razão de criação econômica pela destruição ecológica" (Hungerbuhler et al., 1999 apud SALING et al., 2002). A AEE é uma ferramenta que "fornece as informações necessárias para suportar investimento interno e decisão de portfolio de produtos" e "apresenta quantidades grandes de informações complexas de forma clara e simples de compreender" (ULMAN e SALING, 2010).

A BASF evidencia o fato de que a AEE é uma avaliação comparativa, entre produtos que tenham a mesma unidade funcional ${ }^{3}$. Dessa forma, a eco eficiência de um produto é medida em relação às alternativas avaliadas e não a eco eficiência 'absoluta' de um produto. No método AEE da BASF é necessário incluir na AEE o maior número de produtos possível (até alcançar $90 \%$ das opções disponíveis no mercado para o atendimento da unidade funcional determinada) e considerar o ciclo de vida dos mesmos. Sobre o ciclo de vida são realizadas as avaliações do indicador ambiental e de valor do sistema do produto.

O primeiro passo consiste da definição do objetivo do estudo, e dos produtos alternativos. Definem-se também aspectos de escopo como unidade

\footnotetext{
${ }^{3}$ Unidade funcional: "desempenho quantificado de um sistema de produto para utilização como uma unidade de referência" (ISO 14040, 2006)
} 
funcional e limites do sistema de produto (estabelecendo, portanto, o espectro de aplicação da Avaliação de Ciclo de Vida (ACV): berço ao túmulo, berço ao portão, portão ao portão ou portão ao túmulo).

Em seguida, define-se o custo total do ciclo de vida (indicador de valor). Nesta etapa são considerados custos de matérias-primas, mão de obra, energia, capital de investimento, manutenção, transporte, afastamentos e acidentes de trabalho, despejo de resíduos, entre outros. O custo total é determinado para a unidade funcional do estudo. Uhlman e Saling (2010) esclarecem que "o método utilizado para conduzir o custo do ciclo de vida (CCV) dependerá do benefício que seja proporcionado ao consumidor, dos limites do sistema de produto, bem como, das alternativas consideradas". Porém, especificam que devem ser "considerados custos iniciais e custos futuros, assim como custos associados com impactos ambientais (e.g. aqueles associados ao despejo de resíduos)" (UHLMAN e SALING, 2010). Para isso é preciso estabeler um horizonte temporal, ou então, fazer uso de métodos que incorporem essa dimensão como valor presente líquido (VPL).

O passo seguinte é a avaliação dos impactos ambientais do sistema do produto. O método BASF conduz a avaliação a partir de seis categorias de impacto: consumo de energia, consumo de recursos, emissões (para o ar, água e solo), uso do solo, potencial tóxico e potencial de risco. A quantificação das categorias de impacto deve ser obtida de acordo com as normas ISO 14040 e 14044 (2006a, 2006b), realizando a análise de inventário do ciclo de vida ${ }^{4}$, seguido da avaliação de impacto do ciclo de vida ${ }^{5}$. Estes impactos ambientais são, agrupados, utilizando-se de procedimentos de normalizações e ponderações (UHLMAN; SALING, 2010).

O método apresenta detalhes de como caracterizar as categorias de impacto. Para os impactos de energia, são consideradas as fontes primárias de energia (gás, carvão, biomassa, energia nuclear, entre outros) expressas, em geral, em MJ/unidade funcional.

\footnotetext{
4 Análise de inventário do ciclo de vida: "[...] fase da ACV que envolve a compilação e quantificação das entradas e saídas do sistema de produto objeto do estudo" (SILVA, 2012).

5 Avaliação de impacto do ciclo de vida: "descreve as consequências ambientais dos aspectos ambientais quantificados na fase de Análise de Inventário de modo a se conhecer a significância dos impactos ambientais potenciais associados a esses aspectos ambientais" (SILVA, 2012).
} 
O consumo de recursos ao longo do ciclo de vida é ponderado de acordo com a disponibilidade de reserva explorável de cada recurso (com base em dados de referência obtidos em fontes oficiais como o US Geological Survey). Desta forma, aos recursos com quantidades maiores de reserva são atribuídos fatores de ponderação mais baixos.

Uhlman e Saling (2010) classificam as emissões para o ar nas seguintes subcategorias: aquecimento global, potencial de destruição de ozônio, potencial de criação fotoquímica de ozônio e potencial de acidificação. São também aplicados fatores de ponderação nas emissões para cada uma destas subcategorias. No aquecimento global, por exemplo, todas as emissões são expressas sob a forma de equivalentes de $\mathrm{CO}_{2}$ /unidade funcional.

Já o inventário de emissões na água deverá incluir aspectos ambientais como as Demandas Química e Bioquímica de Oxigênio (DQO e DBO), nitrogênio total, hidrocarbonetos, metais pesados, cloretos, sulfetos, amônio, fosfatos, sólidos suspensos totais e sólidos totais dissolvidos. As emissões hídricas são ponderadas de acordo com o seu volume crítico $^{6}$ e a quantidade de água não contaminada que será necessária para diluir a carga ambiental até valores aceitáveis. Desta forma, às emissões mais poluentes são atribuídos fatores de ponderação maiores.

As emissões para o solo consideram a alocação de rejeitos em cenários típicos de disposição final (e.g. aterros sanitários), sendo categorizadas em classes como: domésticas (municipais), perigosas, de construção, e mineração. $O$ fator de ponderação é obtido por relação de proporcionalidade com o custo de despejo das mesmas. A categoria de impacto uso da terra, por sua vez, avalia os impactos de diferentes formas de transformação e ocupação do solo.

A categoria de impacto potencial de toxicidade "avalia a toxicidade humana dos produtos finais, bem como de reagentes e químicos precursores necessários para sua manufatura e despejo final" (UHLMAN; SALING, 2010). Ela é baseada no potencial tóxico atribuído em diretivas da União Europeia, relacionados a efeitos à saúde humana, nas condições em que o material é manipulado, e em qual estágio do ciclo de vida ele é utilizado. A partir disso, são

\footnotetext{
${ }^{6}$ Volume crítico: definido "para cada poluente; quanto maior o perigo representado por uma substância, menor o seu volume crítico" (UHLMAN e SALING, 2010).
} 
atribuídos fatores de ponderação para cada uma das alternativas analisadas. Por último, a categoria de impacto de potencial de risco considera dados estatísticos de acidentes de trabalho e doenças ocupacionais e também os riscos físicos relacionados aquele produto.

Os passos seguintes consistem de ações de normalização, ponderação e agrupamento dos dados de inventário dos produtos analisados. A normalização é feita entre as categorias de impacto. A alternativa com maior valor de impacto recebe valor um (1) e, a partir disso, àquelas que a ela se seguem são atribuídos valores proporcionais. Concluída essa etapa é possível criar então um gráfico, como aquele apresentado na Figura 7.1, conhecido no jargão do método como "Impressão Digital Ambiental".

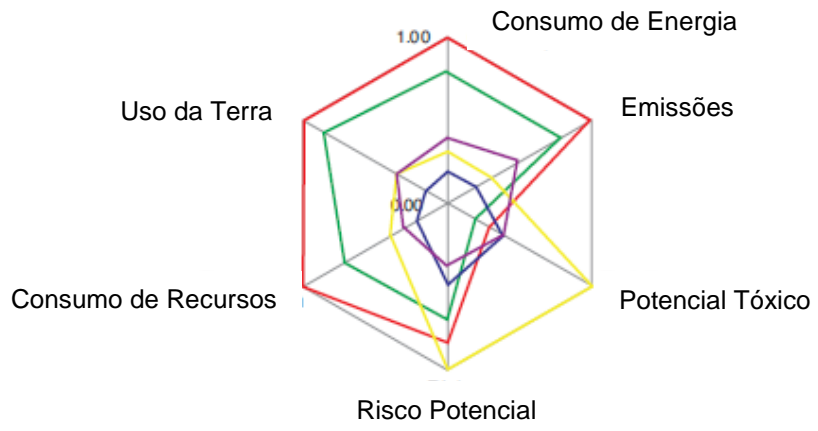

Figura 7.1 - Representação dos Impactos Ambientais da AEE Fonte: Ulman e Saling (2010)

A Impressão Digital Ambiental não registra qualquer indicador ambiental. Seus traçados permitem uma análise de tendência de desempenho dos produtos avaliados. O passo seguinte consiste na ponderação destas categorias de impacto ambiental para a obtenção do indicador ambiental único. Para tanto, são obtidos os fatores de relevância ambientais, de acordo com a contribuição de determinada categoria de impacto do produto versus a contribuição total desta categoria naquela região geográfica (impacto do produto/impacto na região). Também é considerada sua 'relevância social', que reflete a opinião da sociedade a respeito da importância do impacto ambiental obtido, utilizando-se de votações e pesquisas de mercado.

A média geométrica dos fatores de relevância ambiental e social é utilizada como um fator de relevância geral. Os resultados da normalização de cada 
impacto ambiental são então multiplicados por esse fator e somados para representar o impacto ambiental final de cada produto (ULMAN; SALING, 2010).

Os resultados normalizados dos indicadores de valor de sistema de produto, e de desempenho ambiental são confrontados em um gráfico bidimensional com perfil semelhante àquele apresentado na Figura 7.2. A fim de dar maior destaque à informação o gráfico é dividido em quadrantes, sendo o superior direito de maior eco eficiência, e o inferior esquerdo, de menor eco eficiência. Dessa forma, todos os produtos são colocados no gráfico e a análise é realizada por comparação de acordo com sua posição nos quadrantes.

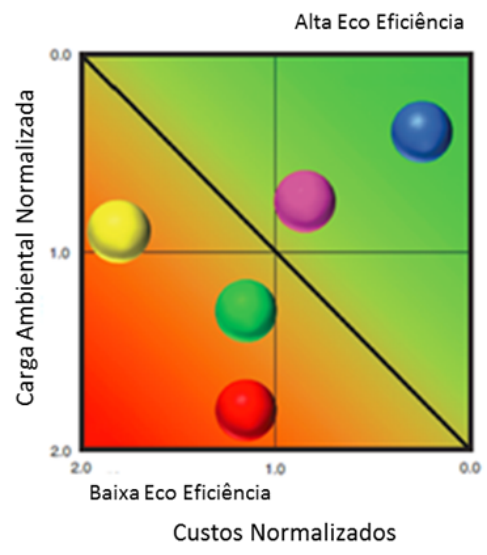

Figura 7.2 - Gráfico Bidimensional para representar resultados da AEE Fonte: Ulman e Saling (2010)

A última etapa do método consiste de uma análise de sensibilidade, que será realziada para verificar a robustez da AEE. São objetos de aferição dessa análise, os efeitos sobre resultados finais, de aspectos estruturais do estudo tais como: preimissas, limites do sistema, e fatores de ponderação da sociedade.

\subsection{Método Bayer}

O método Bayer se propõe a "avaliar grupos de produtos estrategicamente importantes e fornecer o perfil de risco de determiando produto" (KURUNSAARI; ROEVEKAMP; OKANO, 2003). Batizado como EcoCheck, o método foi proposto pela empresa Bayer em 2001 no Relatório Anual de Desenvolvimento Sustentável (Bayer Sustainable Development Report 2001) (SUSTAINABLE, 2004). Apesar do 
documento não apresentar-se em uma forma recuperável, utilizou-se a publicação de KURUNSAARI, ROEVEKAMP e OKANO (2003), que apresentaram as principais etapas do método EcoCheck. O conceito de eco eficiência utilizado pela Bayer é o mesmo apresentado pela WBCSD (World Business Council of Sustainble Development) de que eco eficiência é "atingida ao oferecer bens e serviços com preços competitivos que satisfaçam as necessidades humanas e trazem qualidade de vida, enquanto reduzem progressivamente os impactos ecológicos e intensidade de recursos durante o ciclo de vida até chegar ao nível condizente com a capacidade da terra" (SUSTAINABLE, 2004).

O método EcoCheck permite comparar "produtos ou processos de qualidade similar" (KURUNSAARI; ROEVEKAMP; OKANO, 2003). A AEE se inicia quando uma equipe composta por especialistas nos produtos ou processos em análise especifica pontos focais de cada item. Estes consistem das etapas do ciclo de vida mais importantes no sentido de tornar o produto mais competitivo no mercado, ou que representam possíveis restrições ao negócio. Outro foco desta análise são os parâmetros que estão sob o controle da empresa. Feita tal identificação o processo de avaliação dos produtos passa então por quatro etapas operacionais: definição da área temática; definição dos parâmetros; avaliação; e mapeamento da avaliação em uma escala.

As áreas temáticas representam as diferentes áreas pelas quais os produtos serão avaliados e os parâmetros são pontos específicos de cada área temática que foram definidos como críticos de acordo com o objetivo da AEE (Figura 7.3). As áreas temáticas propostas são: saúde (segurança do produto para o consumidor, processador, cliente ou colaborador), ambiente (avaliação da compatibilidade ambiental do produto), ciclo de vida (consideração de todos os possíveis efeitos de emissões intensas no ambiente e redução dos recursos naturais durante todo o ciclo de vida do produto), tecnologia (segurança de processos produtivos e disponibilidade de matérias-primas), valor público (aceitação do produto num ambiente corporativo) e economia (as oportunidades econômicas e riscos). A partir de cada área temática, determinam-se os parâmetros que serão analisados. Para a área temática economia, por exemplo, podem ser utilizados parâmetros como vendas, lucro, perspectiva de crescimento, entre outros, assim como está indicado na Figura 7.3. 


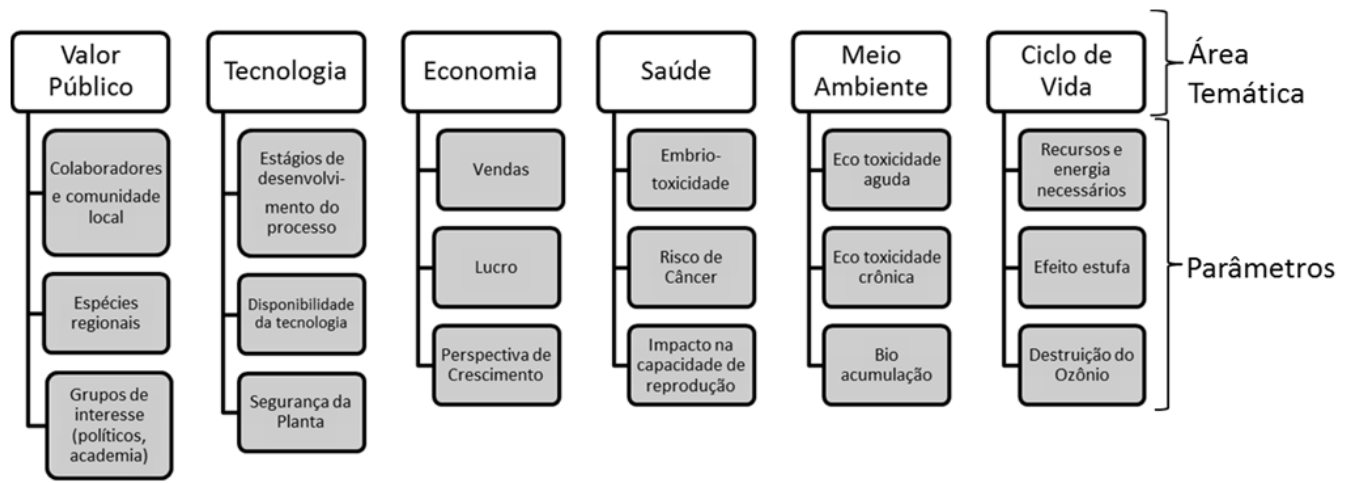

Figura 7.3 - Áreas temáticas e respectivos parâmetros

Fonte: Adaptado de Kurunsaari, Roevekamp e Okano (2003)

Os parâmetros são avaliados utilizando-se de uma escala de 1 a 5 (muito alto risco - 1 , alto risco - 2 , médio risco - 3 , baixo - 4 e muito baixo risco - 5), em relação a um ou mais aspectos. Realiza-se então o mapeamento da avaliação em uma escala, que consiste na obtenção da média das notas atribuídas a cada parâmetro Toxicidade Geral, resultando no valor da escala final para aquele parâmetro.

Os resultados dos parâmetros são então agrupados e projetados num gráfico hexagonal, sendo cada ponta representada por uma área temática (Figura 7.4). A forma de representação da relação entre o desempenho ambiental e o valor do sistema do produto permite que ambas as dimensões possam ser analisadas simultaneamente.

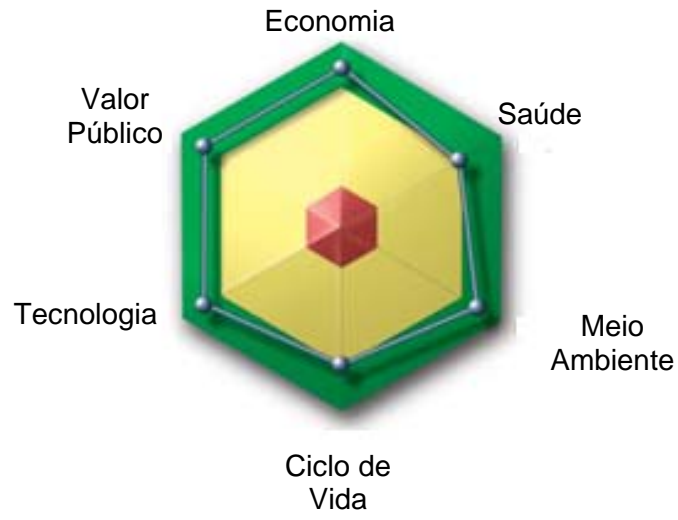

Figura 7.4 - Gráfico dos resultados do método Eco-check Fonte: Sustainable (2004) 
A interpretação dos resultados é feita de acordo com a comparação entre os produtos analisados e a zona (indicada pela cor) em que estão no gráfico. A área em vermelho representa uma zona de 'debilidade' ou fragilidade'. As áreas temáticas de cujos produtos se enquadram nesse segmento devem ser revistas. A área em amarelo refere-se a uma faixa aceitável, mas com potencial para melhoria no desempenho. Finalmente, a área em verde representa a faixa ótima de atributos. Os produtos devem ser analisados em relação aos produtos alternativos e também à sua posição individual no gráfico.

\subsection{Método EcoWater}

O programa de pesquisa EcoWater, foi financiado pelo Sétimo Programa de Pesquisa, Desenvolvimento Tecnológico e Demonstração da União Europeia (ECOWATER, 2015). A iniciativa, iniciada em 2011, compõe-se de diversas etapas de pesquisa, que se estendiam desde uma avaliação dos indicadores de eco eficiência existentes, até a criação de ferramentas de eco eficiência, passando pela formulação de proposta de método de AEE, e sua aplicação em estudos de caso.

Os resultados estão disponíveis, em grande parte, no website do projeto sob a forma de relatórios específicos para cada etapa da pesquisa (ECOWATER, 2015). O presente estudo utilizou-se principalmente do relatório denominado: "Step-wise consolidated guidelines for the development of meso-scale ecoefficiency indicators" (ANGELIS-DIMAKIS, 2015), que descreve o método para obtenção dos indicadores de eco eficiência.

Tal como sugere o próprio título, o foco desse método de AEE é a avaliação de sistema de uso de água. A motivação para a análise de sistemas de uso de água esta baseado nos seguintes fatores (i) a importância da água em grande parte dos processos produtivos; (ii) impacto ambiental e custo significativos relacionados com o tratamento da água para que esta seja aplicável em diferentes propósitos; (iii) a necessidade de uma visão holística de acesso ao desempenho de tecnologias relacionadas ao uso da água; e, (iv) o fato de que o uso de tecnologias de uso de água está relacionado a fatores regulatórios (KOURENTZIS, 2012). 
Desta forma, o objetivo do método EcoWater é desenvolver indicadores de eco eficiência em escala meso para avaliar diferentes tecnologias de uso água em processos produtivos (ANGELIS-DIMAKIS, 2015; KOURENTZIS, 2012). A escala meso refere-se ao escopo da $A E E$, que se estende desde a extração da água, até o descarte da mesma, passando por ações de tratamento e uso (Figura 7.5). Trata-se de um escopo intermediário entre a aplicação micro (referente ao processo produtivo em si), e a aplicação macro (que compreende e.g. o uso de água total em certa região). Neste contexto, os indicadores de eco eficiência devem também reconhecer os diferentes atores das etapas de suprimento de água e processo produtivo e identificar as interações econômicas entre eles.

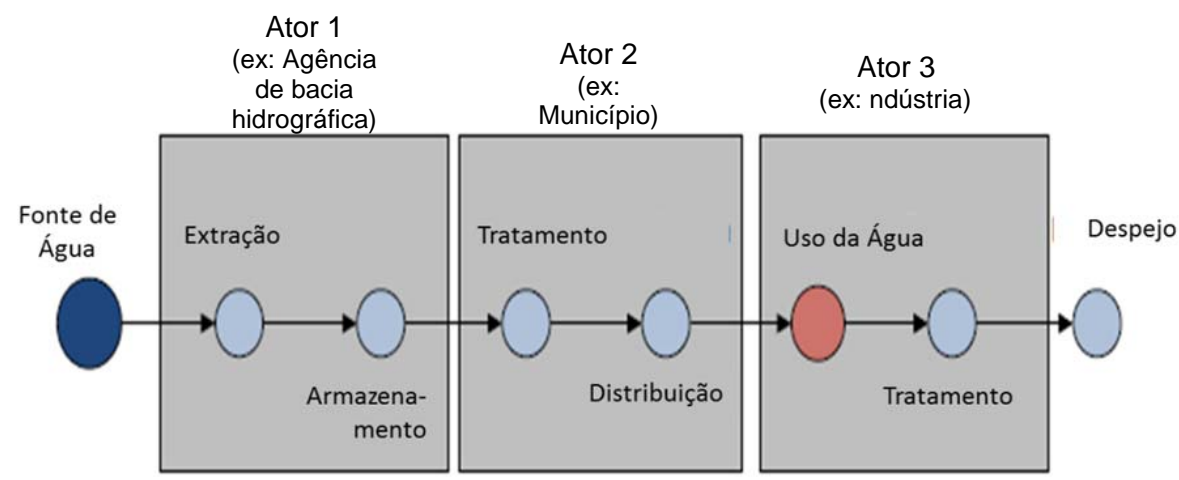

Figura 7.5 - Sistema de Uso da Água em nível Meso Fonte: Kourentzis (2012)

O método consiste em realizar uma AEE de certa tecnologia que esteja em uso (baseline), avaliar, pelo mesmo enfoque, outras tecnologias alternativas e, finalmente, comparar os valores obtidos de eco eficiência com vistas a identificar qual tecnologia será mais apropriada em relação às demais avaliadas para certo uso da água (KOURENTZIS, 2012). O método EcoWater não deixa de ser, portanto, uma análise comparativa. Nesse contexto define-se eco eficiência como a obtenção da "eficiência de recursos (minimização de recursos utilizados na produção por unidades de produtos) e produtividade de recursos (a eficiência de atividades econômicas para gerar valor agregado no uso dos recursos)" (ANGELIS-DIMAKIS, 2015). 
A estrutura metodológica apresentada pelo método EcoWater permite criar indicadores de eco eficiência como uma razão entre o indicador de valor do sistema de produto e o indicador de desempenho ambiental (Equação 7.1).

$$
\text { Eco eficiência }=\frac{(\text { Valor do sistema produto ou serviço })}{\text { Impactos ambientais }}(\text { Eq. 7.1) }
$$

A avaliação do indicador de desempenho ambiental é baseada na norma ISO 14040, consistindo na elaboração do inventário de ciclo de vida e na avaliação de impactos ambientais. São aspectos ambientais do ICV: consumo de água, uso recursos (energia, matérias primas, entre outros), emissões, além de produtos e subprodutos associados ao produto em análise.

A avaliação de impactos ambientais segue a temática descrita pela norma ISO 14040, sendo, portanto realizada para as categorias de impacto de: Mudanças climáticas $\left(\mathrm{tCO}_{2, \mathrm{eq}}\right)$, Destruição da camada de ozônio (kgCFC-11 eq), Eutrofização $\left(\mathrm{kgPO}_{2, \text { eq }}\right.$ ou $\mathrm{kgNO}$ x,eq $)$, Acidificação $\left(\mathrm{kgSO}_{2, \text { eq }}\right)$, Toxicidade humana $\left(\mathrm{kg1.4DCB}\right.$ eq ou $\left.\mathrm{CTU}_{\mathrm{h}}\right)$, Eco toxicidade aquática e terrestre $\left(\mathrm{kg} 1,4 \mathrm{DCB}_{\text {eq }}\right.$ ou $\left.\mathrm{CTU}_{\mathrm{e}}\right)$, Emissão de inorgânicos respiráveis $\left(\mathrm{kgPM}_{10, \mathrm{eq}}\right)$, Radiação ionizante (kBq $\left.\mathrm{U}-235_{\text {ar,eq }}\right)$, Formação de ozônio fotoquímico $\left(\mathrm{kgC}_{2} \mathrm{H}_{4, e q}\right)$, Depleção de recursos minerais $\left(\mathrm{kgSb}_{\mathrm{eq}}\right.$ ou $\mathrm{kgFe} \mathrm{eq}_{\mathrm{eq}}$ ), Combustíveis fósseis (MJ ou TOE), Água $\left(\mathrm{m}^{3}\right)$, e Uso do solo (ha). O método permite que sejam aplicados até catorze indicadores de desempenho ambiental que demonstrem alguma relevância com AEE. Durante as etapas de classificação e caracterização, o EcoWater se utiliza de tabelas de referência que descrevem os precursores de cada categoria em análise, bem como, seus respectivos fatores de impacto.

O indicador de valor de sistema de produto é definido a partir do parâmetro denominado Total de Valor Agregado (TVA) cuja determinação ocorre a partir da aplicação da Equação 7.2. O TVA é expresso em unidades monetárias pelo período de um ano.

$$
T V A=E V U+V P b p-T F C w s-T F C w w-F C
$$

Sendo:

TVA: Total de Valor Agregado;

EVU: valor econômico total do uso da água;

$V P_{b p}$ : receita gerada de qualquer subproduto do sistema; 
$T F C_{\text {ws: }}$ : custo total financeiro em relação à provisão de abastecimento de água para a renderização da água adequado para o propósito de uso específico;

$T F C_{w w}$ custo financeiro total relacionado com o tratamento de águas residuais;

FC: fluxo futuro anual equivalente de caixa gerado a partir da introdução de novas tecnologias no sistema.

Os indicadores de eco eficiência são apresentados sob a forma de perfil de indicadores. Cada índice refere-se a uma categoria de impacto ambiental. Quanto maior for o valor de eco eficiência, maior será a eco eficiência de uma tecnologia em relação à outra.

Num exemplo de aplicação, o método EcoWater avalia a eco eficiência de uma planta têxtil localizada em certa região da Itália (DHI et al., 2014). A indústria é responsável pelo depósito de substâncias toxicas e poluentes que potencialmente causam danos ao ambiente, os quais impactam o ecossistema aquático e a saúde humana. O objetivo dessa AEE foi de "identificar e acessar os impactos ambientais e o desempenho da eco eficiência associada com o valor da cadeia de água da indústria têxtil" (DHI et al., 2014). O escopo da análise corresponde ao processo de tingimento que pode ocorrer tanto pela rota química convencional, como por via natural. Após a aplicação do método EcoWater, obtiveram-se os indicadores de eco eficiência apresentados na Tabela 7.2 (DHI et al., 2014).

Tabela 7.2 - Indicadores de AEE de dois sistemas de corantes (padrão e natural)

\begin{tabular}{|c|c|c|c|}
\hline Indicador de Eco Eficiência & Unidade & $\begin{array}{c}\text { Tipo 1- } \\
\text { Tingimento } \\
\text { Químico Padrão }\end{array}$ & $\begin{array}{c}\text { Tipo - Tingimento } \\
\text { Natural }\end{array}$ \\
\hline Mudança Climática & Euro/CO $\mathrm{CO}_{2, \mathrm{eq}}$ & 648 & 524 \\
\hline Eutrofização & Euro/kgPO${ }_{4}^{-3}$,eq & 2065 & 2072 \\
\hline Acidificação & $\mathrm{Euro} \mathrm{kgSO}_{2}^{-}$,eq & 166 & 97 \\
\hline Toxicidade Humana & Euro/kg 1,4-DB, eq & 3,53 & 4,44 \\
\hline Eco toxicidade da água de fonte natural & Euro/kg 1,4-DB, $_{\text {eq }}$ & 0,47 & 221 \\
\hline Eco toxicidade Terrestre & Euro/kg 1,4-DB,eq & 0,05 & 453 \\
\hline Formação Fotoquímica de Ozônio & Euro/kgC ${ }_{2} \mathrm{H}_{4, \mathrm{eq}}$ & 3233 & 2160 \\
\hline Depleção abiótica de recursos & Euro/kgSb,eq $_{\text {,eq }}$ & 88,02 & 89,31 \\
\hline Depleção de fonte natural de água & Euro/m $\mathrm{m}^{3}$ & 50,99 & 55,47 \\
\hline
\end{tabular}

Fonte: DHI et al. (2014)

A partir dos resultados obtidos concluiu-se que para muitas das dimensões da análise (ou seja, indicadores de eco eficiência) há desempenhos semelhantes entre ambos os métodos de tingimento. Porém, para eco toxicidade da água de fonte natural e terrestre, o tingimento natural apresenta-se mais eco eficiência do 
que o tingimento químico, e indica que a redução do impacto ambiental supera o incremento do custo dos recursos necessários para este tipo de processo.

O programa EcoWater desenvolveu ainda um conjunto de ferramentas para aplicação da sua estrutura metodológica, denominado EcoWater Tool Kit. Figuram entre elas duas ferramentas computacionais para a obtenção dos componentes da eco eficiência: (i) SEAT (Systematic Environmental Analysis Tool), para obtenção do indicador de desempenho ambiental e (ii) EVAT (Economic Value chain Analysis Tool), para a obtenção do indicador de valor do sistema do produto.

\subsection{Método Hahn et al.}

Este método denominado RCR (Return to Cost Ratio) foi proposto por Hahn et al. (2010) como mais uma alternativa aos método de AEE existentes. Sua criação ocorreu pela identificação da necessidade de dispor de uma métrica de AEE que se aproximasse à realidade das empresas. Segundo esta abordagem a eco eficiência é avaliada com base na teoria de custo de oportunidade, pelo fato deste conceito ser relativamente uniforme, e de estar bem estabelecido entre o corpo executivo de muitas organizações, facilitando, portanto a interpretação dos resultados e permitindo identificar de maneira adequada, efeitos que influenciam a eco eficiência ao longo do tempo. O método foi concebido para ser utilizado dentro de um escopo de aplicação do tipo 'portão ao portão', ou seja, compreendendo apenas operações produtivas exercitadas por uma empresa.

O custo de oportunidade é definido como "retorno do uso alternativo de um recurso investido em uma empresa" (HAHN et al., 2010). No contexto desta AEE, o termo 'recurso', limitado à dimensão financeira na conceituação de custo de oportunidade, passa a ser extensível a recursos ambientais. O método Hahn et al. também opera à base de comparações, estabelecidas nesse caso entre eco eficiências baseadas em custos de oportunidade de uma empresa, e aquelas medidas para uma referência (benchmark), exatamente para a qual se estabelecerá o custo de oportunidade de um recurso ambiental.

Inicialmente, calcula-se o custo de oportunidade de um recurso ambiental $\left(\mathrm{OC}_{\mathrm{e}}\right)$, pelo produto entre a quantidade de recurso ambiental utilizada pela 
empresa $\left(E_{c}\right)$ e a eco eficiência da referência utilizada $\left(E_{b}\right)$, tal como indicado na Equação 7.3. De forma geral, esta referência deverá ser representada pelo uso do proposto recurso ambiental pelo mercado, por exemplo, de um país. O valor da eco eficiência da referência é obtida entre a razão do valor agregado líquido pela quantidade de consumo do recurso ambiental.

$$
O C e=E c * E E b \quad(\text { Eq. 7.3) }
$$

No passo seguinte, obtêm-se o valor de eco eficiência baseada no custo de oportunidade de um recurso ambiental $\left(E_{\mathrm{oc}}\right)$. Isso ocorre por meio da relação entre o retorno financeiro da companhia ao utilizar um recurso ambiental (Rc: indicador de valor do sistema de produto) e o custo de oportunidade desse recurso ( $\mathrm{OC}_{\mathrm{e}}$ : indicador de desempenho ambiental) (Equação 7.4). No exemplo apresentado pelo método o indicador de valor de sistema de produto $\left(R_{c}\right)$ aparece representado pelo valor agregado líquido. Traçando um paralelo com as demais abordagens de AEE tratadas neste estudo, para o caso presente $R_{c}$ representa 0 indicador de valor de produto, enquanto que $\mathrm{OC}_{\mathrm{e}}$ refere-se ao indicador de desempenho ambiental.

$$
E E O c=R c / O C e \quad(\mathrm{Eq} .7 .4)
$$

Outro exemplo de aplicação do método Hahn et al. (2010) busca determinar a eco eficiência do uso de $\mathrm{CO}_{2}$ pela empresa Bayer, em comparação ao consumo de $\mathrm{CO}_{2}$ pelo mercado da Alemanha (referência) no ano de 2004. No período a Bayer emitiu 4,10 $\mathrm{Mt} \mathrm{CO}_{2}\left(\mathrm{E}_{\mathrm{c}}\right)$ e teve um valor agregado líquido de 7,92 MM€. No mesmo intervalo de tempo Alemanha emitiu cerca de $886 \mathrm{Mt} \mathrm{CO}_{2}\left(\mathrm{E}_{\mathrm{c}}\right)$, angariando com a ação 1889 MM€ em valor agregado líquido. Desta forma, as respectivas eficiências EE são 1931€/t $\mathrm{CO}_{2}$ para a Bayer e $2133 € / T \mathrm{CO}_{2}$ para a Alemanha. O custo de oportunidade do $\mathrm{CO}_{2}$ é, portanto, de 8,74MM€ $(=4,10 \mathrm{Mt}$ $\mathrm{CO}_{2}$ * $\left.2133 € / \mathrm{tCO}_{2}\right)$. Finalmente a eco eficiência baseada em custo de oportunidade $\left(E_{\mathrm{oc}}\right)$ é de 0,905.

O passo seguinte do método é a representação da eco eficiência baseada no custo da oportunidade $\left(E_{e, o c}\right)$ sob a forma de um fator medido em relação a 
um valor unitário (representado pelo custo de oportunidade da referência utilizada). Este indicador é denominado de RCR (Return to Cost Ratio). Dependendo da sua relação como benchmark há duas possibilidades de representação do RCR; estas aparecem indicadas a seguir pela Equação 7.5.

$$
\begin{gathered}
\text { RCR e }=\text { EEoc }: 1 \text {, se EEoc } \gg 1 \\
\text { ou } \\
R C R e=1: 1 / \text { EEoc }, \text { se EEoc }<1
\end{gathered}
$$

Se aplicado para o exemplo anterior, a representação do RCR da empresa Bayer seria $[1,0: 1,1]$ situação que indica que a empresa está abaixo do custo de oportunidade do $\mathrm{CO}_{2}$ por um fator de 1,1, ou seja, a sua eficiência em relação à emissão de $\mathrm{CO}_{2}$ está 1,1 vezes abaixo da eficiência nacional alemã de emissão de $\mathrm{CO}_{2}$ no ano de 2004 (HAHN et al., 2010).

Sendo o indicador de eco eficiência baseada no custo da oportunidade este irá depender do uso do recurso ambiental (e); do retorno financeiro obtido pela empresa ( $r$ ); e da definição do benchmark (b). Diante desse quadro os autores do método Hahn et al. propõe que, ao longo do tempo, efetue-se uma avaliação de qual desses fatores será mais determinante por impor alterações à eco eficiência de uma empresa. Para isso, são calculados os efeitos de cada um deles em relação aos tempos determinados ( $\mathrm{t}_{0}$ e $\mathrm{t}_{1}$ ) (Equação 7.6, 7.7 e 7.8). Esta análise permite compreender que efeitos deverão ser considerados em processos de tomada de decisão na empresa.

$$
\begin{aligned}
& \mathrm{e} e=\frac{E C, t 1}{E C, t 0} \\
& \mathrm{e} r=\frac{R C, t 1}{R C, t 0} \\
& \mathrm{e} b=\frac{E E b, t 1}{E E b, t 0}
\end{aligned}
$$

Em mais uma aplicação, os autores apresentam o RCR de emissão de $\mathrm{CO}_{2}$ para diversas empresas, entre as quais se encontra a Thyssen Krupp Steel's (TKS). A Figura 7.6 descreve o RCR da empresa entre 2002 e 2004, bem como, 
os efeitos ( $\boldsymbol{r}, \boldsymbol{b}$ e $\boldsymbol{e})$. Avaliando em detalhes o perfil de evolução, observa-se ter havido uma melhora importante no valor do $\operatorname{RCR}$ de $[1.0: 25,8]$ para $[1,0: 15,2]$ indicando assim ganho de eco eficiência em termos de emissão do $\mathrm{CO}_{2}$.

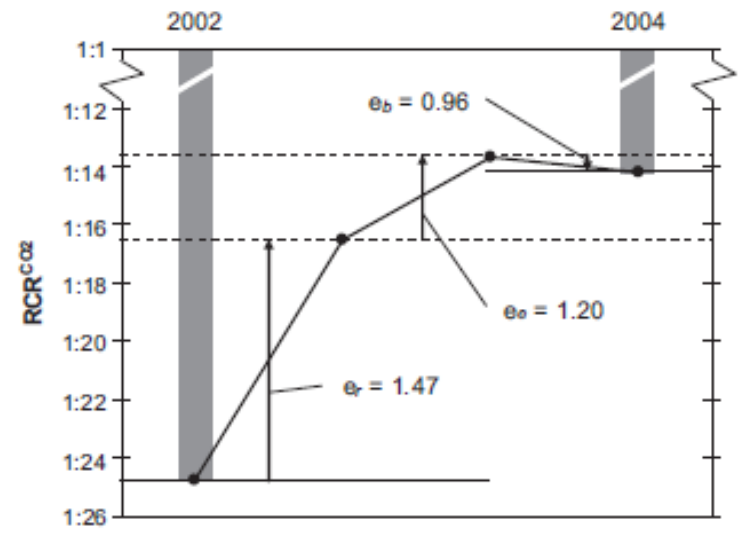

Figura 7.6 - RCR de $\mathrm{CO}_{2}$ para a empresa TKS de 2002 a 2004

Fonte: Hahn et al., 2010

\subsection{Método Kuosmanen e Kortelainen}

Kuosmanen e Kortelainen (2005) apresentam em um artigo científico uma proposta para a realização da AEE, com foco particular na etapa de agrupamento dos indicadores ambientais obtidos na análise. Como discutido previamente, a formulação de indicadores únicos pode ser realizada por diferentes métodos. Um traço comum de todas essas abordagens está no grau de subjetividade introduzido não apenas pelos dados ali empregados, mas também, e muitas vezes, pela forma como esses são tratados. A aplicação de lógicas matemáticas reduz, ao menos em tese, esse efeito. Essa característica confere ao método Kuosmanen e Kortelainen (2005) um diferencial pela relevância em termos científicos. A descrição do método, por outra parte, está limitada à disponibilidade, bastante restrita, de informação quanto a seus elementos estruturais, e a detalhes sobre suas etapas executivas.

Para Kuosmanen e Kortelainen (2005) a eco eficiência é definida como a capacidade de produzir bens, causando mínimos impactos ambientais. É também uma análise comparativa, que pode ser empregada entre produtos e tecnologias, 
apesar de não estar esclarecido no método quais as limitações de uso. A função que relaciona os indicadores é expressa por (Equação 7.9):

$$
\text { Eco Eficiência }=V n / D(Z n) \quad(\text { Eq. 7.9) }
$$

O indicador econômico é representado pelo índice de Valor agregado $\left(V_{n}\right)$ - expresso em unidade monetária, e que pode ser obtido pela diferença entre a Receita total da empresa $\left(\mathrm{R}_{\mathrm{T}}\right)$ e o Custo $(\mathrm{C})$ de produção (Equação 7.10).

$$
V n=R t-C \quad(\text { Eq. } 7.10)
$$

O indicador ambiental $\left(Z_{n}\right)$ deverá ser expresso em termos dos impactos ambientais relevantes para o produto analisado. Os autores discutem as vantagens de analisar o impacto ambiental ao invés de apenas o aspecto ambiental, que pode deixar de capturar o real problema em questão.

Os autores argumentam que uma análise de eco eficiência deverá resultar em um único indicador, e não, em múltiplos indicadores, quando se trata de avaliar a dimensão ambiental. Portanto, os desafios nesse caso residem em harmonizar as diferentes naturezas (unidades) dos indicadores ambientais e, na escolha dos pesos de ponderação a ser atribuídos a cada um deles.

A solução descrita no método Kuosmanen e Kortelainen para contornar tais fontes de imprecisão consiste na utilização da Análise Envoltória de Dados (Data Envelopment Analysis - DEA) como recurso de agrupamento, representado pela função D na Equação 7.9. A utilização do DEA permite encontrar os pesos de cada indicador ambiental que maximizam a eficiência ("fronteira de eficiência"), em relação a um grupo de dados semelhantes aos avaliados, por meio de programação linear.

Como exemplo de aplicação dessa abordagem, Kuosmanen e Kortelainen avaliaram a eco eficiência do transporte por estradas de três cidades. Para tanto, fez-se necessário constituir um grupo de referência composto por todas as demais cidades de mesmo porte que as avaliadas existentes no país.

Kuosmanen e Kortelainen imputam como principal vantagem do uso da DEA para o caso presente a desobrigação de realizar ponderações de dados 
subjetivos e carentes de rigor científico (KUOSMANEN; KORTELAINEN, 2005). Por outro lado, os autores admitem que a coleta de dados de referência para aplicação da técnica em questão pode representar esforço considerável na condução da AEE.

Em termos operacionais, a ferramenta do DEA se utiliza de um programa computacional para determinar, de forma gráfica, as "fronteiras de eficiência" para determinada tecnologia em análise. Dentro desse cenário são estabelecidos fatores de ponderação que resultem em uma eficiência máxima (ou seja, 'fatores ótimos').

O resultado é um valor de eco eficiência para cada produto em questão, que serão distribuídos em uma escala de valores que varia entre $0-1.0$, na qual o valor 1.0 representa o máximo da eficiência. Assim, certa unidade produtiva será classificada como eco eficiente caso apenas não seja de fato possível diminuir um determinado impacto ambiental sem que simultaneamente outro se eleve, ou que o valor agregado seja reduzido.

A interpretação dos resultados proporcionados pelo método de Kuosmanen e Kortelainen poderá ser feita somente entre os dados analisados, por conta de se tratar de uma análise comparativa. Caso o conjunto de dados de referência seja alterado, os resultados dele derivados também fatalmente o serão, ressaltando uma das fraquezas do modelo (KUOSMANEN; KORTELAINEN, 2005).

No exemplo apresentado no Capítulo 3 deste estudo Sanjuan et al. (2011) utilizaram o modelo DEA com adaptações e obtiveram a análise de eco eficiência de dezesseis processos de manufatura de queijo. A adoção dessa abordagem possibilitou a comparação entre os processos e definição daquele com maior grau de eco eficiência.

\subsection{Método MIPS (Material Input per Service unit)}

A sigla MIPS representa a abreviação de Entrada de Material por Unidade de Serviço (Material Input per Service Unit). Este conceito foi apresentado por Schmidt-Bleek como um indicador de eco eficiência em 1992 (HINTERBERGER; 
SCHMIDT-BLEEK, 1999). Neste contexto, eco eficiência é definida como "a soma dos materiais consumidos do berço ao túmulo dividido pela soma dos serviços oferecidos" (SAARI et al., 2006). Diversos artigos científicos foram utilizados para apreender a lógica do método MIPS como indicador de eco eficiência; são estes: Hinterberger e Schmidt-Bleek (1999) Saari et al. (2006) e Kotakorpi, et al., (2008). Este método também é comparativo e os resultados de um produto são analisados em relação a outro com função semelhante. Como sugerido pelo próprio titulo, o indicador de eco eficiência que resulta do MIPS é representado pela razão entre a entrada de material e a unidade de serviço (Equação 7.11).

$$
M I P S=\frac{\text { Entrada de Material }}{\text { Unidade de Servico }}(\mathrm{Eq} .7 .11)
$$

A entrada de material representa o indicador de desempenho ambiental. Ele é obtido realizando-se a soma dos materiais consumidos em todo o ciclo de vida do produto, dentro de classes como: materiais abióticos; materiais bióticos; erosão e/ou movimentos na terra em agricultura e florestas; água; e ar (SAARI et al., 2006; KOTAKORPI et al., 2008).

Os materiais abióticos são representados por recursos ou mesmo, por itens de procedência não renováveis, e, portanto, os materiais bióticos serão sinônimos para esta situação, de renovabilidade. O consumo de ar representa "a quantidade de constituintes atmosféricos a serem quimicamente alterados por ação antropica" (KOTAKORPI et al., 2008), ou ainda, e apenas, a taxa de oxigênio comburido.

O indicador de valor do sistema de produto é representado pela unidade de serviço, a qual se refere à quantidade de vezes que o serviço a ser realziado por aquele produto é oferecido. No caso de uma máquina de lavar, o indicador de valor do sistema de produto poderá ser representado pela quantidade de ciclos que a máquina pode operar (KOTAKORPI et al., 2008).

Os indicadores de eco eficiência são e apresentados sob a forma de um perfil de indicadores, sendo cada um destes últimos, representado pelas categorias de matérias utilizadas, tal como aparece indicado no exemplo constante da Figura 7.7. Nesta ilustração são apresentados os valores de MIPS de recursos abióticos para diferentes tipos de transporte (carro, ônibus e bicicleta). A unidade do indicador de eco eficiência (MIPS) dependerá daquela 
utilizada para representar a unidade de serviço. No exemplo da Figura 7.7, esta foi definida como sendo ' $\mathrm{kg} /$ pessoas- $\mathrm{km}$ ', e representa a massa deslocada por certo meio de transporte por pessoa ao longo de distância unitária. São ainda apresentadas dois indicadores MIPS utilizando-se de duas abordagens de alocação dos aspectos da estrada entre veículos leves (carros) e pesados (ônibus). A primeira, denominada 'veículo', se baseia na média diária de trânsito para realização da alocação. Já a alocação, denominada de 'peso bruto', além da média diária de trânsito, utiliza-se também do peso bruto dos veículos para a alocação dos elementos da estrada.

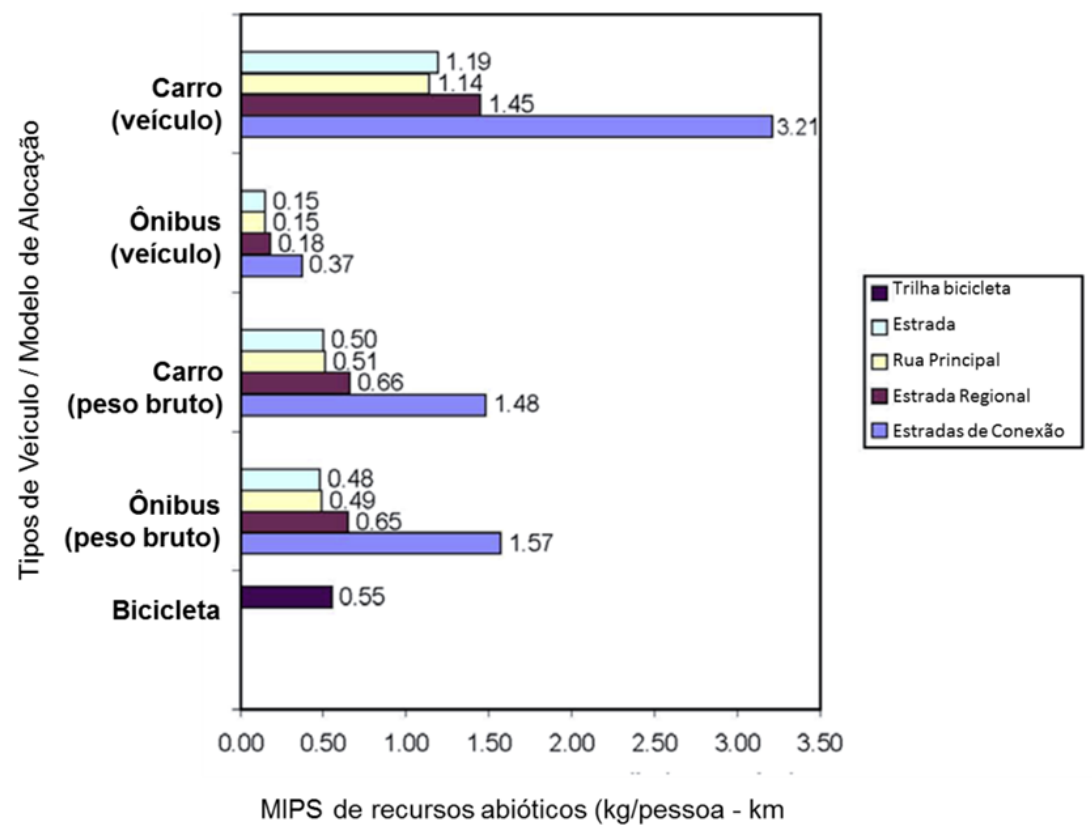

Figura 7.7 - Indicador MIPS de recurso abiótico (kg/pessoa-km)

Fonte: Saari et al. (2006)

Schimdt-Bleek (apud HINTERBERGER; SCHMIDT-BLEEK, 1998) propõe ainda que a utilização de MIPS como uma medida para estimar eco eficiência não somente em produtos, mas também de infraestruturas e serviços, em níveis macro, e para a elaboração de políticas ambientais. 


\subsection{Método NRTEE}

A National Round Table on the Environment and the Economy (NRTEE) foi uma instituição canadense que reuniu representantes de empresas, do meio acadêmico, e de entidades ambientais para tratar de assuntos relativos ao desenvolvimento sustentável (NRTEE, 2001). Há alguns anos a NRTEE identificou a necessidade de padronizar indicadores, conceitos e definições, e regras sobre AEE para permitir que os dados disponíveis nesse segmento fossem comparáveis entre empresas e unidades de negócio.

Nesse contexto, NRTEE disponibilizou um manual para a indústria, baseado nos princípios estabelecidos pela WBCSD (NRTEE, 2001), com foco na análise e na publicação de indicadores de eco eficiência para o uso de energia, despejo de resíduos, e uso água, tratados pela publicação como indicadores principais. Para tanto, a NRTEE se baseou em dois dos sete elementos essenciais de eco eficiência apresentados pela WBCSD: (i) redução de material requerido para bens e serviços; e (ii) redução de energia para bens e serviços. Indicadores ditos complementares podem, no entanto, serem ainda adicionados a essa avaliação.

O manual foi elaborado em conjunto com vinte e duas empresas, entre as quais se destacam Tetra Pak, DuPont, General Motors, Procter\&Gamble, BASF e Nestlé que se dispuseram a aplicar o conceito do método NRTEE, provendo assim a organização com informações e dados (NRTEE, 2001).

Na primeira etapa de aplicação do método NRTEE determina-se "para que" e "para quem" será destinado o resultado de eco eficiência. O diretor financeiro e o diretor de manufatura, por exemplo, podem ter necessidades diferentes de informação. A partir daí, estabelecem-se os limites, período e indicadores apropriados para o projeto. O limite da avaliação pode se referir a um produto, uma área produtiva ou de manufatura, unidade de negócio ou mesmo, toda a empresa, tal como aparece representado na Figura 7.8. Esta característica destaca o âmbito de aplicação do método NRTEE dentro do limite de "portão ao portão", ou seja, nos intramuros da empresa.

O método não exige nem exclui a possibilidade de utilização da lógica do ciclo de vida. No entanto, para os casos em que isso cabe, apresenta um 
indicador que abrange todo o ciclo de vida ou mesmo, outras de suas etapas, como indicador complementar. A decisão da utilização do ciclo de vida dependerá das informações disponíveis e do objetivo da AEE e, para estes casos, o método NRTEE sugere utilizar de indicadores adicionais aos apresentados no guia.

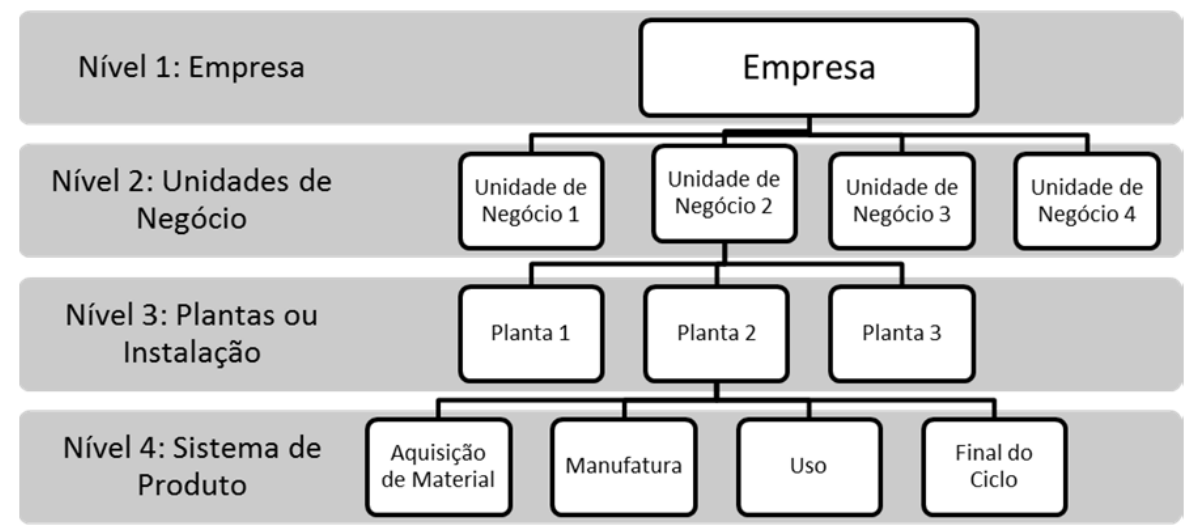

Figura 7.8 - Possíveis limites para os indicadores de eco eficiência

Fonte: NRTEE (2001)

O período analisado deverá ser determinado para que todos os dados sejam coletados na base e também, para verificar se a informação disponível atende ao período estabelecido. Da mesma forma, uma frequência da determinação dos indicadores deverá ser estabelecida para propiciar comparação ao longo do tempo. O indicador de eco eficiência é definido como a relação entre a carga ambiental (consumo de energia, despejo de resíduos ou consumo de água) e a unidade de produção ou serviço (Equação 7.12). Após serem elaborados, os indicadores serão apresentados sob a forma de perfil ambiental, sem sofrer de qualquer mecanismo de agrupamento.

$$
\text { Eco eficiência }=\frac{\text { Carga ambiental }(\text { energia,consumo ou água })}{(\text { unidade de produção ou serviço })}
$$

O denominador, referente ao indicador econômico, pode ser expresso em unidades físicas (e.g. toneladas de produto) ou monetárias (receitas obtidas com vendas). A unidade monetária deverá, porém, ser usada com cautela dada a variação de preços que pode afetar a comparação ao longo do tempo (NRTEE, 2001). 
Diretrizes quanto à forma de elaboração de cada indicador de eco eficiência são apresentadas com vistas a orientar a coleta das informações a serem incluídas na avaliação. Para o indicador de energia, por exemplo, estas orientam sobre quais fontes de energia devem ser incluídos (eletricidade, óleo, gás, carvão, eólica, entre outras). As diferentes fontes de energia devem então ser agrupadas em indicador único (expresso em $\mathrm{MJ}$ ) para que possam ser somadas, compondo, neste caso, o indicador de consumo de energia. O indicador de valor de sistema também deverá ser identificado, assim como a sua unidade, de acordo com o objetivo do projeto. Após a obtenção dos indicadores de desempenho ambiental e de valor do sistema do produto, utiliza-se da equação de eco eficiência, (Eq. 7.12), para obtenção dos indicadores de eco eficiência. O mesmo procedimento deverá ser aplicado para a obtenção dos indicadores de despejo de resíduos e consumo de água, para os quais o método NRTEE também apresenta detalhes quanto à obtenção.

Além do período selecionado para a análise, e dos limites de aplicação do método, a comunicação final dos resultados deve ser feita indicando os motivos da escolha desses itens e o valor obtido para o parâmetro 'unidade de produção ou serviço'. Além disso, devem constar da mesma comunicação o resultado da razão entre indicadores, e os valores absolutos utilizados para estimativa do indicador de eco eficiência. Recomenda-se por fim apresentar os indicadores ao longo do tempo.

O resultado final do método NRTEE será expresso por meio dos indicadores de eco eficiência de uso de energia, resíduos e água, e de indicadores complementares. A Figura 7.9 mostra um exemplo do perfil de desempenho, ao longo do tempo, do indicador de intensidade de energia para certa empresa.

Em termos metodológicos, é possivel observar para o caso em questão, o grau de sensibilidade do indicador de eco eficiência (linha pontilhada) com relação aos demais, de desempenho ambiental (kWh) e valor de sistema de produto (unidades de produção), que estão registrados, respectivamente pelas barras de cores azul e verde 


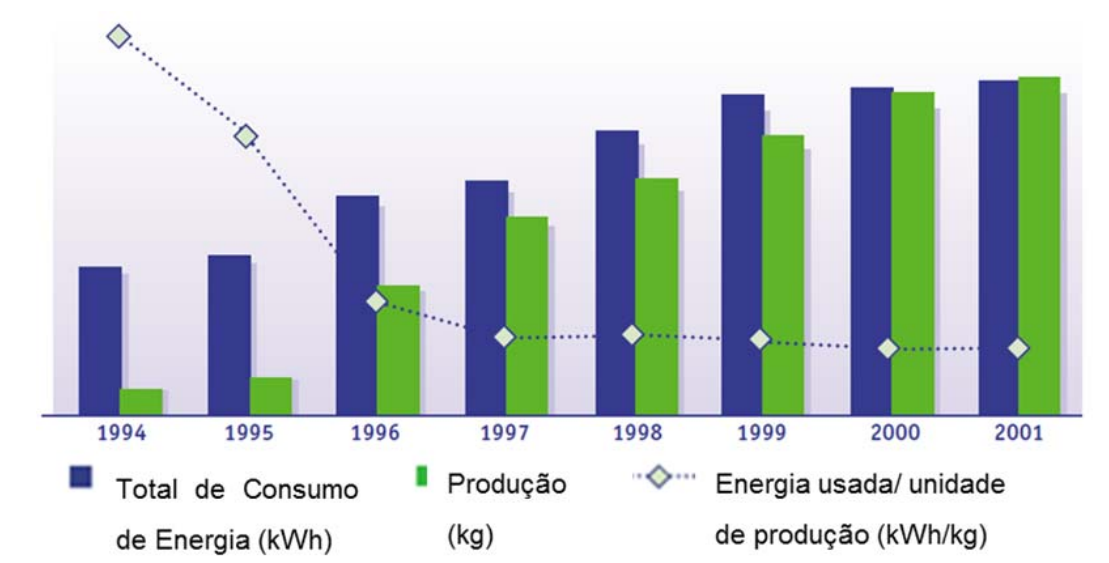

Figura 7.9 - Exemplo de perfil de variação do indicador de consumo de energia Fonte: NRTEE (2001)

\subsection{Método UN ESCAP}

Este método de AEE foi desenvolvido pela United Nations Economic and Social Comission for Asia and the Pacific (UN ESCAP) em 2009. A iniciativa se propõe a apresentar indicadores de eco eficiência para relacionar "atividade econômica, uso de recursos, e impactos ambientais, com vistas a avaliar políticas ambientais com mais eficiência, e auxiliar os elaboradores de políticas públicas a melhorar a eco eficiência do crescimento econômico" (UN ESCAP, 2009).

O método foi também desenvolvido com o intuito de expandir o conceito de eco eficiência, originalmente era limitado às operações da empresa (aplicação micro, como apresentado pela WBCSD), para regiões e países (aplicação macro). Desta forma, o método UN ESCAP permitiria a aplicação do conceito de eco eficiência por gestores públicos e legisladores como indicador de desempenho a ser usado na formulação de políticas públicas (UN ESCAP, 2009).

Tendo em vista suas características e abrangência (de amplitude macro) o método considera que os indicadores de eco eficiência não seriam agregados ou normalizados, mas sim, apresentados sob a forma de perfil de indicadores. $\mathrm{O}$ perfil seria representativo de atividades e setores econômicos considerados relevantes por gestores públicos. É também um método comparativo, ao permitir confrontar a eco eficiência de certa região ao longo do tempo, medindo assim sua 
potencial evolução; ou, comparando desempenhos de diferentes regiões (UN ESCAP, 2009).

Neste caso, a eco eficiência corresponde à razão estabelecida entre custo ambiental (indicador de desempenho ambiental) e resultado econômico (indicador do valor do sistema de produto), assim como consta da Equação 7.13.

$$
\text { Eco eficiência }=\frac{\text { custo ambiental }}{\text { resultado economico }}(\text { Eq 7.13) }
$$

Utilizando-se desse conceito de eco eficiência, o método apresenta um guia para os indicadores aplicáveis, os são apresentados na Tabela 7.3. São apresentados exemplos de indicadores de eco eficiência utilizando diferentes indicadores de desempenho ambiental e de valor do sistema de produto. Observa-se que são utilizadas unidades físicas para representar o indicador de desempenho ambiental e unidades monetárias para representar o indicador de valor de sistema de produto. O método faz divisão em indicadores de "intensidade de uso de recursos" e "intensidade de impacto ambiental", sendo a diferença entre eles a forma como é expresso o indicador de desempenho ambiental (UN ESCAP, 2009). Além disso, determina-se também o resultado do quociente entre indicadores gerais da economia (nos níveis micro e macro de eco eficiência, do crescimento econômico e da sociedade) e indicadores específicos para cada setor (agricultura, indústria, manufatura, setor público e de serviços, e transporte) (UN ESCAP, 2009).

Tabela 7.3 - Exemplo de indicadores de Eco Eficiência do método da UN ESCAP Intensidade de Uso de Recursos Intensidade de Impacto Ambiental

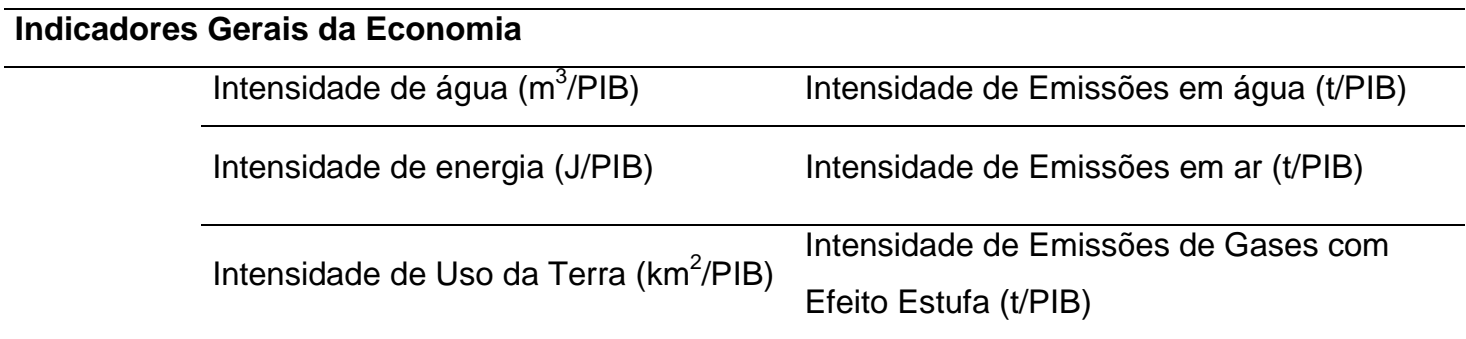




\begin{tabular}{|c|c|c|}
\hline & Intensidade de Material (DMIT/PIB) & \\
\hline \multicolumn{3}{|c|}{ Indicadores de Setores } \\
\hline \multirow{3}{*}{ Agricultura } & Intensidade de água (m³/PIB) & Intensidade de emissões de $\mathrm{CO}_{2}$ (t/PIB) \\
\hline & Intensidade de energia (J/PIB) & \\
\hline & Intensidade de uso da Terra (km²/PIB) & \\
\hline \multirow{3}{*}{ Indústria } & Intensidade de energia (J/PIB) & Intensidade de emissões de $\mathrm{CO}_{2}(\mathrm{t} / \mathrm{PIB})$ \\
\hline & Intensidade de água (m³/PIB) & $\begin{array}{l}\text { Intensidade de descarte de resíduos Sólidos } \\
\text { (t/PIB) }\end{array}$ \\
\hline & Intensidade de material (DMI/PIB) & \\
\hline \multirow{3}{*}{ Manufatura } & Intensidade de energia (J/PIB) & Intensidade de emissões de $\mathrm{CO}_{2}$ (t/PIB) \\
\hline & Intensidade de água (m³/PIB) & Intensidade de DBO (t/PIB) \\
\hline & Intensidade de material (DMI/PIB) & $\begin{array}{l}\text { Intensidade de descarte de resíduos sólidos } \\
\text { (t/PIB) }\end{array}$ \\
\hline \multirow{3}{*}{$\begin{array}{l}\text { Setores } \\
\text { Públicos e } \\
\text { Privados }\end{array}$} & Intensidade de energia (J/PIB) & Intensidade de emissões de $\mathrm{CO}_{2}$ (t/PIB) \\
\hline & Intensidade de água (m³/PIB) & Intensidade de descarte de água (m³/PIB) \\
\hline & Intensidade de uso da Terra (km²/PIB) & $\begin{array}{l}\text { Intensidade de resíduos sólidos municipais } \\
\text { (t/PIB) }\end{array}$ \\
\hline $\begin{array}{l}\text { Setor de } \\
\text { Transportes }\end{array}$ & $\begin{array}{l}\text { Intensidade de uso de combustível } \\
\text { (J/PIB) }\end{array}$ & Intensidade de emissões de $\mathrm{CO}_{2}$ (t/PIB) \\
\hline
\end{tabular}

Fonte: UN ESCAP (2009)

Para emissões hídricas faz-se uso de DBO e DQO (Demandas Química e Bioquímica de Oxigênio), enquanto para as emissões para o ar, são consideradas perdas de $\mathrm{NO}_{x}, \mathrm{SO}_{x}, \mathrm{CO}$, entre outros (com exceção dos Gases de Efeito Estufa). As emissões de gases de efeito estufa, por sua vez, incluem $\mathrm{CO}_{2}$, metano $\left(\mathrm{CH}_{4}\right)$ óxido de dinitrogênio $\left(\mathrm{N}_{2} \mathrm{O}\right)$, hexafluoreto de enxofre $\left(\mathrm{SF}_{6}\right)$, perfluorocarbono, e hidrofluorocarbono.

O material de referência disponível sobre o método UN ESCAP traz ainda alguns estudos de caso para regiões (nordeste da Ásia) e paises (Vietnam) (UN ESCAP, 2009). O perfil de indicadores pode ser apresentado de forma numérica ou gráfica. Um exemplo para esta segunda possibilidade aparece indicado na Figura 7.10 que descreve os indicadores de eco eficiência do uso de energia para diversos países no período de tempo compreendido entre 1990 e 2006. Os

\footnotetext{
${ }^{7}$ DMI: entrada direta de material / direct material input.
} 
valores são expressos em termos da relação entre o consumo energia (em kg equivalentes de óleo) e o PIB de cada nação.

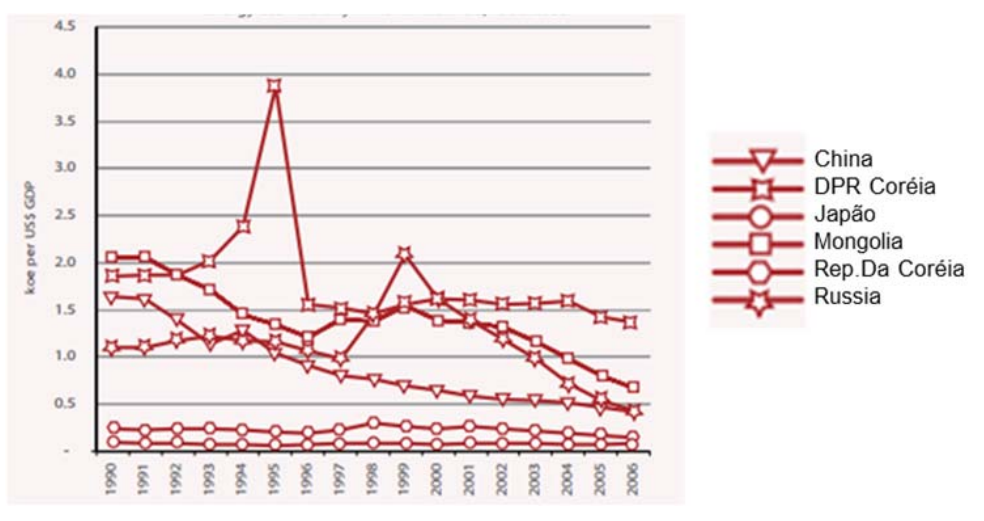

Ilustração 7.10 - Intensidade de uso de energia (kg equivalente de óleo/\$) na região nordeste da Ásia

Fonte: UN ESCAP ( 2009)

\subsection{Método United Nations (UN)}

O método cuja elaboração pode ser atribuída às Nações Unidas (UN) é o último de uma serie de três publicações relacionadas a aspectos econômicos e ambientais de empresas. O método UN (2004), foi elaborado com o objetivo de apresentar um guia para definição, reconhecimento, medição e divulgação de informações ambientais e econômicas utilizando-se de meios tradicionais para contabilidade e comunicação de dados. Além disso, tem o propósito de melhorar e harmonizar métodos para que a divulgação de indicadores de eco eficiência seja padronizada e ocorra de forma relevante, permitindo comparações entre desempenhos de empresas do mesmo segmento e dando suporte à processos gerenciais de tomada de decisão.

A principal característica desse método está no embasamento dos conceitos de contabilidade financeira por ele empregados, como o International Accounting Standards (IAS), para a apresentação da AEE. A lógica por detrás do método UM (2004) compreende utilizar padrões já conhecidos para estabelecer e 
prover informações aplicáveis a um grande número de usuários possibilitando assim uma comparação dos indicadores de uma empresa ao longo do tempo.

O guia apresenta uma estrutura geral da análise de eco eficiência, estabelecendo o objetivo, seu escopo (e.g. os objetivos dos indicadores de eco eficiência) e a quem ele se refere (e.g. o setor privado, mas que também é extensível ao setor público). O indicador de eco eficiência é definido como a razão entre uma variável ambiental e uma variável financeira (Equação 7.14).

$$
\text { Eco eficiência }=\frac{\text { Variável Ambiental }}{\text { Variável Financeira }}
$$

No método UN (2004), a AEE restringe-se aos limites físicos de uma empresa ou região (abordagem do tipo 'portão ao portão'). Apesar dos benefícios que proporciona, a abordagem de ciclo de vida é vista nesse caso como custosa e pouca prática dada a necessidade de grande volume de dados. Além disso, como o método apresenta uma abordagem de contabilidade financeira, a adoção do enfoque 'portão ao portão' torna congruentes os indicadores ambiental e econômico. Para o caso em que certa análise predisponha a inclusão de outros estágios do ciclo de vida, o método UN (2004) pode ainda ser empregado, contanto que todos os indicadores sejam condizentes com o referido escopo de aplicação.

Os indicadores ambientais são representados por uma combinação de aspectos e impactos ambientais. São eles: uso de água, uso de energia, contribuição para aquecimento global, substâncias destruidoras do ozônio e resíduos. Todos esses parâmetros são expressos em unidades físicas. A adição de novos indicadores é encorajada quando estes se mostrarem importantes para a organização objeto do estudo.

O procedimento para quantificação dos indicadores ambientais está detalhado no guia que fundamenta o método. Para efeito, por exemplo, da definição do indicador uso de água são estabelecidas subcategorias tais como: origem do recurso (águas superficiais, subterrâneas ou fornecidas); tipo de uso (doméstico, industrial, comercial, etc.); e formas de dissipação (incorporação em produtos ou por humanos, evaporação entre outros). A partir dessa categorização 
é possível obter o valor (em volume) de água utilizado pela empresa, realizandose a somatória de todos os volumes de uso de água identificados (UN, 2004).

A análise de eco eficiência deve expressar todas as subcategorias relevantes e utiliza-se de planilhas de trabalho disponibilizadas pelo método. Assim como para a água, também para o uso de energia, são discutidas diferentes fontes de energia. Para esse elemento, porém, o método apresenta tabelas de consulta com valores energéticos de produtos (e.g. produtos que usam petróleo e carvão), eficiência de combustíveis, conversão de unidades e também um exemplo de cálculo de eco eficiência para o uso de energia. Os demais elementos ambientais são discutidos da mesma forma.

O indicador de valor de sistema de produto é descrito como valor agregado, valor agregado líquido, lucro, bens e serviços adquiridos, sendo todos eles expressos em unidades monetárias. Como já mencionado, nesta situação devem ser seguidos princípios de contabilidade financeira.

O produto da aplicação do método compreende um perfil de indicadores de eco eficiência referentes aos cinco elementos ambientais (uso de água, uso de energia, contribuição para aquecimento global, substâncias destruidoras da camada de ozônio, e geração de resíduos), apresentado sem qualquer interassociação.

\subsection{Método TU Delft (Universidade Delft de Tecnologia)}

Após analisar o conceito de eco eficiência que foi proposto pelo WBCSD (VERFAILLIE; BIDWELL, 2000) pesquisadores e acadêmicos da Universidade Delft de Tecnologia (TU Delft) decidiram ampliar sua abrangência de forma a torná-lo mais prático e, portanto, acessível, a empresas públicas e privadas. Essa revisão pretendeu fazer da eco eficiência uma métrica capaz de ajudar na identificação de políticas públicas, dar suporte ao design de produto tendo em conta seu impacto ecológico, e até, dar subsídios à criação de portfólios de produtos mais sustentáveis (VOGTLANDER et al., 2001, HENDRIKS et al., 2006).

A partir desse esforço foi concebido o método Relação Eco Custos - Valor (Eco-Cost - Value Ratio, EVR). O termo 'eco custo' indicado como numerador do quociente que consta da Equação 7.15 representa o indicador de desempenho 
ambiental usado pelo método, ao passo que o termo 'valor' traduz o indicador de valor de sistema do produto. Por último o resultado 'razão Eco custo Valor (EVR)' representa o indicador de eco eficiência obtido desta aplicação.

$$
\text { Razão Eco custo Valor }(E V R)=\frac{\text { Eco custo }}{\text { Valor }}
$$

Como os indicadores de desempenho ambiental e de valor de sistema de produto são representados por unidades monetárias, o indicador 'Eco custo valor' é adimensional. Este fato também permite que os indicadores de desempenho ambiental (eco custos) sejam agrupados em índice único, gerando por conta disso, também um indicador único de eco eficiência (EVR).

Eco custo (indicador de desempenho ambiental) é definido como o custo da prevenção dessa carga (VOGTLANDER et al., 2001). São os custos "virtuais" para reduzir a poluição e depleção de materiais a um nível em que estes sejam coerentes com a capacidade de carga do planeta (TU DELFT, 2014; HENDRIKS et al., 2006).

Eles são denominados virtuais por não se incorporarem em efetivo a cadeia de valor do produto, o que faz com que os mesmos sejam determinados por meio de valores hipotéticos. Estes custos são estimados com base nas ações técnica necessárias para prevenir poluição e depleção do recurso. Os eco custos podem ser classificados em diretos e indiretos. São eco custos diretos aqueles relativos a prevenção da poluição (despendidos para reduzir emissões); energia (custos de implantação de fontes sustentáveis de energia); e depleção de materiais (como os associados a matérias-primas subtraídas de frações recicladas). Já os eco custos indiretos compreendem depreciação (custos referentes ao uso de equipamentos e construções), e trabalho (dispêndios com deslocamento de pessoas e utilidades nos locais de trabalho). O valor final do eco custo da AEE é a somatória dos três eco custos diretos e dois indiretos, e resulta em valor único de eco custo.

Exemplificando: os eco custos da prevenção da poluição são obtidos em quatro etapas: avaliação de ciclo de vida (ACV); caracterização de emissões sob a forma de 'classes de impactos decorrentes de poluição' (Acidificação, Eutrofização, entre outros); Conversão destas em termos de uma base comum 
para categoria de impacto (expressa em "kg equivalentes" do padrão da categoria) utilizando dados do Eco Indicador 95; e multiplicação do valor obtido na etapa anterior pelo custo de prevenção (custo marginal / kg equivalentes" do padrão da categoria para recuperação do nível de poluição de acordo com a capacidade da terra) (Figura 7.11) (VOGTLANDER et al., 2001). Desta forma, os eco custos são obtidos a partir dos dados ambientais e transformados em dados econômicos (representados por custos em unidades monetárias).

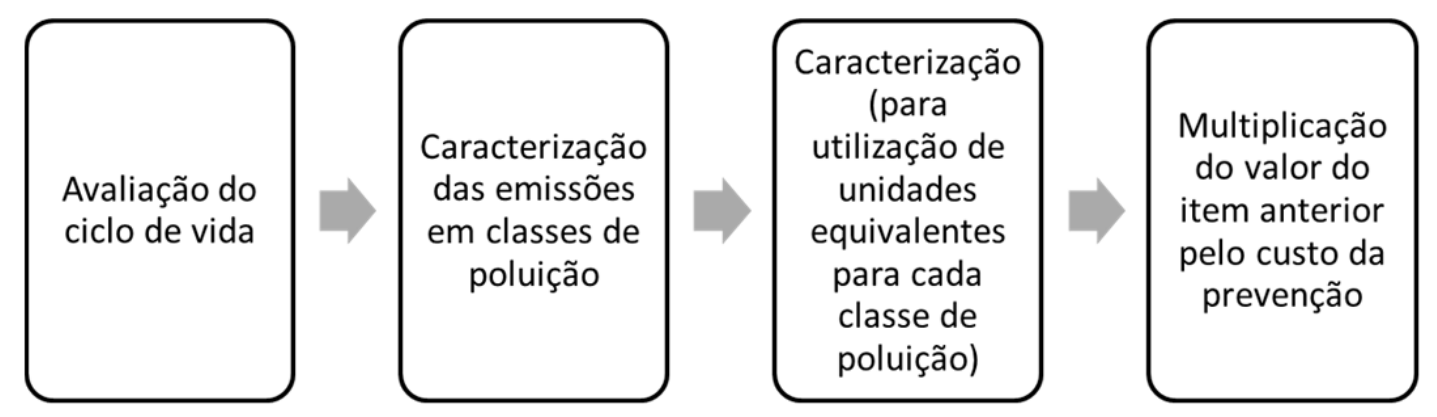

Figura 7.11 - Etapas para obtenção do Eco custo

Fonte: Adaptado de Vogtlander et al., (2001)

O mesmo acontece para os eco custos referentes ao trabalho. Nesse caso são considerados os impactos ambientais resultantes de atividades e servços tais como aquecimento, iluminação, uso de computadores, transporte, entre outros. Uma estimativa para representar a totalidade desses eco custos de trabalho é adotar o valor de $10 \%$ do custo do ciclo de vida do produto sendo analisado. (HENDRIKS et al., 2006).

A determinação dos eco custos ocorre a partir da aplicação de valores de referência nos indicadores ambientais do produto. Estes valores estão disponíveis na literatura que descreve o método e permitem a representação dos indicadores ambientais em unidades monetárias (eco custos) ao invés de físicas. .São apresentados a seguir, a título de exemplificação, valores de eco custos para emissões tóxicas que foram obtidos utilizando-se os preços indicados pela Europa Ocidental 1998: 6,40 €/kg SO eq; 3,05 €/kgPO 4 eq, 114,00€/t $\mathrm{CO}_{2}$ eq, entre outros (HENDRIKS et al., 2006). Por serem gerados sempre em unidades monetárias os eco custos podem ser somados, produzindo assim o indicador único. 
O indicador do valor do sistema do produto, denominado simplesmente de 'valor', consiste do montante monetário conferido pela sociedade para certo produto ou serviço.

AEE realizadas por meio do método TU Delft serão sempre análises comparativas. Quanto menor o valor de EVR, mais eco eficiente será um produto em relação ao demais analisados. Os resultados podem ser apresentados sob a forma de valores numéricos, ou via dispositivo gráfico. O método se baseia na ACV de produtos e se utiliza dos princípios indicados nas normas ISO 14040 e ISO 14044 como alocação e análise de sensibilidade (HENDRIKS et al., 2006).

\subsection{Método WBCSD}

Tla como já fora apresentado antes o guia gerado pela WBCSD apresentou um dos conceitos pioneiros de eco eficiência, adotado inclusive por muitos métodos que tratam do tema. Nesta aplicação, eco eficiência é "atingida ao oferecer bens e serviços com preços competitivos que satisfaçam as necessidades humanas e trazem qualidade de vida, enquanto reduzem progressivamente os impactos ecológicos e intensidade de recursos durante o ciclo de vida até chegar ao nível condizente com a capacidade da terra" (VERFAILLIE; BIDWELL, 2000).

Segundo o método WBCSD a AEE pode ser atingida por meio da adoção de sete elementos: as reduções (i) do uso de materiais; (ii) consumo energético; (iii) e de dispersão de substâncias tóxicas; (iv) aumento da taxa de reciclabilidade,

(v) maximização do uso recursos de renováveis; (vi) aumento do tempo de vida util do produto, e (vii) o aumento da intensidade do serviço.

Para medir eco eficiência, a WBCSD dispõe de uma estrutura que apresenta algum grau de flexibilidade, concebida dessa forma a fim de poder ser aplicada e interpretada em diferentes tipos de negócio. Os indicadores de eco eficiência são calculados utilizando-se a Equação 7.16. A forma como o indicador foi concebido, tendo a dimensão econômica como numerador permite estabelecer uma relação de proporcionalidade direta, e, portanto, neste caso: quanto mais 
elevado for o valor do indicador, maior será também o grau de eco eficiência do objeto de análise.

$$
\text { Eco eficiência }=\frac{\text { Indicador de valor do produto ou serviço }}{\text { Indicador de Influência ambiental }}
$$

Quanto ao potencial de uso, os indicadores de eco eficiência podem ser classificados em dois grupos: (i) geralmente aplicáveis; e (ii) específicos de negócio. Aqueles ditos como 'geralmente aplicáveis' servem, ao menos em tese, para qualquer tipo de organização humana. Os autores recomendam inclusive que estes indicadores sejam calculados e apresentados em qualquer relatório de eco eficiência. Os 'indicadores geralmente aplicáveis de valor de produtos ou serviços' são representados por quantidades de bens ou serviços, ou por vendas líquidas (VERFAILLIE; BIDWELL, 2000).

Os 'indicadores geralmente aplicáveis de influência ambiental' referem-se aos consumos de energia, materiais, e água, bem como, a emissão de Gases de Efeito Estufa e, de substâncias destruidoras da camada de ozônio. Tais índices aparecem relacionados na Tabela 7.4 conjuntamente com outros indicadores potencialmente aplicáveis. Aqueles são denominados potenciais por não apresentarem consenso internacional para a sua obtenção. Entre eles, estão o uso de valor agregado ou lucro líquido para a quantificação do indicador de valor do produto. Também se incluem nesse caso indicadores de desempenho ambiental como a emissão de gases ácidos para o ar - casos de amônia $\left(\mathrm{NH}_{3}\right)$, ácidos clorídrico $(\mathrm{HCl})$ e fluorídrico $(\mathrm{HF})$, óxidos de nitrogênio $\left(\mathrm{NO}_{2}\right)$ e de enxofre $\left(\mathrm{SO}_{2}\right)$ e misturas de ácidos sulfúricos - e resíduos.

Os 'indicadores geralmente aplicáveis' podem, porém não serem suficientes para obter o perfil 'real' de eco eficiência de determinada empresa, tendo em vista as especificidades do empreendimento quanto: ao porte; tecnologia de processo; forma de gestão; entre outros aspectos técnicos e até, culturais. Para esses casos foram estabelecidos os 'indicadores específicos' do negócio que são igualmente relevantes aos 'geralmente aplicáveis'. Nestes casos, podem ser considerados como indicadores econômicos parâmetros tais como: EBIT (Lucro antes de Juros e Imposto de Renda/Earnings before interest and taxes); margem bruta; e, valor agregado. Para os indicadores de desempenho 
ambiental podem-se citar resíduos despejados em aterros, criação de oxidantes fotoquímicos (composto pela medição de Compostos orgânicos voláteis e $\mathrm{NO}_{\mathrm{x}}$ ), entre outros. Estes indicadores devem ser escolhidos de acordo com as necessidade e particularidades de cada empresa.

Tabela 7.4 - Indicadores Geralmente Aplicáveis

\begin{tabular}{ll}
\hline Indicador Geralmente Aplicável & Indicador \\
\hline Valor de produtos ou serviços & - Quantidade de bens ou serviços \\
& - Vendas Líquidas \\
\hline Influência ambiental de produtos ou & - Consumo de Energia \\
serviços & - Consumo de materiais \\
& - Consumo de água \\
& - Emissão de gases de efeito estufa \\
& - Emissão de substâncias destruidoras do \\
& ozônio \\
\hline
\end{tabular}

Fonte: Verfaillie e Bidwell (2000)

O foco de aplicação do método WBCSD está no âmbito das empresas e, portanto, o escopo da AEE é, em geral, do tipo 'portão ao portão'. Esse escopo é representado pelos indicadores geralmente aplicáveis. Outas partes do ciclo de vida do produto ou serviço também podem ser analisados; no entanto, para estes casos recomenda-se que sejam utilizados os indicadores específicos.

Os resultados do método de AEE WBCSD são expressos sob a forma de um perfil de indicadores, estabelecido de acordo com a necessidade e a relevância do setor ou produtos em estudo. Nos exemplos apresentados no guia da WBCSD, os indicadores são analisados de forma comparativa em diferentes períodos de tempo, tal como está apresentado na Figura 7.12 que segue abaixo. $\mathrm{Na}$ ilustração podem ser observados os indicadores de eco eficiência 'massa de produto/emissão de gás de efeito estufa' e "venda líquida/emissão de gás de efeito estufa'.

Os indicadores são comparados entre os anos 1990 e 2002, com intervalo de dois anos. 


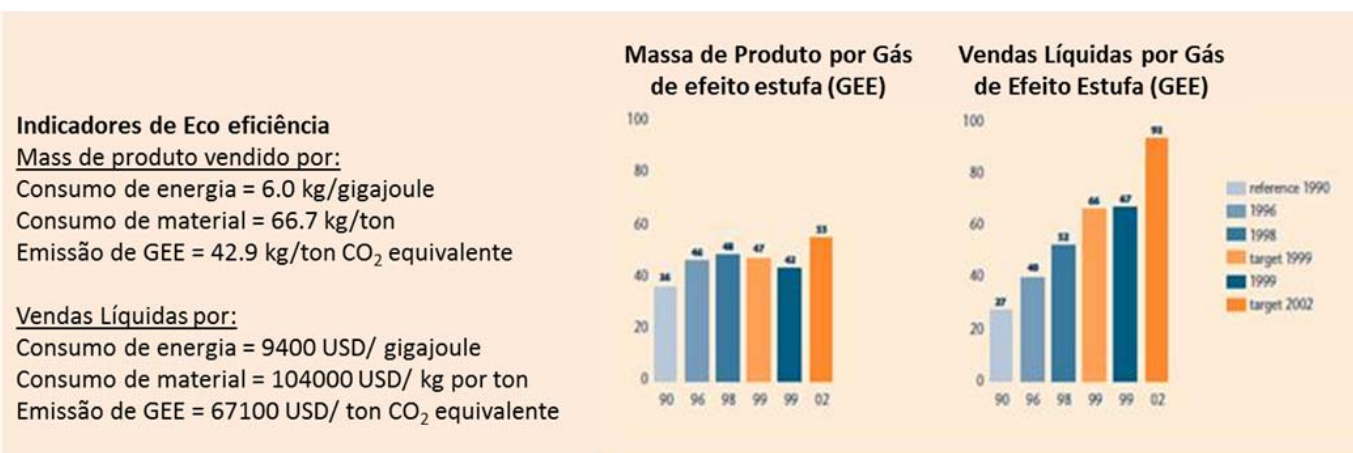

Figura 7.12 - Indicadores de Eco Eficiência de uma empresa ao longo do tempo Fonte: Verfaillie e Bidwell (2000)

O método WBCSD reporta ainda, que a determinação dos indicadores deve seguir 8 (oito) princípios capazes de garantir as relevância e consistência do método: 1) Ser relevante e significativo em relação à proteção do ambiente e saúde humana e/ou melhoria da qualidade de vida, 2) Prover informações que suportem processos de tomada de decisões voltados para a melhoria do desempenho da organização, 3) Reconhecer a diversidade inerente ao negócio, 4) Dar suporte a ações de benchmarking e de monitoramento ao longo do tempo, 5) Ser claramente definido, mensurável, transparente e verificável, 6) Ser compreensível e significante para determinados stakeholders, 7) Ser baseado na avaliação geral da operação, produtos e serviços da empresa, focando em especial nas áreas que estão sob gerenciamento direto da mesma; e 8) Identificar opções relevantes e significantes referente aos aspectos posteriores e anteriores às atividades da companhia.

Esses princípios são importantes para orientar decisões metodológicas associadas à ACV a serem tomadas no curso do estudo, tais como a fixação das fronteiras do sistema em estudo, necessidades de alocação, ou mesmo, as bases para aplicação de Análise de Sensibilidade.

A WBCSD ressalta a importância do uso de transparência, além da necessidade de cautela quando da comparação entre empresas. Para efeito de divulgação, devem ser apresentados os indicadores ambiental e econômico, além da relação entre eles. Ainda no caso da comparação entre empresas, sugere-se que a comparação entre indicadores 'geralmente aplicáveis' seja privilegiada em relação aos 'indicadores específicos. Mesmo assim, em qualquer caso deve-se 
sempre às particularidades dessas mesmas organizações. Sugere-se ainda que seja realizada a comparação entre podutos, serviços ou operações semelhantes (VERFAILLIE; BIDWELL, 2000). 


\section{FORMULAÇÃO DE REQUISITOS DE CARACTERIZAÇÃO DE MÉTODOS DE} AEE

A formulação de requisitos para caracterização dos métodos de AEE tem por finalidade permitir a avaliação dessas abordagens de maneira analítica, sistemática e padronizada, com vistas a identificar semelhanças e diferenças entre os mesmos. O processo baseou-se primeiramente na avaliação da estrutura metodológica apresentada na norma ISO 14045 (ISO, 2012) e para tanto, foram observados os seguintes etapas: (i) requisitos gerais, (ii) definição de objetivo e escopo, (iii) avaliação ambiental, (iv) avaliação do valor do sistema de produto, (v) quantificação de eco eficiência, (vi) análise de sensibilidade e (vii) incerteza e interpretação.

Partindo-se desse universo foram então selecionados os itens considerados necessários para a caracterização dos métodos de AEE. Dados seus conteúdos e especificidades, nem todos os itens supramencionados se prestam a dar suporte à elaboração de requisitos de seleção. Por conta disso, apenas aqueles que dispõem sobre as Avaliações Ambientais e do Valor do Sistema de Produto, a Quantificação de Eco Eficiência foram efetivamente utilizados.

Em seguida, foi realizada uma etapa iterativa, utilizando-se do conhecimento previamente obtido das características dos métodos de AEE. Neste momento, analisou-se as etapas previamente extraídas da norma ISO 14045 e buscou-se a identificação das características que poderiam ser elementos de diferenciação no caso de comparação dos métodos de AEE.

As etapas denominadas Avaliação Ambiental e do Valor do Sistema de Produto foram identificados como requisitos necessários para a caracterização dos métodos de AEE, pois como a junção destes dois indicadores torna possível a obtenção do indicador de eco eficiência, são imprecindíveis para a avaliação dos métodos de AEE. Além disso, sendo estas etapas de obtenção destes indicadores passíveis de diferenças entre os métodos, conforme orientado pela norma ISO 14045 (2012), considerou-se que estas etapas seriam principais requisitos de comparação entre os AEE. Nestes aspectos da AEE, deseja-se determinar o tipo do indicador ambiental (Requisito 1), o tipo de indicador de valor 
de sistema de produto (Requisito 2) e também a abrangência de aplicação de ambos (Requisito 3).

Para a Quantificação da Eco Eficiência, considerou-se relevante avaliar o tipo de indicador de eco eficiência determinado nesta etapa (Requisito 4). Sendo permitidas diversas formas de relacionar o indicador ambiental e de valor de sistema de produto, este requisito irá permitir a diferenciação entre os métodos de AEE em relação à apresentação dos resultados da $A E E$ e quais as consequências relacionadas à interpretação e comunicação dos resultados para diferentes públicos.

A Tabela 8.1 apresenta o resultado desta ação, ao relacionar etapas da norma ISO 14045 (2012) aos requisitos que dela derivam. Tendo em vista o objetivo deste estudo, todos os requisitos formulados são de caráter classificatório, e assim, não se prestam a excluir métodos de AEE do âmbito de aplicação da pesquisa.

Nas sessões que se seguem, os requisitos de caracterização dos métodos de AEE são detalhados em termos de características, aplicações e de expectativas quanto à realização desta incursão acadêmica.

Tabela 8.1 - Requisitos para caracterização de Métodos de AEE

\begin{tabular}{ll}
\hline Aspectos da AEE & Requisito \\
\hline Avaliação Ambiental & $\begin{array}{l}\text { Requisito 1 - Tipo de indicador de desempenho } \\
\text { ambiental }\end{array}$ \\
$\begin{array}{l}\text { Avaliação do valor do sistema de } \\
\text { produto }\end{array}$ & $\begin{array}{l}\text { Requisito 2 - Tipo de indicador de valor de } \\
\text { sistema de produto }\end{array}$ \\
$\begin{array}{l}\text { Avaliação Ambiental e Avaliação } \\
\text { do Valor do Sistema de Produto }\end{array}$ & Requisito 3 - Abrangência de aplicação \\
Quantificação de Eco Eficiência & Requisito 4 - Tipo de indicador de eco eficiência \\
\hline
\end{tabular}

\subsection{Requisito 1 - Tipo de indicador de desempenho ambiental}

O tipo de indicador de desempenho ambiental é um requisito essencial tanto para caracterização de métodos de AEE, como, para efeito de especificação 
de usos potenciais em que estes serão mais efetivos. $O$ processo para composição de indicadores ambientais considera, em geral de maneira sinérgica, três funções de controle: (i) tipo de variável que irá representar o desempenho ambiental; (ii) forma de apresentação desse resultado; e (iii) unidade utilizada para representação do indicador.

Quanto ao tipo de variável são duas as possibilidades mais frequentemente empregadas: a) aspectos ambientais; e b) impactos ambientais. Muito embora em termos conceituais exista uma relação de causa e efeito claramente definida entre aspectos e impactos ambientais - o que poderia sugerir similaridade entre essas opções -, em termos práticos para efeito de constituição de um indicador ambiental há grande diferença entre ambas as abordagens.

A opção pelo uso de aspectos ambientais irá condicionar a análise a uma mensuração de consumos e emissões associadas ao objeto de avaliação do método de AEE. Por um lado, esta abordagem inviabiliza a realização de projeções em termos de magnitude de efeitos (a qual, inclusive, é prerrogativa dos impactos ambientais). Por outro, o uso de aspectos ambientais é vantajoso, pelos fatos de: (i) serem, ao menos em tese, de obtenção mais fácil por estarem incorporados às rotinas industriais; (ii) já fazerem parte dos bancos de dados das organizações; (iii) serem palpáveis e facilmente inteligíveis pelos gestores; e (iv) não acumularem incertezas de método.

Além de consolidar a relação entre as ações antrópicos e os efeitos sobre o ambiente, o uso de impactos ambientais tem, de sua parte, a vantagem de oferecer ao gestor a possibilidade de verificar quais seriam os desdobramentos coletivos de ações e condutas potenciais de melhoria para determinada categoria ambiental.

Por exemplo, ao utilizar-se de um indicador ambiental que avalie os efeitos provocados por certo produto quanto às Mudanças Climáticas, o gestor tem à disposição não apenas as contribuições de $\mathrm{CO}_{2}$ para essa categoria, mas também daquelas provenientes de emissões de $\mathrm{CH}_{4}, \mathrm{~N}_{2} \mathrm{O}$, ozônio $\left(\mathrm{O}_{3}\right)$, clorofluorcarbonos (CFCs) e outros Gases de Efeito Estufa. Além disso, ele pode ainda se inteirar da magnitude das contribuições desses precursores para a base comum de referência da categoria ( $\mathrm{kg} \mathrm{CO}_{2}$ eq.), fornecida por fatores de impacto específicos para cada substância. Esse diferencial pode auxiliar não apenas na 
identificação de focos de impacto, mas também, e talvez até, antes, na seleção de alternativas de mitigação, redução, ou minimização desses efeitos.

A apresentação do indicador de desempenho ambiental está vinculada ao tipo de variável utilizada. Nesse caso, há duas possibilidades de abordagem: a) uso de valor (ou indicador) único; ou b) por meio do estabelecimento de perfil ambiental.

Os indicadores únicos resumem o desempenho ambiental a um índice. A praticidade dessa abordagem tende, via de regra, a racionalizar o processo de tomada de decisão gerencial. Por outro lado, e como não poderia deixar de ser, o indicador único é também generalista e, portanto, dificulta uma visão detida dos focos de efeitos ambientais.

A associação entre indicadores únicos e aspectos ambientais apresenta por particularidade a discretização de certo consumo ou emissão. Ou seja, para casos em que o indicador de desempenho ambiental tiver que ser traduzido por diferentes aspectos ambientais a alternativa seria criar distintos indicadores de $A E E$, os quais seriam avaliados de maneira independente.

Já a prática de concepção de indicadores únicos derivados de impactos ambientais é normativa e consta das orientações ditadas pelas ISO 14040 e 14044 (2006; 2006a) mesmo que como elemento facultativo da etapa metodológica de Avaliação de Impactos Ambientais. Isso ocorre dado a subjetividade introduzida pelos procedimentos utilizados nesta transformação: Normalização e Ponderação. Uma alternativa a adoção desses procedimentos seria de estabelecer uma lógica que se baseassem em métodos qualiquantitativos, e que fosse capaz de aglutinar aspectos ambientais com vistas a gerar o indicador único. No entanto, como antes mencionado, tal prática não estaria respaldada por requisitos normativos.

A expressão do indicador ambiental sob a forma de perfil dá ao gestor uma ideia ampla e completa de todas as interações do objeto de verificação da AEE com seu entorno, independentemente deste ser constituído por aspectos, ou impactos ambientais. Por outro lado, esses resultados serão sempre discretizados - quer por consumo e/ou emissões, quer por categoria de impacto - e assim, lhes faltaria o diferencial que o indicador único pode proporcionar, com todas as incertezas e limitações de método que o cercam. 
Neste requisito também se avalia a unidade utilizada para a representação do indicador ambiental. A unidade física é bastante frequente para representação de emissões de gases (e.g., $\mathrm{kg} \mathrm{CO}$ ), uso de água $\left(\mathrm{m}^{3}\right)$, despejo de resíduos $(\mathrm{kg})$, entre outros aspectos ambientais. Há também a possibilidade de representar os mesmos indicadores utilizando-se de unidades monetárias, situação em que os aspectos ambientais são refletidos, e.g., sob a forma de custos relativos ao descarte, ou à recuperação de certo recurso natural, sempre de acordo com a proposta do método de AEE.

O tipo de indicador, a forma de representá-lo, e a unidade em que o mesmo será expresso podem alterar a forma de execução do método de AEE, interferindo na sua complexidade e também nos recursos necessários para sua realização.

\subsection{Requisito 2 - Tipo de indicador valor do sistema de produto}

De acordo com a ISO 14045 (ISO, 2012) o indicador do valor do sistema de produto pode ser representado por um valor funcional, monetário, estético, cultural, histórico, ou mesmo, de outra dimensão. O processo de obtenção do indicador de valor de sistema do produto compreende duas ações: (i) definição da unidade utilizada; e (ii) descrição do elemento que esta unidade representará.

Sendo o método de AEE relevante no meio empresarial, há uma tendência, de certa forma até, natural, pela utilização de valor monetário para representação do sistema de produto.

Neste caso, preço, valor agregado, vendas líquidas, entre outros, são exemplos de elementos utilizados para representar os indicadores de valor do sistema do produto que utilizam a unidade monetária. No cado do uso de uniddes físicas, pode-se utilizar elementos como quantidade de bens e serviços para represenetar o indicador de valro de sistema de produto.

Cada um desses indicadores de valor tem particularidades com relação às suas abrangência e forma de obtenção. Portanto, essa característica passa a ser importante para efeito de identificar usos para determinado método de AEE. 


\subsection{Requisito 3 - Abrangência de aplicação}

Apoiado no enfoque de que se serve a ISO 14045 tratar do mesmo aspecto, este requisito visa analisar a abrangência de aplicação dos métodos de AEE.

De maneira consonante com suas homólogas de mesmo classe - ISO 14040 e 14044 (2006a; 2006b) - a norma ISO 14045 (2012) expressa o conceito de ciclo de vida como o conjunto ordenado de transformações antrópicas necessárias para que determinada função seja cumprida por um produto, processo, ou serviço. Este arrajo se incia com a extração de recursos junto ao ambiente, e se estende até o descarte do produto (desativação do processo, ou descontinuação do serviço), o qual se dá quando o exercício da função já não mais ocorre (SILVA, 2012).

Tal forma de abordagem coloca o foco de atuação da avaliação de impactos ambientais sobre a função a ser atendida e, portanto, considera além das etapas associadas à cadeia de manufatura, também aspectos de pósprodução (uso e descarte final). Essa abrangência (plena) é conhecida entre os praticantes da ACV como do 'berço ao túmulo' (cradle-to-grave).

No entanto, o ciclo de vida pode ser ajustado a escopos menos abrangente por conta dos resultados pretendidos com esse tipo de verificação. Análises que se atenham apenas ao ciclo produtivo, em que o produto (processo ou serviço) torna-se foco da análise têm abrangência do tipo 'berço ao portão da fábrica' (cradle-to-gate). Há outras que por observar um conjunto limitado - que pode ser até unitário - de estágios de transformação (foco sobre o processo) praticam abrangências do tipo 'portão ao portão' (gate-to-gate).

Uma parcela da comunidade científica defende ainda escopos que tratem apenas de efeitos de pós-produção, ou, do 'portão ao túmulo' (gate-to-grave), sobretudo para serviços, em que, em geral, impactos ambientais decorrentes da instalação de um empreendimento mostram-se pouco significantes se comparados à realização da atividade em si (WILLIAMS, 2009).

Uma AEE homogênea deve ter sobrepostas as abrangências adotadas tanto na determinação do indicador ambiental como do indicador do valor do sistema de produto (UN, 2001). Portanto, imagina-se que o Requisito 3 seja capaz 
não apenas de verificar essa congruência, como também, de servir de sinalizador de potenciais aplicações dos métodos de AEE em função de suas amplitudes de uso.

\subsection{Requisito 4 - Tipo de Indicador de eco eficiência}

O âmbito de aplicação do Requisito 4 analisa dois elementos essenciais a quaisquer métodos de AEE: (i) o tipo de indicador por eles utilziados; e (ii) forma de apresentação dos resultados obtidos.

O tipo de indicador de eco eficiência, ou seja, a forma de relacionamento dos indicadores de desempenho ambiental e de valor do sistema de produto, pode ser um fator de diferenciação entre os métodos de AEE.

A pesquisa que selecionou os métodos de AEE a serem verificados neste estudo permitiu identificar procedimentos diversos para coordenação dessas duas dimensões. A norma ISO 14045 (2012) não sugere, ou padroniza qualquer método para definição do indicador de AEE. Antes disso e inclusive, tal como se poderia supor de antemão, o arrazoado normativo estabelece apenas requisitos bastante gerais que o indicador deverá atender, como: (i) que o aumento da eficiência para determinado valor do sistema de produto precisa necessariamente representar uma melhoria ambiental; e (ii) que o aumento da eficiência para certo impacto ambiental deve representar um acréscimo do valor do sistema de produto (ISO, 2012).

A forma de relacionamento dos indicadores de desempenho ambiental e de valor de sistema do produto pode ocorrer, simplesmente estabelecendo-se a razão entre ambos. Há também a possibilidade de uso de uma representação visual por meio da adoção de dispositivo gráfico. Neste último caso, não haveria necessariamente a necessidade de empregar-se uma expressão matemática para compor o indicador de eco eficiência, sendo a leitura e interpretação dos resultados realizada de acordo com o lugar geométrico ocupado pelo índice em um sistema dotado de eixos.

Deve-se, ainda, considerar a forma de apresentação dos indicadores de eco eficiência. Assim como a apresentação dos resultados dos indicadores 
ambientais, é possível fazer uso de um único indicador ou mesmo, do perfil de indicadores.

Geralmente, a opção por indicador único de eco eficiência é consequência da decisão de se utilizar de indicador único também para o indicador ambiental. A importância de identificação do formato de apresentação está baseada no tipo de interpretação dos resultados e na possibilidade de geração de conclusões utilizando-se destes resultados.

Essas circunstâncias abrem a perspectiva para que os métodos de AEE sejam não apenas caracterizados segundo tal especificidade, como também, que os usos potenciais a que estes se destinam possam ser igualmente pautados pela mesma característica. 


\section{DISCUSSÃO}

Neste capítulo, em uma etapa inicial, as características dos métodos de AEE em relação aos requisitos de caracterização definidos no capítulo anterior serão discutidos. A seguir, a discussão se ocupará de identificar usos potenciais para os métodos de AEE e suas características. Por último, será abordada a relação entre as características dos métodos de AEE e dos usos potenciais identificados.

\subsection{Caracterização dos métodos de AEE}

A partir das informações apresentadas no Capítulo 7 elaborou-se uma matriz que permite comparar as características e especificidades dos métodos de AEE e requisitos de caracterização, definidos no Capítulo 8 e mostrado na Tabela 9.1. Nela os atributos de cada requisito, ou seja, as diferentes variações verificadas a partir de cada requisito estão destacados utilizando-se de siglas.

Para exemplificar a mecânica de construção da Tabela 9.1, toma-se por exemplo a aplicação do Requisito 1, Tipo de Indicador de Desempenho Ambiental, onde foram considerados, para efeito de análise do indicador ambiental, os seguintes atributos: (i) composição do indicador ambiental a partir de aspectos ambientais (AA), ou de impactos ambientais (IA); (ii) adoção de indicador único (IU), ou de perfil de indicadores (PI); e (iii) forma de expressão do indicador, que pode ocorrer a partir de unidade física (UF) ou unidade monetária (UM). A legenda informa o significado de cada atributo e sua respectiva sigla. Cada grupo de características aparece identificado na matriz com uma cor, a fim de destacar os limites de cada requisito.

Quanto ao preenchimento da matriz, a posição da matriz relativa a característica destacada por determinado atributo recebeu o símbolo $(\checkmark)$. Para os casos em que a característica é opcional, ou mesmo, quando esta não é a opção principal do método, utilizou-se o símbolo (!). Finalmente, quando um método de AEE não atende a certo atributo, o campo correspondente foi deixado em branco. 
Tabela 9.1 - Confrotação dos métodos de AEE com requisitos para sua caracterização

\begin{tabular}{|c|c|c|c|c|c|c|c|c|c|c|c|c|}
\hline \multicolumn{2}{|c|}{$\frac{\text { Métodos de AEE }}{\text { Requisitos }}$} & \multirow[t]{2}{*}{ BASF } & \multirow{2}{*}{$\begin{array}{c}\text { Bayer } \\
\checkmark\end{array}$} & \multirow[t]{2}{*}{ EcoWater } & \multirow{2}{*}{\begin{tabular}{|c|} 
Hahn et al. \\
$\checkmark$
\end{tabular}} & \multirow[t]{2}{*}{$\begin{array}{c}\text { Kuosmanem } \\
\text { e } \\
\text { Kortelainen }\end{array}$} & \multirow{2}{*}{$\begin{array}{c}\text { MIPS } \\
\checkmark\end{array}$} & \multirow{2}{*}{$\begin{array}{c}\text { NRTEE } \\
\checkmark\end{array}$} & \multirow{2}{*}{$\begin{array}{c}\text { UN ESCAP } \\
\checkmark\end{array}$} & \multirow{2}{*}{$\begin{array}{l}\text { UN } \\
\checkmark\end{array}$} & \multirow{2}{*}{$\begin{array}{c}\begin{array}{c}\text { TU } \\
\text { Delft }\end{array} \\
\checkmark\end{array}$} & \multirow{2}{*}{$\begin{array}{c}\text { WBCSD } \\
\checkmark\end{array}$} \\
\hline \multirow{6}{*}{ 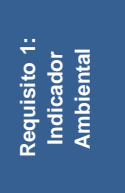 } & $A A$ & & & & & & & & & & & \\
\hline & IA & $\checkmark$ & $\checkmark$ & $\checkmark$ & & $\checkmark$ & & & & & & $!$ \\
\hline & IU & $\checkmark$ & & & $\checkmark$ & $\checkmark$ & & & & & $\checkmark$ & \\
\hline & $\mathrm{PI}$ & & $\checkmark$ & $\checkmark$ & & & $\checkmark$ & $\checkmark$ & $\checkmark$ & $\checkmark$ & & $\checkmark$ \\
\hline & UF & $\checkmark$ & $\checkmark$ & $\checkmark$ & . & $\checkmark$ & $\checkmark$ & $\checkmark$ & $\checkmark$ & $\checkmark$ & & $\checkmark$ \\
\hline & UM & & & & $\checkmark$ & & & & & & $\checkmark$ & \\
\hline \multirow{11}{*}{ 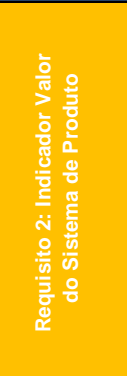 } & UM & $\checkmark$ & $\checkmark$ & $\checkmark$ & $\checkmark$ & $\checkmark$ & & $!$ & $\checkmark$ & $\checkmark$ & $\checkmark$ & $\checkmark$ \\
\hline & UF & & & & & & $\checkmark$ & $\checkmark$ & & & & $\checkmark$ \\
\hline & QBS & & & & & & & $\checkmark$ & & $\checkmark$ & & $\checkmark$ \\
\hline & $\mathrm{CCV}$ & $\checkmark$ & & & & & & & & & & \\
\hline & PR & & $!$ & & & & & & & & & \\
\hline & PIB & & $!$ & & & & & & $\checkmark$ & & & \\
\hline & VA & & $!$ & $\checkmark$ & $\checkmark$ & $\checkmark$ & & & & $\checkmark$ & & $!$ \\
\hline & $\mathrm{LL}$ & & $\checkmark$ & & & & & & & $\checkmark$ & & $!$ \\
\hline & $\mathrm{VL}$ & & $\checkmark$ & & & & & $!$ & & & & $\checkmark$ \\
\hline & EC & & & & & & & & & & $\checkmark$ & \\
\hline & UFU & & & & & & $\checkmark$ & & & & & \\
\hline \multirow{4}{*}{ 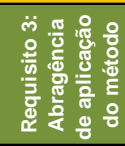 } & BT & $\checkmark$ & $\checkmark$ & $\checkmark$ & & $\checkmark$ & $\checkmark$ & $!$ & $!$ & & $\checkmark$ & $!$ \\
\hline & $\mathrm{BP}$ & $!$ & & & & & & $!$ & $!$ & & & $!$ \\
\hline & PP & $!$ & & & $\checkmark$ & & & $\checkmark$ & $!$ & $\checkmark$ & & $\checkmark$ \\
\hline & PT & $!$ & & & & & & $!$ & $!$ & & & $!$ \\
\hline \multirow{5}{*}{ 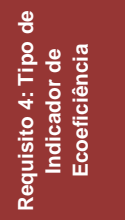 } & IAB/IVSP & & & & & & $\checkmark$ & $\checkmark$ & & $\checkmark$ & $\checkmark$ & \\
\hline & IVSP/IAB & & & $\checkmark$ & $\checkmark$ & $\checkmark$ & & & $\checkmark$ & & & $\checkmark$ \\
\hline & RG & $\checkmark$ & $\checkmark$ & & & & & & & & & \\
\hline & IU & $\checkmark$ & & & & $\checkmark$ & & & & & $\checkmark$ & \\
\hline & $\mathrm{PI}$ & & $\checkmark$ & $\checkmark$ & $\checkmark$ & & $\checkmark$ & $\checkmark$ & $\checkmark$ & $\checkmark$ & & $\checkmark$ \\
\hline
\end{tabular}

Fonte:Autora

Legenda: AA: Aspecto Ambiental; IA: Impacto Ambiental; IU: Indicador único; PI: Perfil de Indicadores; UM: Unidade Monetária; UF: Unidade Física; QBS: quantidade de bens ou serviços; CCV: Custo do ciclo de vida; PR: Preço; PIB: Produto Interno Bruno; VA: Valor Agregado; VL: Vendas Líquidas; LL: Lucros líquidos; EC: Eco custo; UFU: unidade funcional; BT: berço-aotumulo; BP: berço-ao-portão; PP: portão-ao-portão; PT: portão-ao-túmulo; IAB: Indicador Ambiental; IVSP: Indicador de Valor de Sistema de Produto; RG: representação gráfica.

\subsubsection{Análises dos métodos de AEE quanto ao Requisito 1 - Tipo de Indicador Ambiental}

Quanto ao tipo de variável para composição do indicador de desempenho ambiental identificou-se que os métodos Hahn et al., MIPS, NRTEE, UN ESCAP, UN e TU Delft usam apenas aspectos ambientais. Já os métodos BASF, EcoWater e Kuosmanen e Kortelainen, baseiam suas análises apenas nos impactos ambientais. Observe-se que o método Kuosmanen e Kortelainen, apesar de estabelecer o uso de impactos ambientais, não os especificam efetivamente, como outros métodos. Isto provavelmente é devido ao fato da sua 
exposição dar maior enfoque na aplicação da ferramenta DEA (Data Envelopment Analysis) na AEE e, por consequência, abordar de forma mais sucinta outras etapas do método.

Por fim, outros métodos, tais como Bayer e WBCSD, trazem uma combinação do uso de aspectos e impactos. No método Bayer, por exemplo, são inclusos na AEE elementos como uso de recursos e energia (apectos ambientais), assim como ecotoxicidade e potencial de destruição da camada de ozônio (impactos ambientais). O método WBCSD sugere a criação de indicadores de eco eficiência 'geralmente aplicáveis' em qualquer AEE que utilizem como indicador aspectos ambientais (Consumo de Energia, Consumo de materiais, Consumo de água, Emissão de gases de efeito estufa e Emissão de substâncias destruidoras do ozônio). Porém, permite a criação de indicadores adicionais, denominados 'específicos ao negócio', em que podem ser incluídos outros aspectos ambientais que não mencionados anteriormente ou, ainda, a utilização de impactos ambientais para representar o indicador ambiental.

Analisando os indicadores ambientais, observa-se também que, de forma geral, emissões para o ar e para a água, bem como, a geração de resíduos sólidos são elementos comuns a todos os métodos. A apresentação do método NRTEE, por exemplo, consiste na descrição da obtenção dos indicadores de eco eficiência destes três elementos apenas. Apesar de outros serem possíveis, não estão abordados diretamente no método. Os demais métodos incluem elementos adicionais como uso do solo, toxicidade e uso de energia, além de categorias de impactos ambientais. Apesar dessa diferença, a grande parte das abordagens permite a criação de novos indicadores de eco eficiência dependendo dos objetivo e escopo de aplicação do método de AEE.

No tocante à forma de representação do indicador de desempenho ambiental percebeu-se que os métodos BASF, Hahn et al., Kuosmanen e Kortelainen e TU Delft agrupam os indicadores ambientais na AEE, diferenciamse entre si quanto à construção do agrupamento. No método BASF o agrupamento ocorre por meio da aplicação dos procedimentos de ponderação e normalização, baseando-se em pesquisas sociais e dados de referências quanto à magnitude do impacto. O método de Kuosmanen e Kortelainen utiliza-se da ferramenta matemática DEA, que ao ser aplicada, permite ponderação objetiva 
dos indicadores ambientais analisados. Destaque-se ainda que os métodos BASF e Kuosmanen e Kortelainen expressam o indicador ambiental por unidades físicas.

Para os métodos de Hahn et al. e TU Delft, os indicadores de desempenho ambiental são expressos em unidades monetárias; portanto, para esses casos o agrupamento é realizado a partir da somatória simples dos indicadores avaliados. Esta proposta parece interessante para o meio empresarial, por se aproximar da realidade de avaliação de valores financeiros (ao invés de ambientais). Por outro lado, a opção por expressar aspectos ambientais por meio de unidades econômicos, não é usual entre os métodos de AEE, pois descaracteriza o caráter físico daqueles parâmetros, além de exigir conhecimento técnico específico para a transformação dos indicadores ambientais em valores monetários.

Os métodos que se utilizam de um perfil de indicadores para representar o indicador ambiental são Bayer, EcoWater, MIPS, NRTEE, UN ESCAP, UN e WBCSD. Nesses casos, o número e o tipo de indicadores são variáveis. O método NRTEE, por exemplo, trabalha com três principais indicadores (uso de energia, despejo de resíduos e uso água), enquanto que o MIPS usa cinco, ou até, seis indicadores (materiais abióticos, materiais bióticos, erosão e/ou movimentos na terra em agricultura e florestas, água e ar). De qualquer forma, todos os métodos permitem uma análise isolada dos diferentes indicadores ambientais. Todos estes métodos utilizam-se de unidades físicas para a representação dos indicadores de desempenho ambiental.

\subsubsection{Análises dos métodos de AEE quanto ao Requisito 2 - Tipo de Indicador de Valor de Sistema de Produto}

Apesar das variadas possiblidades de representações do indicador de valor de sistema de produto sugeridos pela norma ISO 14045 (2012), os métodos de AEE selecionados utilizam, em sua maioria, unidades monetárias ou unidades físicas para representar esse indicador. Esta prática é coerente devido à relação da AEE e a sua aplicação em empresas, onde valores monetários são largamente utilizados. 
Os métodos BASF, Bayer, EcoWater, Hahn et al., Kuosmanen e Kortelainen, UN ESCAP, UN e TU Delft representam o indicador de valor de sistema de produto utilizando-se da unidade monetária. O método MIPS, no entanto, usa da unidade física para representá-lo. Nas suas propostas, os métodos NRTEE e WBCSD ambas as unidades (monetária ou física) podem ser utilizadas para represenetar o indicador de valor de sistema de produto. No método NRTEE, adicionalmente, argumenta-se que valores monetários devem ser empregados com cautela devido às flutuações nos preços de produtos, as quais podem influenciar os resultados da AEE, quando comparados ao longo do tempo.

A adoção de unidades físicas aparenta ser uma alternativa prática, por se tratar, em geral, de um valor conhecido e/ou de fácil obtenção. As unidades de produção podem ser opções interessantes para apresentação deste indicador a um público familiarizado com tais valores como os gerentes de processo. Para públicos mais familiarizados com valores monetários, é possível que a unidade física não seja a abordagem mais indicada. A utilização de unidades físicas, como mencionado, elimina as flutuações de preço que podem afetar os resultados.

Uma vez identificada a unidade de representação, este requisito também avalia o elemento que esta unidade representa em termos de indicador de valor de sistema de produto. Foram identificados nove elementos na apresentação dos métodos de AEE (QBS: quantidade de bens ou serviços; CCV: Custo do ciclo de vida; PR: Preço; PIB: Produto Interno Bruno; VA: Valor Agregado; VL: Vendas Líquidas; LL: Lucros líquidos; EC: Eco custo; UFU: unidade funcional).

Alguns dos métodos fazem uso de mais de um elemento, tais como Bayer, UN e WBCSD, mas, nessas situações, não foi possível identificar se há um elemento preferencial, ou mais apropriado. O método Bayer apresenta como exemplo alguns parâmetros como lucro, entre outros, mas permite que outros sejam estipulados. Já o método UN, cita elementos como valor agregado, lucro ou bens (todos eles, expressos em unidades monetárias), permitindo também que outros elementos sejam utilizados sem, no entanto excluir outras possibilidades. Finalmente, o método WBCSD descreve o 'indicador geralmente aplicável' por meio de quantidade de bens e serviços ou até, de vendas líquidas, mas permite que para os 'indicadores específicos ao negócio' outros elementos sejam 
selecionados para representar o indicador de valor de sistema de produto. Estes podem ser representados por valor agregado, margem bruta, entre outros.

Os demais métodos apresentam de forma mais enfática um único elemento para representar o indicador de valor de sistema do produto. Os métodos EcoWater, Hahn et al. e Kuosmanen e Kortelainen sugerem o uso de valor agregado. O método BASF utiliza-se do custo do ciclo de vida, enquanto o TU Delft utiliza-se do 'eco custo' (um elemento definido pelo método, que consiste no custo da prevenção dessa carga ambiental) e o UN ESCAP o uso do PIB. O método NRTEE dá preferência para quantidade de bens ou serviço, mas quando aplica unidade monetária, costuma optar por vendas líquidas.

O método MIPS é talvez aquele que mais se diferencia dos demais ao utilizar do 'número de vezes que um serviço é oferecido' como elemento de representação do valor do sistema de produto. Este formato - claramente baseado no conceito de unidade funcional que pauta estudos de $A C V$-, que é pouco difundido entre os métodos de AEE, é interessante para efeito de análise do uso dos produtos ao longo do tempo. No entanto, sua aplicação pode eventualmente ser condicionada ao conhecimento do conceito de unidade funcional, o qual, nem sempre, é imediato ou de senso comum, fora dos domínios de aplicação da ACV.

Os métodos BASF, Kuosmanen e Kortelainen, MIPS, NRTEE, UN ESCAP e WBCSD apresentam poucas informações sobre a obtenção do indicador de valor de sistema de produto quando comparados com a sua descrição sobre o indicador de desempenho ambiental. Essa disparidade pode estar relacionada ao fato de que os controles financeiros serem práticas comuns para empresas e governos e pela existência de métodos financeiros e de contabilidade consolidados para a obtenção deste indicador. Isso demandaria, ao menos em tese, menor nível de explicação sobre esses conteúdos em comparação com aquele de fundo ambiental. Por outra parte, o método UN se destaca por apresentar informações mais detalhadas sobre o tema e destacar este aspecto na apresentação do método.

Destaca-se, por fim, a possibilidade de uso de unidades físicas como meio de representação do indicador de valor do sistema de produto, opção que indica 
ser este um valor contabilizado pelas empresas para situações de tal natureza, que tem por vantagem ser de simples interpretação.

\subsubsection{Análises dos métodos de AEE quanto ao Requisito 3 - Abrangência de Aplicação}

Em termos de abrangência, os métodos BASF, Bayer, EcoWater, Kuosmanen e Kortelainen, MIPS e TU Delft adotam por escopo de aplicação o ciclo de vida pleno do produto. Este enfoque é vantajoso, pois permite identificar não apenas os efeitos - principalmente ambientais - gerados ao longo dos diversos estágios do ciclo de vida do produto, mas também, verificar aqueles derivados de suas interações.

No entanto, tamanha amplitude pode simplesmente não ser de interesse da organização que conduz a AEE, tendo em vista sua finalidade; ou mesmo, ser prejudicada pela ausência de dados consistentes para representar toda aquela extensão. Para estes casos, passa a ser mais atraente o uso de uma abrangência restrita a apenas parte do ciclo de vida, como ocorre com os métodos Hahn et al., NRTEE, UN e WBCSD.

O método BASF é versátil com relação a abrangência, que varia de acordo com os objetivos e o escopo da análise. Os métodos NRTEE e WBCSD, apesar de darem maior ênfase na abrangência 'portão ao portão', mencionam que outros indicadores de eco eficiência podem ser aplicados para escopos com mais etapas do ciclo de vida.

O UN ESCAP não aborda diretamente a abrangência de aplicação em relação ao ciclo de vida. Uma análise dos indicadores, geralmente aplicados no método, sugere que a amplitude pode ser flexível em termos de escopo de aplicação e que esta decisão irá depender principalmente, de quais estágios serão utilizados para representar os indicadores ambientais. Por exemplo, ao apresentar o indicador de emissão de $\mathrm{CO}_{2} / \mathrm{PIB}$, o método UN ESCAP indica que a emissão do gás refere-se às emissões do setor industrial. No entanto, não há qualquer referência sobre qual(is) etapa(s) do ciclo de vida foi(ram) relacionada(s) para totalização desse valor de emissão. Por essa razão, decidiu-se atribuir o 
código (!) ao UN ESCAP para todas as possibilidades de abrangência verificadas pelo Requisito 3.

De maneira ampla, o aspecto de abrangência de aplicação é abordado pelos métodos de AEE apenas no âmbito do indicador de desempenho ambiental. Por conta disso, automaticamente, passa a constituir-se em área de oportunidade de desenvolvimento, uma verificação desse enfoque em termos do indicador de valor do sistema de produto. Isso porque, a composição do valor monetário elemento mais usado para representar este indicador - nem sempre está relacionada com a abrangência correspondente do indicador ambiental. Por exemplo, ao fazer opção por elementos como preço ou custo do produto para representação do indicador de valor do produto muitos métodos de AEE incorrem em dissintonia com a abrangência do indicador ambiental, quando para este se aplique qualquer escopo que não aquele do tipo berço ao portão. Tal discrepância de ordem metodológica fica porém atenuada, pois em muitos casos os métodos de AEE atuam comparando desempenhos, o que faz com que essa inconstência se dilua ou fique amortecida. A congruência entre abrangências dos indicadores de valor e ambiental é inclusive abordada pelo método UN.

Uma situação especial ocorre com o método MIPS uma vez que a opção pelo uso de unidade funcional para representar o indicador de valor de sistema de produto define, de imediato, a abrangência de aplicação do método como sendo do berço ao túmulo. A mesma abrangência é adotada pelo método na aplicação do indicador ambiental.

\subsubsection{Análises dos métodos de AEE quanto ao Requisito 4 - Tipo de Indicador de Eco Eficiência}

Uma varredura do universo de métodos de AEE selecionado para a análise fez perceber a existência de três tipos de indicadores de eco eficiência: (i) a razão entre os indicadores de desempenho ambiental e de valor de sistema de produto (IAB/IVSP); (ii) a relação inversa (IVSP /IAB); e (iii) a representação gráfica. 
Os métodos MIPS, NRTEE, UN e TU Delft se utilizam da razão (IAB/IVSP), ao passo que o EcoWater, Hahn et al., Kuosmanen e Kortelainen, UN ESCAP e o WBCSD consideram como indicador de eco eficiência o quociente (IVSP/IAB).

Antes de efetuar qualquer reflexão sobre o tema, destaca-se a importância de conhecer a composição do indicador de eco eficiência para uma correta leitura e adequada interpretação dos resultados. Assim, para situações cujo índice é definido pela razão (IAB/IVSP) quanto maior for o valor do indicador de eco eficiência, menor será a eco eficiência do produto. Consequentemente, nos casos para os quais o indicador for expresso como (IVSP/IAB) a relação de proporcionalidade é direta entre o valor gerado pelo índice e a eco eficiência do objeto de análise.

Os métodos BASF e Bayer, diferem-se dos demais ao utilizarem de uma forma de representação na qual os indicadores ambiental e de valor de sistema de produto são colocados em um mesmo gráfico, sem, no entanto, serem relacionados por meio de funções matemáticas. No caso do método BASF, o gráfico é constituído por um sistema bidimensional de eixos; no método Bayer o gráfico é do tipo radar, no qual cada uma das pontas representa um indicador.

Considerou-se relevante a identificação de quais seriam os indicadores de eco eficiência dos métodos de AEE. O método da UN ESCAP, por exemplo, indica quais devem ser os indicadores principais para os diferentes setores da economia (agricultura, manufatura, entre outros). Da mesma forma, o método EcoWater sugere indicadores de eco eficiência a serem utilizados na avaliação de sistema de água. Outros métodos apresentam indicadores versáteis, ou seja, que podem ser aplicados em qualquer tipo de empresa ou setor, como o NRTEE, UN e WBCSD.

A forma de apresentação dos indicadores de eco eficiência também pode ser variável. Métodos como BASF, Kuosmanen e Kortelainen e TU Delft o fazem a partir de indicador único. Já seus homólogos Bayer, EcoWater, Hahn et al., MIPS, NRTEE, UN ESCAP, UN e WBCSD expressam o resultado sob a forma de perfil de indicadores.

A obtenção de um indicador único de eco eficiência implica em que ambas as dimensões, ambiental e econômica sejam representadas também por um único indicador. Como já ressaltado nesta mesma discussão, os métodos que agrupam 
indicadores ambientais - baseados em normalização e ponderação -, ou mesmo, aqueles que usam de valores numéricos (monetários) para representa-los, permitem a obtenção de um único indicador de eco eficiência. Já o agrupamento do indicador de valor de sistema de produto ocorre por conta da somatória de valores de parcelas diversas, computadas no âmbito do escopo estabelecido para aplicação do método de AEE. Esse procedimento se respalda no fato de a unidade de valor selecionada para representar tal dimensão, ser comum por toda a extensão do mesmo escopo a despeito desta ser física ou monetária.

Os efeitos da opção por determinado formato de indicador de eco eficiência se refelete na interpretação dos resultados da análise. Da mesma forma que ocorre com a Análise de Ciclo de Vida (ACV), ambas as abordagens possuem vantagens e desvantagens e assim, aspectos inerentes ao estudo - tais como resultados a serem obtidos, propósitos a que se destinam esses mesmos resultados e público-alvo a ser contemplado com sua comunicação - passam a ser importantes para efeito desta decisão.

De qualquer forma, é possível intuir que a comunicação dos resultados de um estudo de AEE a um público pouco familiarizado com implicações ambientais será mais efetiva se realizada por meio de perfil de indicadores ao invés de basear-se em indicador único. A justificativa para isso reside, em verdade, na expressão da dimensão ambiental. A adoção do perfil de indicadores suscita que esta seja expressa em termos de efeitos ambientais conhecidos - ou mais familiares - do público não militante na matéria, como mudanças climáticas e depleções de água ou recursos fósseis. Já o agrupamento imposto pelo indicador único predispõe que os mesmos desdobramentos sejam relacionados entre si, usando para isso bases de referências abstratas e, em certos caso, sem sentido físico - como Points $(\mathrm{Pt})$ - ou muito específicas e por isso, de difícil entendimento para o mesmo interlocutor - caso de Disability-Adjusted Life Year (DALY ${ }^{8}$ ).

A opção por perfil de indicadores desobriga da aplicação de métodos de agrupamento dos indicadores ambientais e assim da indesejável subjetividade que por eles é introduzida. Por fim, no âmbito do processo gerencial de tomada

8 O parâmetro DALY indica o número de anos que determinado indivíduo pode esperar viver de forma saudável, sem limitações ou imcapacidades. A Organização Mundial da Saúde (OMS) reconhece tratar-se de um método mais preciso de análise de uma população, ao levar em conta factores de qualidade de vida que não são contabilizados para a esperança de vida. 
de decisão o uso do perfil de indicadores mostra-se também mais efetivo em identificar fragilidades associados a produtos, processos e serviços.

Esta análise induz pensar que as diferenças entre os tipos de indicador de eco eficiência condicionam a forma de condução das AEE. Em termos operacionais isso faz sentido. Como ilustração, o uso do método Kuosmanen e Kortelein predispõe que o executor da AEE tenha conhecimento, ao menos instrumental, sobre a técnica DEA para que a iniciativa chegue a bom termo. $\mathrm{Na}$ mesma linha, no caso de opção pelo método BASF a representação gráfica dos resultados é possível apenas via agrupamento dos indicadores ambientais. Ao menos em tese, os fatores de ponderação utilizados neste procedimento podem ser customizados pelo executor da AEE. No entanto, há pouca informação sobre a forma como esses pesos são obtidos, ou mesmo, como a ponderação em si é conduzida. Com tão baixo grau de operabilidade, o executor adota, invariavelmente, fatores previamente estabelecidos pelo método, sem saber se estes correspondem à realidade da avaliação que efetua, ou mesmo, conhecer as conseqüências dessa decisão. Diante de tais limitações metodológicas é plausível que a aplicação deste método se viabilize apenas com a contratação de uma consultoria competente. Da mesma forma, o método TU Delft, assim como outros métodos congéneres, requer dos usuários conhecimentos específicos para transformar os indicadores ambientais em eco custos.

\subsection{Usos possíveis para métodos de AEE e suas características em relação ao indicador de EE}

\subsubsection{Determinação dos usos possíveis para um método de AEE}

Nesta etapa do estudo são identificadas aplicações potenciais para os métodos de AEE selecionados. Como apresentado anteriormente, o conceito de EE foi criado para dar suporte às organizações interessadas em praticar o desenvolvimento sustentável. Nesse contexto, a possibilidade de poder identificar quais métodos de AEE seriam mais adequados ao atendimento de atividades de 
interesse das organizações pode representar um diferencial de gestão para muitas organizações.

Para identificar as aplicações potenciais de métodos de AEE foram considerados dois requisitos. O primeiro considerou ações de gestão empresarial para quais uma abordagem com características como as da AEE pode ser aproveitada. O segundo requisito compreendeu usos para os quais os métodos de AEE em si se auto-denominam aplicáveis.

Especialistas da área ambiental e suas correlatas foram convidados a tomar parte de um 'brainstorming' para propor ações que, ao menos em primeira instância, estariam compreendidas nos domínios do primeiro requisito. Concluída essa etapa, a autora deste estudo se ocupou de realizar uma pesquisa bibliográfica específica para identificar propósitos para os quais os métodos de AEE em análise se dizem efetivos.

O universo de possibilidades gerado a partir das ações anteriores foi a seguir submetido a um procedimento de triagem para adquirir sua forma final. Como resultado deste encadeamanto lógico foram identificados as seguintes aplicações potenciais: (i) Monitoramento de processo com vistas à melhoria contínua; (ii) Selecção e classificação de produtos; (iii) Atendimento a requisitos legais e outros requisitos; e, (iv) Marketing, rotulagem de produtos e comunicação ambiental.

A aplicação de AEE no monitoramento de processos com vista à melhoria contínua é prática recorrente em muitos setores produtivos. A maior função deste monitoramento está refletida na existência de modelos e normas, como a norma ISO 9001 (ABNT ISO, 2000), que visa a gestão da qualidade "para o desenvolvimento, implementação e melhoria da eficácia de um sistema de gestão da qualidade para aumentar a satisfação do cliente pelo atendimento aos requisitos do cliente".

Uma abordagem sugerida pela ISO 9001 para levar adiante esse propósito consiste do PDCA, cuja lógica operativa compreende atividades de planejamento, implementação, monitoramento e execução de ações para a melhoria contínua de processos. Em sua implementação são invariavelmente considerados controles em linhas de manufatura (como uso de água, eficiência no uso de matérias primas, comparação entre eficiências de produtos, entre outros) (CICLO, 2015). 
Os indicadores das áreas produtivas são em geral controlados por gestores que atuam em áreas ou subáreas de manufatura e analisados ao longo do tempo.

A aplicação denominada seleção ou classificação de produtos abrange diferentes situações de comparação triviais e em muitos casos, necessárias, nas empresas. Estas se voltam a atividades de desenvolvimento de novos produtos; definição de tecnologia de produção; avaliação de regiões; entre outros. A seleção ou classificação pode ser aplicada para produtos, processos, tecnologias, regiões ou unidades. São, invariavelmente, produtos das seleções e classificações: aquisição de equipamentos ou tecnologias; validação de fornecedores de matérias-primas e insumos; definição de embalagem para produtos; e implementação de melhorias em determinadas regiões.

Outra aplicação potencial para os métodos de AEE reside no atendimento a requisitos legais e de outra natureza. Agências regulatórias vêm intensificando as normas e legislações sobre as responsabilidades das empresas e um exemplo dessa conduta, ocorrido recentemente no Brasil, é a criação e implementação da Política Nacional de Resíduos Sólidos (BRASIL, 2010), que apresenta, dispõe e dá forma a regulamentações atuais ao tratamento, a coleta, e o despejo de rejeitos de diferentes procedências e características.

Atualmente não há relação entre indicadores de eco eficiencia e as leis e regulamentos, porém, considera-se que com a tendência do crescimento da fiscalização ambiental, as empresas podem ainda influenciar as novas regulamentações para a utilização de indicadores de eco eficiência como métricas de sustentabilidade.

Por último, a possível aplicação dos métodos de AEE em ações de marketing, rotulagem de produtos e comunicação ambiental abrange a comunicação, tanto de âmbito interno, como externo, de aspectos de sustentabilidade. Essa prática, inclusive, tornou-se cotidiane e necessária para a gestão das empresas (OLIVEIRA, 2014; WALMART BRASIL, 2015) e se utiliza de diferentes formas e vias para atender a seus propósitos. O GRI (Global Reporting Initiative) (GRI, 2015) consiste, por exemplo, de uma dessas ferramentas da comunicação. Diretrizes e orientações de caráter geral a serem aplicados para disseminação de conteúdos relativos à matéria ambiental são inclusive objeto de normatização, sob a forma da ABNT NBR ISO 14063 (ABNT ISO, 2009). 
A forma de comunicação varía em função do públio-alvo, que pode variar desde o consumidor final (para quem se destinam ações de rotulagem de produtos e propagandas de marketing), ou mesmo, para acionistas (para quem a comunicação ocorre de forma estruturada, detida e contextualizada a partir de relatórios externos). Nestas aplicações, deve-se considerar que a abrangência da divulgação é externa e, portanto, pode ser questionada. É necessário que as análises que levaram a obtenção das características ambientais do produto sejam devidamente documentadas e validadas por especialistas. Desta forma, os indicadores de eco eficiência podem ser utilizados para a comunicação do desempenho ambiental do produto em questão.

\subsubsection{Especificação das características do indicador de EE para cada aplicação identificada}

Considerando as informações descritas no item 9.2.1, foram organizadas na Tabela 9.2 as características das potenciais aplicações de métodos de AEE. Para a identificação destas características foram utilizados os mesmos requisitos previamente estabelecidos para avaliação dos métodos de AEE (Tabela 9.1).O processo de preenchimento da matriz também ocorreu de maneira semelhante. Quando certa aplicação potencial apresentou a característica destacada por determinado atributo o campo relativo a esta posição na matriz recebeu o símbolo $(\checkmark)$. Para características opcionais, ou mesmo, aquela que não é a opção principal da aplicação potencial, fez-se uso do símbolo (!). Finalmente, quando a aplicação potencial de AEE não atende a certo atributo, o campo foi deixado em branco.

A utilização do mesmo raciocínio, tanto no uso dos requisitos quanto para o processo de preenchimento, para a elaboração das Tabelas 9.1 e 9.2, permite, em continuidade a essa investigação, a associação entre as características dos métodos de AEE e dos seus possíveis usos. Esta associação será realizada de forma qualitativa e em nível de tendência e será discutida detalhadamente no item 9.3. 
Tabela 9.2 - Características das potenciais aplicações de métodos de AEE

\begin{tabular}{|c|c|c|c|c|c|}
\hline \multicolumn{2}{|c|}{$\frac{\text { Potenciais Aplicações }}{\text { Requisitos }}$} & $\begin{array}{l}\text { Monitoramento de } \\
\text { processo com } \\
\text { vistas à melhoria } \\
\text { contínua }\end{array}$ & $\begin{array}{c}\text { Seleção e } \\
\text { Classificação de } \\
\text { Produtos }\end{array}$ & $\begin{array}{c}\text { Atendimento a } \\
\text { requisitos legais } \\
\text { e outros } \\
\text { requisitos }\end{array}$ & $\begin{array}{c}\text { Marketing, rotulagem } \\
\text { de produtos e } \\
\text { comunicação } \\
\text { ambiental }\end{array}$ \\
\hline \multirow{6}{*}{ 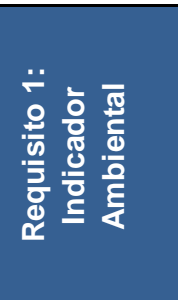 } & AA & $\checkmark$ & $\checkmark$ & $\checkmark$ & $\checkmark$ \\
\hline & IA & & $\checkmark$ & & $\checkmark$ \\
\hline & IU & & $\checkmark$ & & $\checkmark$ \\
\hline & $\mathrm{PI}$ & $\checkmark$ & $\checkmark$ & $\checkmark$ & $\checkmark$ \\
\hline & UF & $\sqrt{ }$ & $\bar{\checkmark}$ & $\checkmark$ & $\checkmark$ \\
\hline & UM & & $\checkmark$ & & \\
\hline \multirow{11}{*}{ 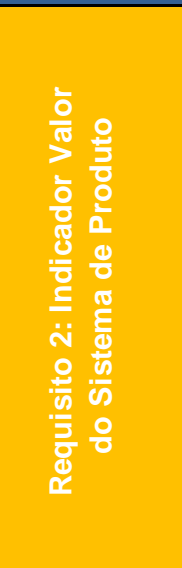 } & UM & ! & $\checkmark$ & $\checkmark$ & \\
\hline & UF & $\bar{\checkmark}$ & $\checkmark$ & $\checkmark$ & $\checkmark$ \\
\hline & QBS & $\checkmark$ & $\checkmark$ & $\checkmark$ & $\checkmark$ \\
\hline & $\mathrm{CCV}$ & & $\checkmark$ & $\checkmark$ & \\
\hline & $\mathrm{PR}$ & & $\checkmark$ & $\checkmark$ & \\
\hline & PIB & . & $\checkmark$ & $\checkmark$ & \\
\hline & VA & ! & $\checkmark$ & $\checkmark$ & \\
\hline & LL & & $\checkmark$ & $\checkmark$ & \\
\hline & $\mathrm{VL}$ & & $\checkmark$ & $\checkmark$ & \\
\hline & EC & & $\checkmark$ & $\checkmark$ & \\
\hline & UFU & & $\checkmark$ & & $\checkmark$ \\
\hline \multirow{4}{*}{ 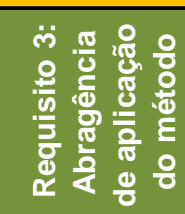 } & BT & & $\checkmark$ & $\checkmark$ & $\checkmark$ \\
\hline & $\mathrm{BP}$ & & & & \\
\hline & $\mathrm{PP}$ & $\checkmark$ & & $\checkmark$ & \\
\hline & $\overline{\mathrm{PT}}$ & & & & \\
\hline \multirow{5}{*}{ 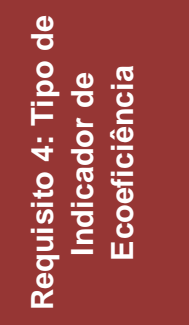 } & IAB/IVSP & $\checkmark$ & $\checkmark$ & $\checkmark$ & $\checkmark$ \\
\hline & IVSP/IAB & $\checkmark$ & $\checkmark$ & $\checkmark$ & $\checkmark$ \\
\hline & RG & $\checkmark$ & $\checkmark$ & & $\checkmark$ \\
\hline & IU & & $\checkmark$ & & $\checkmark$ \\
\hline & $\mathrm{PI}$ & $\checkmark$ & $\checkmark$ & $\checkmark$ & $\checkmark$ \\
\hline
\end{tabular}

Fonte: Autora

Legenda: AA: Aspecto Ambiental; IA: Impacto Ambiental; IU: Indicador único; PI: Perfil de Indicadores; UM: Unidade Monetária; UF: Unidade Física; QBS: quantidade de bens ou serviços; CCV: Custo do ciclo de vida; PR: Preço; PIB: Produto Interno Bruno; VA: Valor Agregado; VL: Vendas Líquidas; LL: Lucros líquidos; EC: Eco custo; UFU: unidade funcional; BT: berço-aotumulo; BP: berço-ao-portão; PP: portão-ao-portão; PT: portão-ao-túmulo; IAB: Indicador Ambiental; IVSP: Indicador de Valor de Sistema de Produto; RG: representação gráfica. 


\subsubsection{Monitoramento de processo com vistas à melhoria contínua}

O procedimento de verificação do uso de métodos de AEE para efeito de monitoramento de processo com vistas à melhoria contínua considerou aspectos como praticidade, tempo e facilidade de interpretação dos resultados; e perfil do público a que esses resultados se destinam. Com relação a esta última característica admitiu-se que a análise dos resultados da AEE seria realizada por executivos de nível gerencial da empresa.

Nesse contexto, o uso de aspectos ambientais é mais recomendável para composição do indicador ambiental devido a maior facilidade de sua obtenção (em comparação com impactos ambientais), clareza, potencial de expressão da realidade física, e objetividade, proprocionada para efeito de análise dos gestores.

Para este mesmo uso, representar o indicador ambiental, a partir de um perfil de indicadores, constitui ação mais efetiva devido aos seguintes aspectos: (i) o perfil de indicadores proporciona um quadro completo do objeto de análise, trazendo informações não apenas sobre cada índice em particular, como também da interação entre indicadores; (ii) evita uma etapa adicional, e subjetiva, de agrupamento. Complementarmente a isso, sugere-se o uso de unidades físicas para representá-los a fim de conferir-lhes a magnitude e dimensão devidas.

As componentes que caracterizaram o indicador ambiental acabaram sendo também determinantes para especificar o indicador de valor do sistema de produto. Para efeito de monitoramento de processo a opção por representá-lo sob a forma de unidades físicas é coerente uma vez que (i) esta permite uma análise 'in loco' da unidade fabril, por apontar - quando associado ao indicador ambiental - consumos e emissões específicas por unidade de produto, ou mesmo, por unidade de ativos/intermediários de processo, na situação em que tal verificação ocorre no âmbito de um setor produtivo, (ii) trata-se de um dado disponível na empresa; e, por fim, (iii) é familiar, e portanto, de mais fácil compreensão por parte dos gestores.

A unidade monetária - sob a forma de Valor Agregado, por exemplo também é uma possibilidade adequada de representação do indicador de valor do sistema de produto. No entanto, verificações no âmbito 'portão ao portão', para as quais há fragmentação do processo em setor produtivos, seriam de difícil 
operacionalização dada a ausência de informações de ordem econômica para tais estágios.

\subsubsection{Seleção e Classificação de Produtos}

Na aplicação de métodos de AEE, para ações de seleção e classificação, o tanto uso de aspectos como de impactos para composição do indicador ambiental é indistinto. Nestes casos também são válidas representações desse índice tanto na forma de perfil de indicadores, como de parâmetro único. Para públicos menos familiarizados com temáticas ambientais é recomendável o uso de um único indicador, assim como para situações que compreendam processos decisórios.

De qualquer forma, a escolha do tipo de indicador ambiental deve ocorrer com base no objeto da comparação, propósitos a que se destinam a AEE e público-alvo. Em qualquer situação, porém, fará mais sentido expressá-lo sob a forma de unidades físicas, pelos motivos expostos no detalhamento da aplicação anterior. Porém, devido a abrangência desta aplicação e ao fato da AEE ser comparativa, a utilização de unidade monetária também poderia ser aplicada neste potencial uso.

O indicador de valor de produto é igualmente flexível, podendo compreender unidades monetárias ou físicas, de acordo com o objetivo da análise e público-alvo. Decidida qual será a unidade pode-se, então, determinar qual elemento será utilizado para tal indicador. Invariavelmente, as opções acabam recaindo sobre os elementos descritos na Tabela 9.2, tais como a quantidade produzida de bens para unidades físicas, ou valor agregado, PIB, vendas líquidas, entre outros, para unidades monetárias.

Em relação à abrangência de aplicação, um escopo do tipo 'berço ao túmulo' tem por vantagens cobrir integralmente o ciclo de vida do objeto de análise. A limitação maior associada a tal abordagem reside na disponibilidade de informação, nem sempre plena e uniforme, para todos os estágios contemplados.

É adequado que o indicador de eco eficiência seja expresso por meio da razão entre a dimensão ambiental e econômica, abordagem mais tradicional em termos de gestão do que suas variantes gráficas. Admitindo-se que a relação 
entre indicador e grau de eco eficiência seja clara, a forma pela qual o índice ambiental e de valor do sistema de produto são relacionados é irrelevante, podendo ser (IAB/IVSP) ou (IVSP/IAB). Nos casos de indicador único para expressão do resultado de AEE, a representação gráfica também é uma alternativa possível.

\subsubsection{Atendimento a requisitos legais e outros requisitos}

Neste tipo de aplicação, a opção por um método de AEE está condicionada a aspectos normativos e/ou de legislação. De forma geral, porém, pormenores tais como praticidade e rapidez de geração de resultados, bem como, a existência de uma robusta fundamentação teórica são determinantes. Além disso, é razoável considerar que as informações estarão disponíveis para diversos públicos.

A utilização de aspectos ambientais mostra ser mais efetiva para essa classe de aplicações, pelo fato de - assim como nos caso anteriores - serem dados de mais fácil obtenção e interpretação que os aspectos ambientais para um público leigo na questão ambiental. Pelos mesmos motivos, é indicado que a apresentação do indicador ambiental seja na forma de perfil e esteja suportada por unidades físicas.

Quanto ao indicador de valor de sistema de produto, entende-se que, tanto a unidade física quanto monetária sejam aplicáveis. Aliás, é precisamente em virtude desta variabilidade que todos os elementos relativos ao referido requisito aparecem assinalados na Tabela 9.2. Observe-se, porém, que a opção pelo uso de unidade funcional poderá restringir a aplicação do método de AEE para os contexto legal e normativo, dada a abrangência do caráter de suas disposições, que compreende em geral um número elevado e bastante diversificado de setores produtivos.

Em termos de abrangência, uma análise do tipo 'berço ao portão' na qual fossem, contemplados diversos estágios de tratamento de matéria, poderia trazer dividendos importantes. No entanto, variações tecnológicas, processuais e mesmo, operacionais, poderiam ser limitantes, sobretudo nos casos em que a AEE fornecesse subsídios para consolidação de padrões de emissão. Por conta 
disso, uma restrição de foco para o nível 'portão ao portão' apresenta-se como sendo mais prudente. Por último, a apresentação dos indicadores de eco eficiência em forma de razão entre os indicadores ambiental e de valor de sistema de produto é sem dúvida a mais adequada para este uso. A adoção de perfil de indicadores mostra-se também uma alternativa coerente; por permitir uma melhor análise mais completa do desempenho de uma organização ou segmento. No entanto, cuidados adicionais devem ser observados a fim de proporcionar um grau suficiente de harmonização entre os indicadores que compõem o perfil.

\subsubsection{Marketing, rotulagem de produtos e comunicação ambiental}

Uma característica essencial dessa aplicação reside no fato de que as formas de comunicação a ela associadas ocorrem para públicos externos à organização. Portanto, é quase que mandatório, que os resultados gerados pela AEE permitam fácil interpretação, sem, no entanto deixar conotações de inconsistência ou fragilidade conceitual.

Dado um cenário, consideram-se aceitáveis opções tanto por aspectos como por impactos para representação do indicador de desempenho ambiental. A opção por certa variante está condicionada à informação a ser comunicada e, mais uma vez, ao perfil do público-alvo. Para consumidores finais é recomendável fazer uso de aspectos ambientais por se tratarem de informações de maior conhecimento e domínio da população. Na comunicação entre organizações o uso de impactos ambientais pode ser mais apropriado, por fornecer ao interlocutor uma dimensão no nível de desdobramentos decorrentes em função dos consumos e emissões associadas a insumos, aditivas e até processos.

A exigência de abranger um público bastante diversificado sugere que a expressão dos indicadores ambientais se dê sob a forma de perfil, evitando o uso do trâmite de agrupamento e, portanto, as limitações e condicionantes que a ele se vinculam. Porém, de acordo com o objetivo e público- alvo é possível que um único indicador seja mais apropriado.

Considera-se que a unidade física seja a melhor alternativa para representar o indicador ambiental, pois são menos susceptíveis à variações 
quando comparadas às unidades monetárias. Estas variações poderiam ser prejudiciais em comunicações externas, como na rotulagem de produtos.

A representação do indicador de valor do sistema de produto também está condicionada ao público escolhido no objetivo da AEE. A unidade física é mais atraente à comunicação externa e, na rotulagem de produtos, por evitar correlações monetárias nem sempre bem-vindas. Considera-se, ainda, que a unidade funcional, apesar do conceito ser menos difundida para o público geral, pode ter uma utilização positiva de acordo com a aplicação específica.

A abrangência da aplicação do método é considerada como um dos aspectos essenciais ao marketing ambiental, pelo fato desta se constituir, quase sempre, em comunicação externa. Assim é de importância capital avaliar todas as etapas do ciclo de vida do objeto de aplicação da AEE.

No presente caso, a representação do indicador de eco eficiência pode ser feita via razão (direta ou mesmo, inversa) entre o indicador ambiental e o de valor de sistema de produto, assim como a sua representação gráfica. Por fim, o uso de perfil de indicadores de eco eficiência se mostra mais benéfico à comunicação do que seu congênere unitário. O perfil fornece mais elementos ao interlocutor, permitindo-lhe a formulação de um quadro amplo em termos de desempenho. $O$ inconveniente desta abordagem reside em situações para as quais o indicador ambiental seja expresso segundo impactos ambientais não conhecidos do interlocutor. Reconhece-se, portanto, que a utilização do indicador único também poderá ser coerente em determinadas situações, como àquelas em que utilza-se a representação gráfica ou que é direcionada para comunicação entre organizações.

\subsection{Especificação de usos efetivos potenciais dos métodos de AEE}

O procedimento adotado para analisaros métodos de AEE caracterizou-se por apresentar várias etapas. Aquelas de identificação e triagem mostraram haver na literatura técnica diversos métodos disponíveis para realização da AEE. Como não poderia deixar de ser, evidenciou que esses métodos incorporam diferentes formatos e propostas de objetivos. Outra etapa, a aplicação dos requisitos de 
caracterização, proporcionou o mapeamento de suas especificidades e evidenciou diferenças entre os mesmos. A próxima etapa - quase que natural foi justapor características e particularidades de cada método de AEE, às especificidades requeridas em cada aplicação potencial anteriormente identificada. O produto final desse procedimento forma recomendações - ainda que em nível conceitual e baseadas em tendência dada a característica qualitativa deste estudo - dos aproveitamentos mais indicados para cada método.

Quanto à aplicação para efeito de monitoramento de processos com vistas à melhoria continua, concluiu-se que os mais indicados são os métodos Bayer, NRTEE, WBCSD e UN.

Os métodos NRTEE e WBCSD, concebidos para serem aplicados internamente nas empresas, tiveram sua condução confirmada para esse fim mostrando-se coerente e imediata. O método Bayer apresenta semelhanças nos requisitos referentes ao indicador ambiental e tipo de indicador de eco eficiência, para os quais se pode imputar grande relevância mesmo que em um exame de ordem qualitativa. Além disso, no método Bayer, permite-se a determinação dos elementos relevantes e aplicáveis ao objetivo da AEE, que também coincide com a necessidade de fácil aplicação e adaptação neste uso potencial.

O método UN também foi considerado aplicável para o monitoramento de processos, dadas suas semelhanças com as expectativas para este uso em termos dos requisitos: tipo de indicador ambiental, abrangência de aplicação, e tipo de indicador de eco eficiência. Em particular, o método destaca-se pela aplicabilidade em escopos do tipo 'portão ao portão', requerido para esta aplicação.

Os métodos voltados para a seleção e classificação de produtos são BASF, EcoWater, Kuosmanen e Kortelainen, MIPS, Hahn et al., TU Delft, UN ESCAP e UN. Tal incidência se deve a dois fatores preponderantes: (i) a abrangência deste uso potencial; e (ii) a motivação que levou à criação dos métodos.

O método EcoWater foi criado com vistas a comparar diferentes sistemas de uso de água. O mesmo ocorre com o UN ESCAP, concebido para contrapor regiões a partir de seus desempenhos de eco eficiência. Outros métodos, como BASF, Kuosmanen e Kortelainen, MIPS, Hahn et al., TU Delft e UN não foram 
concebidos para um uso específico, conforme descrito no método anterior, porém, demonstraram-se aplicáveis neste uso potencial devido às suas estruturas metodológicas que permitem a inclusão de diversos produtos a serem comparados ou a comparação em relação a uma referência (como no método Hahn et al.).

Além disso, os métodos BASF, EcoWater, Kuosmanen e Kortelainen e MIPS requerem uma abrangência do tipo 'berço ao túmulo', apontada como requisito de destaque para essa aplicação. Muito embora aplicável dentro de um escopo do tipo 'portão ao portão'.

O uso associado ao atendimento a requisitos legais e outros requisitos toma como principais peculiaridades a aplicação e a fiscalização. Ou seja, passam a serem elegíveis para este uso os métodos de AEE que suportarem a geração de indicadores que possam, não apenas ser constituídos por empresas, mas também, fiscalizáveis.

Diante desse quadro, admitiu-se serem mais apropriados os métodos de abrangência 'portão ao portão', cuja gestão está sob intervenção direta da organização.

Também considerou-se como requisito importante a utilização de aspectos ambientais para compor o indicador correspondente, e expressão de resultados na forma de perfis - tanto de indicadores ambientais, como de eco eficiência -, com o intuito de manter gerar resultados de AEE sem influências, tando de métodos de avaliação de impactos, como do agrupamento de indicadores.

Assim, atenderam a todas as condições formuladas apenas os métodos NTTEE, UN e WBCSD. Os demais foram excluídos por deterem uma ou mais caraterísticas específicas que os descredenciaram. O método BASF necessita de conhecimentos científicos próprios para sua aplicação. O custo a ele associado também representa uma barreira à sua implementação por inviabilizá-la para empreendimentos de pequeno e médio porte. Uma restriçao dessa natureza não pode estar associada ao atendimento de um requisito legal ou de caráter normativo. O mesmo motivo excluiu os métodos Kuosmanen e Kortelainen e EcoWater.

Os métodos Hahn et al. e TU Delft foram desconsiderados em razão de privilegiarem o uso de unidade monetária para representação do indicador 
ambiental, atributo este que torna inviável seu uso para efeito de composição de leis ou regulamentos, principalmente em termos de controle.

Por fim, os métodos BASF, EcoWater e MIPS mostram ser mais aplicáveis no caso de marketing, rotulagem de produtos e comunicação ambiental. A análise baseou-se na característica da necessidade de divulgação dos resultados da AEE e considerou-se importante, principalmente, a adoção de abrangência do tipo 'berço ao túmulo'.

No método BASF o uso de indicador único combinado com a facilidade de interpretação dos resultados (realizada de acordo com a posição no gráfico bidimensional) poderia ser considerado uma vantagem do método para esta aplicação, principalmente para a comunicação entre organizações. Já o método EcoWater, apesar de apresentar um perfil de indicadores, mantem a abordagem do 'berço ao túmulo' e uma fácil interpretação de seus indicadores. O métodos Bayer e Kuosmanem e Kortelainen, apesar de também apresentarem a abordagem de ciclo de vida, foram excluídos devido a outras características dos mesmos. Para o método Bayer, considerou -se que o uso perfil de indicadores de eco eficiência associada à necessidade de interpretação da representação gráfica dificultaria a interpretação dos resultados para o público geral. Já para o métodos Kuosmanem e Kortelainen foi excluído devido a necessidade de conhecimento específico para o agrupamento dos indicadores ambientais.

O método MIPS merece destaque nesse caso por tomar por referência a unidade funcional. Muito embora o conceito não seja conhecido do público, seu conteúdo tende a ser de fácil interpretação por estar associado a ações cotidianas (por exemplo, o número de lavagens de uma lavadora, ou de quilômetros rodados por um automóvel).

Os resultados dessa análise estão distantes de serem absolutos. A confrontação entre os métodos de AEE e potenciais usos para que estes são recomendáveis procurou determinar tendências e propensões. Isso pode ser verificado uma vez que as aplicações selecionadas para efeito desta verificação constituem-se de agrupamentos de possibilidades diversas, característica esta que, de uma forma ou de outra, exerceu influência sobre os resultados obtidos que não podem ser negligenciados. A despeito dessa limitação o processo foi capaz de chegar a termos conclusivos dentro dos limites a que se propôs. 


\section{CONCLUSÕES}

Este estudo tem como objetivo apontar os tipos de métodos de avaliação de eco eficiência (AEE) mais adequados para ações gerenciais para as quais caibam tais abordagens.

Tendo em vista as discussões empreendidas do capítulo anterior, concluise que:

- Quanto às aplicações para monitoramento de processos, com vistas à melhoria contínua, os métodos de AEE mais adequados foram Bayer, NRTEE, WBCSD e UN. Isso em virtude da facilidade e praticidade de aplicação destes métodos, considerando o público alvo e necessidade de avaliações frequentes. Considera-se que estas características são conferidas pelo uso preferencial de aspectos ambientais, unidades físicas para representar o indicador de valor de sistema de produto e a abordagem portão ao portão;

- Para a seleção e classificação de produtos, os métodos BASF, EcoWater, Kuosmanen e Kortelainen, MIPS, Hahn et al., TU Delft, UN ESCAP e UN demonstraram são recomendados devido às suas estruturas metodológicas que permitem a inclusão de diversos produtos a serem comparados entre si ou em relação a uma referência;

- No que se refere a usos voltados ao atendimento de requisitos legais e/ou de outras naturezas, os métodos NRTEE, WBCSD e UN são os mais indicados, pois utilizam a abordagem 'portão ao portão', aspectos ambientais e perfil de indicadores para representar os indicadores ambientais e indicadores de eco eficiência, fatores que permitem que sejam constituídos por empresas e sejam fiscalizáveis;

- Por fim, em aplicações de marketing, rotulagem e comunicação são recomendados os métodos BASF, EcoWater e MIPS justificados pela necessidade de divulgação dos resultados da AEE, adoção de 
abrangência do tipo 'berço ao túmulo' e apresentação dos resultados que permita fácil interpretação, de acordo com o público-alvo.

Finalmente, concluiu-se que, para a escolha adequada do método de AEE, conhecimento prévio das características de cada abordagem é necessário, pois as particularidades de cada método tornam os mesmos mais apropriados para determinadas aplicações. 


\section{RECOMENDAÇÕES DE TRABALHOS FUTUROS}

Durante a realização desta pesquisa, identificaram-se questões referentes à análise de métodos de AEE que podem ser abordadas em pesquisas futuras.

Para tal propõe-se:

- Análise dos métodos de AEE utilizando-se de ferramentas como o AHP (Analytic Hierarchy Process / Processo Analítico Hirárquico);

- Realização de estudo de caso com os métodos descritos para melhor diferenciação e identificação de possíveis diferenças nos seus resultados;

A realização destas propostas permitirá a continuidade da análise dos métodos de AEE de forma quantitativa e, portanto, destacará ainda mais as diferenças e similaridades entre os mesmos. 


\section{REFERÊNCIAS BIBLIOGRÁFICAS}

ASSOCIAÇÃO BRASILEIRA DE NORMAS TÉCNICAS. NBR ISO 14063: Gestão ambiental comunicação ambiental - Diretrizes e exemplos. Rio de Janeiro, 2009. $29 \mathrm{p}$.

ASSOCIAÇÃO BRASILEIRA DE NORMAS TÉCNICAS. NBR ISO 9001: Sistemas de gestão da qualidade - Requisitos. Rio de Janeiro, 2000. 30 p.

ANGELIS-DIMAKIS, T. EcoWater. Deliverable 5.1 - Step-wise consolidated guidelines for the development of meso-scale eco-efficiency indicators. 2015. 39 p. Disponível em: <http://environ.chemeng.ntua.gr/ecowater>. Acesso em: 23 de mar. 2015.

BRASIL. Lei Federal No 12.305, de 2 de agosto de 2010. Política Nacional de Resíduos Sólidos. Brasília, 2010.

CAVALCANTI, R. LAS NORMAS DE LA SERIE ISO 14.000. Apresentado em: Curso Internacional de Aspectos Geológicos de Protección Ambiental, 2, Sao Paulo, 5-20-jun. 2000 Campinas.

DHI et al. EcoWater. Deliverable 4.2 - Baseline eco-efficiency assessment of water use in industrial sectors. 2014. 59 p. Disponível em: < http://environ.chemeng.ntua.gr/ecowater $>$. Acesso em: 23 de mar. 2015.

ECOWATER. Meso-level eco-efficiency indicators to assess technologies \& their uptake in water use sectors. Disponível em: http://environ.chemeng.ntua.gr/ecoWater/Default.aspx?t=0. Acesso em: 15 de mar. 2015.

EHRENFELD, J. R. Eco-efficiency - Philosophy, theory, and tools. Journal of Industrial Ecology, v. 9, n. 4, p. 6-8, 2005.

UN ESCAP. Eco-efficiency Indicators: Measuring Resource-use Eco-efficiency and the Impact of Economic Activities on the Environment, 2009. 25 p. Disponível em: $\quad$ https://sustainabledevelopment.un.org/content/documents/785eco.pdf. Acesso em: 23 de mar. 2015.

FET, A. M.; MICHELSEN, O. Industrial Ecology and Eco-Efficiency - An introduction to the concepts. In: NATO/CCMS Pilot Study on Cleaner Products and Processes, Vilnius, Lithuania, Maio 12-16th, 2002.

GABRIEL R., BRAUNE A. Eco-efficiency Analysis: Application and User Contacts. Journal of Industrial Ecology, v. 9, n. 4, p. 19-21, 2005.

GRI - Global Reporting Initiative. Enpowering sustainable decisions.. Disponível em: <https://www.globalreporting.org/Pages/default.aspx>. Acesso em: 15 de set. 2015.

HAHN, T. et al. Opportunity cost based analysis of corporate eco-efficiency: A methodology and its application to the CO2-efficiency of German 
companies. Journal of Environmental Management, v. 91, n. 10, p. 1997-2007, 2010.

HENDRIKS Ch.F.; VOGTLANDER J.G.; JANSSEN MS.G.M.T. The Eco-cost/value ratio, a tool to determine the long-term strategy of de-linking economy and environmental ecology. International Journal of Ecodynamics. V. 1, n. 2, 2006. $13 \mathrm{p}$.

HINTERBERGER, F.; SCHMIDT-BLEEK, F. Dematerialization, MIPS and Factor 10 - Physical sustainability indicators as a social device. Ecological Economics, v. 29, n. 1, 1999. 4 p.

HUPPES, G.; ISHIKAWA, M. A framework for quantified eco-efficiency analysis. Journal of Industrial Ecology, v. 9, n. 4, 2005a. 17 p.

HUPPES, G.; ISHIKAWA, M. Eco-efficiency and its terminology. Journal of Industrial Ecology, v. 9, n. 4, 2005b. 4 p.

HUPPES, G.; ISHIKAWA, M. Why eco-efficiency? Journal of Industrial Ecology, v. 9, n. 4, 2005c. 4 p.

INTERNATIONAL ORGANIZATION FOR STANTARDIZATION. ISO 14040:2006 - Environmental management - Life cycle assessment - Principles and framework. Genebra, 2006a. 20p.

INTERNATIONAL ORGANIZATION FOR STANTARDIZATION. ISO 14044:2006 - Environmental management - Life cycle assessment - Requirements and guidelines. Genebra, 2006b. 46p.

INTERNATIONAL ORGANIZATION FOR STANTARDIZATION. ISO 14045:2012 Environmental management - Eco-efficiency assessment of product systems Principles, requirements and guidelines. Genebra, 2012. 38 p.

KOTAKORPI,E.; LAHTEENOJA, S.; LETTERNMEIER, M. Household MIPS Natural resource consumption of Finnish households and its reduction. The Finish Environment, $2008 . \quad$ Disponível em: http://old.seri.at/documentupload/Homepage\%20SERI\%20D/finmips report en.pdf>. Acesso em 15 mar. 2015.

KOURENTZIS, V. EcoWater. Deliverable 1.4 - Review of existing frameworks and tools for developing eco-efficincy indicators. 2012. 97 p. Disponível em: <http://environ.chemeng.ntua.gr/ecowater>. Acesso em: 23 de mar. 2015.

KUOSMANEN, T. Measurement and Analysis of Eco-efficiency. Journal of Industrial Ecology. v. 9, n. 4, p. 15-18, 2005

KUOSMANEN, T.; KORTELAINEN, M. Measuring eco-efficiency of production with data envelopment analysis. Journal of Industrial Ecology, v. 9, n. 4, p. 59$72,2005$. 
KURUNSAARI, H.; ROEVEKAMP, F.; OKANO, H. The eco-check in relation to target costing in ecodesigning - The resource-based view. 3rd International Symposium on Environmentally Conscious Design and Inverse Manufacturing - Ecodesign '03, 2003. 7 p.

MARZULLO, R. Analise de ecoeficiencia de óleos vegetais oriundos da soja e palma, visando a produção de biodiesel. 2007. 302 p. Dissertação (Mestrado). Escola Politécnica da Universidade de São Paulo. São Paulo,11 out, 2007.

NRTEE - NATIONAL ROUND TABLE ON THE ENVIRONMENT AND THE ECONOMY. Eco-efficiency indicators - Calculating Eco-efficiency Indicators: A Workbook for Industry. 2001. 60 p.

OECD - Organization for Economica Co-operation and Development. Ecoefficiency. 1998. $86 \mathrm{p}$.

OLIVEIRA, C. R. Comunicação Ambiental como Estratégia Organizacional. In: $9^{\circ}$ Interprograma de mestrados. Faculdade Cásper Libero. Nov, 2013. Disponível em: <http://casperlibero.edu.br/wp-content/uploads/2014/04/Carlos-Roberto-deOliveira.pdf>. Acesso em 15 de set. 2015.

CICLO PDCA. Disponível em: $<$ http://www.cedet.com.br/index.php?/Tutoriais/Gestao-da-Qualidade/ciclo-pdcaplan-do-check-act-planejar-fazer-verificar-agir.html>. Acesso em 15 de set. de 2015.

POPE, J.; ANNANDALE, D.; MORRISON-SAUNDERS, A. Conceptualising sustainability assessment. Environmental Impact Assessment Review, v. 24, n. 6, p. 595-616, 2004.

SAARI et al. Influence of vehicle type and road category on natural resource consumption in road transport. Transportation Research Part D 12, p. 23-32, 2007

SALING, P. et al. Eco-efficiency analysis by BASF: the method. International Journal of Life Cycle Assessment. v. 7, n. 4, 2002. 16 p.

SANJUAN, N. et al. Measuring and Improving Eco-efficiency Using Data Envelopment Analysis A Case Study of Mahon-Menorca Cheese. Journal of Industrial Ecology, v. 15, n. 4, 2011. 15 p.

SCHMIDT, I. et al. SEEbalance ${ }^{\circledR}$ Managing Sustainability of Products and Processes with the Socio-Eco-Efficiency Analysis by BASF. Greener Management International. 2004. 16 p.

SILVA, G. A. Indicadores de Sustentabilidade. São Paulo: Universidade de São Paulo, 2012.143 p. Apostila para o Programa de Educação Continuada - PECE, disciplina Ensino e Aprendizado à Distância Gestão e Tecnologia Ambientais, eAB-034. 
SILVA, G.A. OLIVEIRA, S. A. Glossário de Avaliação de Ciclo de Vida. 96 p. 2014. Disponível em:

$<$ http://www.espacoeco.org.br/media/55031/Gloss\%C3\%A1rio-de-

Avalia\%C3\%A7\%C3\%A3o-de-Ciclo-de-Vida-05-11-14.pdf >. Acesso em: 15 set. 2015.

SUSTAINABLE DEVELOPMENT REPORT 2004. Bayer. Disponível em:

$<$ http://www.bayer.com/en/sustainable-development-report-

004.pdfx?forced=false> Acesso em: 23 mar. 2015.

TU Delft. Delft Univerity of Technology. The Model of the Eco-costs / Value Ratio (EVR). Disponível em: <http://www.ecocostsvalue.com/>. Acesso em: 12 de setembro, 2014.

UHLMAN, B. W.; SALING, P. Measuring and Communicating Sustainability through Eco-Efficiency Analysis. Chemical Engineering Progress, v. 106, n. 12, p. $17-26,2010$.

UNITED NATIONS. A Manual for the Preparers and Users of Eco-efficiency Indicators. United Nations Conference on Trade and Development. New York and Geneva, 2004. p. 127

VAN BERKEL, R. Cleaner production and eco-efficiency initiatives in Western Australia 1996-2004. Journal of Cleaner Production, v. 15, n. 8-9, p. 741-755, 2007.

VERCALSTEREN, A. SPIRINCKX, GEERKEN, T. Life cycle assessment and ecoefficiency analysis of drinking cups used at public events. International Journal of Life Cycle Assessment. v. 15, n. 2, p. 221-230, 2010.

VERFAILLIE, H.; BIDWELL, R. Measuring eco-efficiency - A guide to reporting company performance. World Business Council of Sustainable Development. 2000. 35 p. Disponível em:

$<$ http://www.wbcsd.org/web/publications/measuring eco efficiency.pdf>. Acesso em 15 mar., 2014.

VOGTLANDER, J. G.; BREZET, H. C.; HENDRIKS, C. F. The Virtual Eco-Costs '99 - A Single LCA-Based Indicator for Sustanability and the Eco-Costs - Value Ratio (EVR) Model for Economic Allocations. International Journal of Life Cycle Assessment. v. 6, n. 3, p. 157-166, 2001.

WALMART BRASIL. Informações sobre estratégias de sustentabilidade da empresa. Disponível em: <http://www.walmartbrasil.com.br/responsabilidadecorporativa/sustentabilidade/>. Acesso em: 15 de set. 2015.

WILLIAMS A.S. Life Cycle Analysis: A Step by Step Approach. 2009. Technical Report TR-040. Illinois Sustainable Technology Center. 27p. Disponível em: $<$ http://www.istc.illinois.edu/info/library docs/TR/TR040.pdf>. Acesso em: mar. 2015. 


\section{GLOSSÁRIO}

Análise de inventário do ciclo de vida - "[...] fase da ACV que envolve a compilação e quantificação das entradas e saídas do sistema de produto objeto do estudo" (SILVA, 2012).

Avaliação de impacto do ciclo de vida - "descreve as consequências ambientais dos aspectos ambientais quantificados na fase de Análise de Inventário de modo a se conhecer a significância dos impactos ambientais potenciais associados a esses aspectos ambientais" (SILVA, 2012).

Avaliação de Ciclo de Vida (ACV) - Compilação e avaliação das entradas, saídas e dos impactos ambientais potenciais de um sistema de produto ao longo do seu ciclo de vida. (SILVA; OLIVEIRA, 2014).

Berço ao portão (cradle to gate) - Modelo de $A C V$, que inclui a parte à montante do ciclo de vida do produto, ou seja, todos os estágios, desde a extração da matéria-prima até o produto no portão da fábrica (BAUMANN; TILLMAN, 2004 apud SILVA; OLIVEIRA, 2014).

Berço ao túmulo (cradle to grave) - Modelo de ACV que inclui todo o ciclo de vida do produto, ou seja, todos os estágios, desde a extração da matéria prima à disposição dos resíduos. (BAUMANN; TILLMAN, 2004 apud SILVA; OLIVEIRA, 2014).

Ciclo de Vida - o sistema constituído pelo conjunto de todas as ações antrópicas ocorridas para que o produto cumpra sua função (SILVA, 2012).

Desempenho ambiental - resultados mensuráveis relacionados aos aspectos ambientais (ISO, 2012).

Indicador de eco eficiência - medida que relaciona o desempenho ambiental de um sistema de produto ao valor do sistema de produto (ISO, 2012). 
Indicador de valor de sistema de produto - quantidade numérica que representa o valor do sistema de produto (ISO, 2012).

Indicador de desempenho ambiental - quantidade numérica que representa o desempenho ambiental (adaptado de SILVA; OLIVEIRA, 2014).

Portão ao portão (gate to gate) - Modelo de ACV, que inclui a parte do ciclo de vida do produto referente ao processo produtivo, ou seja, todos os estágios, desde a entrada até a saída do produto no portão da fábrica (adaptado de SILVA; OLIVEIRA, 2014).

Portão ao túmulo (gate to grave) - Modelo de ACV, que inclui a parte do ciclo de vida do produto referente ao processo produtivo, ou seja, todos os estágios, desde a entrada até a saída do produto no portão da fábrica (adaptado de SILVA; OLIVEIRA, 2014).

Sistema de produto - conjunto de processos elementares, com fluxos elementares e de produto, desempenhando uma ou mais funções definidas e que modela o ciclo de vida de um produto (ISO, 2012).

Valor de sistema de produto - valia ou desejabilidade atribuída a um sistema de produto (ISO, 2012). 